\title{
Ist-Situation der Landnutzung in Deutschland
}

\author{
Jana Hoymann, Sarah Baum, Peter Elsasser, Rene Dechow, \\ Martin Gutsch und Johanna Fick
}

\section{Inhaltsverzeichnis}

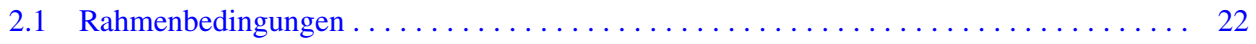

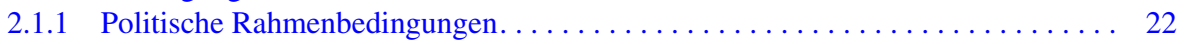

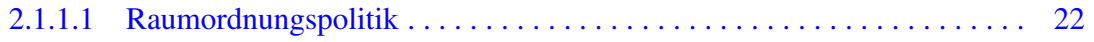

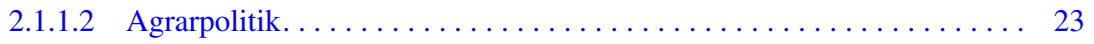

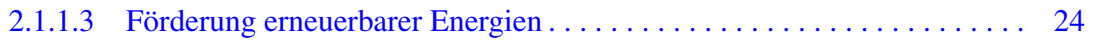

2.1.1.4 Naturschutz- und Umweltpolitik. . . . . . . . . . . . . . . . 26

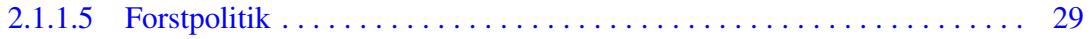

2.1.2 Agrarökonomische Rahmenbedingungen . . . . . . . . . . . . . . . . . . 30

2.1.3 Forstökonomische Rahmenbedingungen ...................... 32

2.1.4 Gesellschaftliche Rahmenbedingungen. . . . . . . . . . . . . . . . . . . . . . 34

J. Hoymann ( $\bowtie)$

Bundesinstitut für Bau-, Stadt- und Raumforschung im Bundesamt für Bauwesen und Raumordnung, Bonn, Deutschland

E-Mail: cc-landstrad@thuenen.de

S. Baum · J. Fick

Thünen-Institut für Ländliche Räume, Braunschweig, Deutschland

R. Dechow

Thünen-Institut für Agrarklimaschutz, Braunschweig, Deutschland

P. Elsasser

Thünen-Institut für Internationale Waldwirtschaft und Forstökonomie, Hamburg-Bergedorf, Deutschland

M. Gutsch

Potsdam-Institut für Klimafolgenforschung e.V., Potsdam, Deutschland

(C) Der/die Autor(en) 2021

H. Gömann und J. Fick (Hrsg.), Wechselwirkungen zwischen Landnutzung und

Klimawandel, https://doi.org/10.1007/978-3-658-18671-5_2 


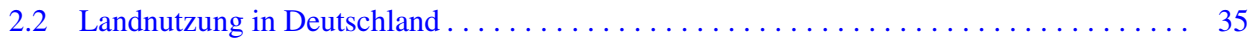

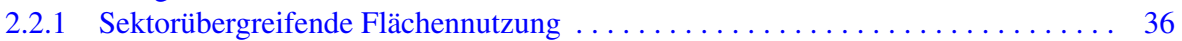

2.2.2 Siedlungs- und Verkehrsfläche . . . . . . . . . . . . . . . . . . . . . . . 39

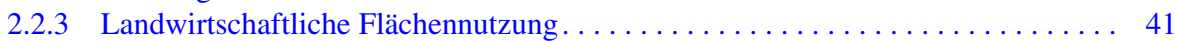

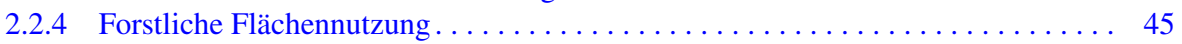

2.3 Einordnung landnutzungsinduzierter THG-Emissionen $\ldots \ldots \ldots \ldots \ldots \ldots \ldots \ldots \ldots$

2.3.1 Allgemeiner Überblick über THG-Emissionen in Deutschland . . . . . . . . . 48

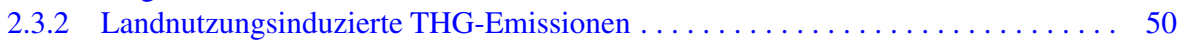

2.3.2.1 Landnutzungsinduzierte THG-Emissionen in der Landwirtschaft . . . . . 53

2.3.2.2 Landnutzungsinduzierte THG-Emissionen der Forstwirtschaft . . . . . . . 58

2.3.2.3 Landnutzungsinduzierte THG-Emissionen der Siedlungs- und

Verkehrsflächen......................... 60

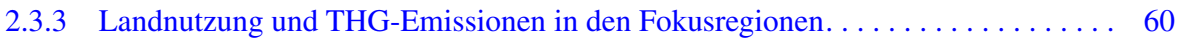

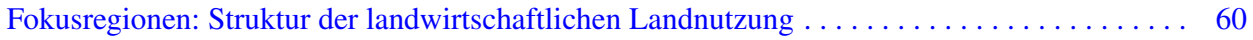

Fokusregion Altmark (Landkreise Stendal und Altmarkkreis Salzwedel) . . . . . . . . . . 61

Fokusregion Rhein (Landkreise Rheinisch-Bergischer Kreis und Rhein-Sieg-Kreis) . . . . . . . 64

Literatur. . . . . . . . . . . . . . . . . . . . . . . . . . . . . . . . 66

\subsection{Rahmenbedingungen}

Jana Hoymann, Sarah Baum, Peter Elsasser und Johanna Fick

\subsubsection{Politische Rahmenbedingungen}

\subsubsection{Raumordnungspolitik}

Unter Raumordnungspolitik werden alle Maßnahmen verstanden, die der Raumordnung dienen. Deren Aufgabe ist es, auf überörtlicher Ebene die raumbedeutsamen Fachplanungen sektorübergreifend zu koordinieren und aufeinander abzustimmen sowie zur Ordnung, Sicherung und Entwicklung der Raumnutzungen und Raumfunktionen beizutragen (vgl. Fürst und Scholles 2008, S. 70). Den rechtlichen Rahmen hierfür bildet das Raumordnungsgesetz (ROG). Nach der darin festgelegten Leitvorstellung der Raumordnung sind der Gesamtraum sowie die Teilräume der Bundesrepublik Deutschland nachhaltig zu entwickeln ( 1 (2) ROG). Dies beinhaltet die Zielsetzung, die sozialen und wirtschaftlichen Ansprüche an den Raum mit seinen ökologischen Funktionen in Einklang zu bringen, sodass eine dauerhafte, großräumig ausgewogene Ordnung mit gleichwertigen Lebensverhältnissen in den Teilräumen gewährleistet ist. Dies soll im Rahmen zusammenfassender, überörtlicher und fachübergreifender Raumordnungspläne, durch raumordnerische Zusammenarbeit und durch Abstimmung raumbedeutsamer Planungen und Maßnahmen erfolgen.

Die Ziele, Grundsätze und sonstigen Erfordernisse der Raumordnung sind bei raumbedeutsamen Planungen und Maßnahmen öffentlicher Stellen zu berücksichtigen. Mit Blick auf die gesellschaftlichen Ansprüche an die Landnutzung sind ausgeglichene soziale, infrastrukturelle, wirtschaftliche, ökologische und kulturelle Verhältnisse im 
Gesamtraum und in den Teilräumen anzustreben. Hierbei ist ein komplexes System unterschiedlicher, teilweise gegenläufiger Ziele und Anforderungen auszutarieren. Neben der Versorgung mit Dienstleistungen und Infrastrukturen der Daseinsvorsorge ist der Raum im Hinblick auf eine langfristig wettbewerbsfähige und räumlich ausgewogene Wirtschaftsstruktur und wirtschaftsnahe Infrastruktur sowie auf ein ausreichendes und vielfältiges Angebot an Arbeits- und Ausbildungsplätzen zu entwickeln. Gleichzeitig ist die Siedlungstätigkeit räumlich zu konzentrieren und die Zerschneidung der freien Landschaft und von Waldflächen sowie die Flächeninanspruchnahme im Freiraum zu vermeiden bzw. zu minimieren. Für die Land- und Forstwirtschaft sind die räumlichen Voraussetzungen zu erhalten oder zu schaffen, sodass sie ihre Funktion für die Nahrungs- und Rohstoffproduktion erfüllen können. Historisch geprägte und gewachsene Kulturlandschaften sind in ihren prägenden Merkmalen und mit ihren Kultur- und Naturdenkmälern zu erhalten und die Funktionsfähigkeit der Böden, des Wasserhaushalts, der Tier- und Pflanzenwelt sowie des Klimas einschließlich der jeweiligen Wechselwirkungen zu entwickeln. Belange des Klimawandels werden im Grundsatz Nr. 6 des $§ 2$ (2) ROG explizit aufgegriffen, wonach den räumlichen Erfordernissen des Klimaschutzes Rechnung zu tragen ist, sowohl durch Maßnahmen, die dem Klimawandel entgegenwirken, als auch durch solche, die der Strategie „Klimaanpassung“ dienen.

Auf der Ebene der Raumordnung in den einzelnen Bundesländern werden die Vorgaben des ROG aufgegriffen und in Landesplanungsgesetzen umgesetzt und angepasst. In den Ländern sind Raumordnungspläne für das Landesgebiet (landesweiter Raumordnungsplan) und Raumordnungspläne für die Teilräume der Länder (Regionalpläne) aufzustellen. Die Regionalpläne sind aus dem jeweiligen Raumordnungsplan für das Landesgebiet zu entwickeln und dienen der Umsetzung der Ziele und Grundsätze der Landesplanung und deren räumlicher Konkretisierung. Die nachgelagerte kommunale Bauleitplanung hat sich bei der Aufstellung von Bauleitplänen an die Ziele der Raumordnung anzupassen ( 1 (4) BauGB).

Die Raumordnung auf Bundesebene nimmt zudem Einfluss auf die räumliche Entwicklung durch die Verabschiedung von Leitbildern der Raumordnung, die sich an raumplanerische Entscheidungsträger in Bund und Ländern richten und über empfohlene Handlungsansätze Eingang in die Praxis finden sollen. Die aktuell gültigen Leitbilder stammen aus dem Jahr 2016. Der Klimawandel findet in einem eigenen Leitbild nun deutlich mehr Gewicht als noch in den alten Leitbildern aus dem Jahr 2006, indem ein eigenes Teilziel „Räumliche Strukturen an den Klimawandel anpassen“ verankert wird.

\subsubsection{Agrarpolitik}

Prägend für die landwirtschaftliche Landnutzung ist die Gemeinsame Agrarpolitik (GAP) der Europäischen Union. Sie wurde in mehreren Schritten beginnend mit der Reform im Jahr 1992 von einem auf Preisstützung ausgerichteten Marktordnungssystem in ein marktorientiertes System mit Direktzahlungen überführt. Im Rahmen dieser Reform wurden die gestützten Preise für wichtige Produkte wie Getreide, Rindfleisch, Milch und Zucker sukzessive gesenkt und Einkommenseinbußen in der Landwirtschaft 
durch Ausgleichszahlungen kompensiert, die in späteren Reformschritten in von der Produktion entkoppelten Direktzahlungen umgewandelt wurden.

Produktionsmengenregulierende Maßnahmen wie Flächenstilllegungen wurden auch vor dem Hintergrund steigender Nachfrage nach Agrarrohstoffen im Jahr 2007 aufgehoben. Verbleibende Regelungen, wie die Quotierung der Produktion von Milch und Zucker, liefen im Jahr 2015 bzw. 2017 aus. Zur Förderung einer umweltverträglichen landwirtschaftlichen Produktion wurden im Rahmen der Entwicklung ländlicher Räume Agrarumweltmaßnahmen eingeführt und darüber hinaus die Gewährung eines Teils der entkoppelten Direktzahlungen an die Einhaltung von Produktionsauflagen geknüpft (Cross Compliance).

Im Zuge der GAP-Reform 2015 wurden die Direktzahlungen stärker auf die Entlohnung von für die Gesellschaft erbrachten Leistungen orientiert. Das sogenannte Greening verpflichtet Landwirte, Höchstanteile bei den Anbaukulturen einzuhalten, Dauergrünland zu erhalten und mindestens $5 \%$ ihrer Ackerflächen als ökologische Vorrangflächen bereitzustellen und auf diesen dem Klima- und Umweltschutz besonders förderliche Landbewirtschaftungsmethoden anzuwenden (BMEL 2015a). Darüber hinaus können Landwirte wie bisher Agrarumweltmaßnahmen umsetzen, die über die sogenannte zweite Säule der Agrarpolitik gefördert werden und beispielsweise zur Erreichung der Ziele der Wasserrahmenrichtlinie beitragen. Beispielsweise dient die Förderung emissionsmindernder Ausbringungstechnik für flüssige Wirtschaftsdünger sowohl der Reduzierung von Nährstoffeinträgen in Gewässer als auch der Minderung von THGEmissionen (MKULNV 2016).

\subsubsection{Förderung erneuerbarer Energien}

Seit Anfang der 2000er-Jahre hat die Energiepolitik durch die Förderung erneuerbarer Energien, mit der neben Energiesicherheit auch Klimaschutzziele verfolgt werden sollten, für die Landwirtschaft spürbar an Bedeutung gewonnen. Dabei sind die Förderung der energetischen Verwendung von Biomasse sowie die Förderung des Einsatzes von Biokraftstoffen von besonderem Interesse. Im Strombereich schafft das ErneuerbareEnergien-Gesetz (EEG), das im Jahr 2000 in Kraft trat und 2004, 2009, 2012 und 2016 novelliert wurde, über festgesetzte Stromeinspeisepreise Anreize, Biomasse in Strom umzuwandeln. Insbesondere die Einführung eines Bonus für nachwachsende Rohstoffe im Zuge der Novellierung 2004 sowie eines sogenannten Güllebonus mit der Novellierung 2009 lösten einen Boom in der Biogasbranche und der Nachfrage nach Gärsubstraten zur Produktion von Biogas aus (Wissenschaftlicher Beirat Agrarpolitik 2007), und wirkten sich auf die landwirtschaftliche Landnutzung aus (Gömann et al. 2013). Ferner kann der Förderung von Windkraft sowie Solarenergie ebenfalls eine gewisse Bedeutung für die Flächennutzung bzw. das Landschaftsbild beigemessen werden.

Die Steigerung der Verwendung regenerativ erzeugten Stroms bzw. von Biokraftstoffen wurde durch die EU-Richtlinien 2001/77/EG bzw. 2003/30/EG vorangetrieben. Demnach sollten in den Mitgliedstaaten der EU bis zum Jahr 2010 ein Stromanteil aus erneuerbaren Energien am Bruttostromverbrauch in der EU-15 von $22 \%$ sowie ein Biokraftstoffanteil von 5,75\% an sämtlichen Kraftstoffen erreicht werden. Die Förderung 
erneuerbarer Energien wurde durch die Richtlinie 2009/28/EG weiterentwickelt. Demnach wird in der Europäischen Union ein Anteil der erneuerbaren Energien am Bruttoendenergieverbrauch von $20 \%$ im Jahr 2020 angestrebt, darunter mindestens $10 \%$ im Verkehrssektor. Für die Mitgliedstaaten wurden unterschiedliche Zielwerte festgelegt; der für Deutschland liegt bei $18 \%$, wovon 10,9\% aus Bioenergie stammen sollen (BMELV/BMU 2010).

In nationalen Aktionsplänen veröffentlichten die Mitgliedstaaten Informationen zu den sektorspezifischen Zielen für erneuerbare Energie und nationalen Maßnahmen zu deren Verwirklichung. In Deutschland wurden die genannten Richtlinien zur Förderung der erneuerbaren Energien u. a. durch das Erneuerbare-Energien-Gesetz (EEG), die Biomasseverordnung und das Biokraftstoffquotengesetz (BioKraftQuG 2006) umgesetzt. Während im EEG die Stromerzeugung aus erneuerbaren Energien wie der Biomasse durch Anreizmechanismen gefördert wird, sollten die Ziele im Biokraftstoffbereich zunächst auch durch eine Mineralölsteuerbefreiung erreicht werden. Der Anreizmechanismus wurde durch die Einführung von Beimischungsquoten ersetzt. Das BioKraftQuG wurde 2009 geändert, um den Einsatz von Biokraftstoffen stärker auf die Reduzierung von THG auszurichten. So wird der Anteil der ab dem Jahr 2015 durch Biokraftstoffe vermiedenen THG-Emissionen stufenweise erhöht, und zwar von $3 \%$ im Jahr 2015 auf 4,5\% bis zum Jahr 2017 und $7 \%$ bis zum Jahr 2020 an der Gesamtmenge Otto- und Dieselkraftstoffs. Zur Erfüllung der Biokraftstoffquoten bzw. THG-Reduktionsquoten können nur nachhaltig erzeugte Biokraftstoffe anerkannt werden (BLE 2010). Neben den nationalen legislativen Maßnahmen werden auf Bundesland- und Regionalebene Informationskampagnen durchgeführt sowie regionale Programme initiiert (z. B. Niedersachsen Netzwerk Nachwachsende Rohstoffe - 3N, Landeswettbewerb „100-ProzentErneuerbare-Energien-Kommune“ in Schleswig-Holstein) (vgl. Bundesregierung 2010).

Für den Verkehrsbereich wird das Mindestziel von $10 \%$ erneuerbarer Energie definiert. Für den Stromverbrauch ist ein Gesamtanteil von mindestens $30 \%$ vorgesehen, aus denen $8 \%$ aus Bioenergie stammen sollen (vgl. Tab. 2.1).

Tab. 2.1 Nationale Ziele des Anteils erneuerbarer Energien (EE) und Bioenergien am Gesamtenergieverbrauch. (Quelle: BMELV/BMU 2010)

\begin{tabular}{l|l|l|l|l}
\hline & \multicolumn{2}{l}{$\mathbf{2 0 0 7}$} & $\mathbf{2 0 2 0}$ \\
\hline Anteil EE am gesamten... & EE insgesamt & $\begin{array}{l}\text { drunter } \\
\text { Bioenergie }\end{array}$ & $\begin{array}{l}\text { EE } \\
\text { insgesamt }\end{array}$ & $\begin{array}{l}\text { darunter } \\
\text { Bioenergie }\end{array}$ \\
\hline Primärenergieverbrauch & $6,7 \%$ & $4,9 \%$ & $16 \%$ & $11 \%$ \\
\hline Endenergieverbrauch & $8,6 \%$ & $6,2 \%$ & $18 \%$ & $10,9 \%$ \\
\hline Kraftstoffverbrauch [1] & n. a. & n. a. & $12 \%$ & $12 \%$ \\
\hline $\begin{array}{l}\text { Stromverbrauch/Stromver- } \\
\text { sorgung }\end{array}$ & $14,2 \%$ & $3,9 \%$ & $\geq 30 \%$ & $8 \%$ \\
\hline Endenergieverbrauch für Wärme & $6,6 \%$ & $6,1 \%$ & $14 \%$ & $9,7 \%$ \\
\hline
\end{tabular}

n. a. =nicht ausgewiesen in BMELV/BMU (2010), EE: erneuerbare Energien 


\subsubsection{Naturschutz- und Umweltpolitik}

Neben dem Klimaschutz bestehen im Bereich des Natur-, Umwelt- und Ressourcenschutzes vielfältige sektorübergreifende Rahmenbedingungen, die für die Landnutzung von Bedeutung sind. Im Folgenden werden die wichtigsten Regelungen dargestellt.

\section{- Boden}

Für den Bodenschutz auf EU-Ebene liegt ein Vorschlag der EU-Kommission für eine Richtlinie vor (EU-KOM 2006), der die in der Richtlinie 2004/35/EG geregelte Umwelthaftung zur Vermeidung und Sanierung von Umweltschäden aufgreift. Darüber hinaus besteht kein gemeinschaftlicher Rahmen für den Bodenschutz in den Mitgliedstaaten.

In Deutschland steht für den Schutz des Bodens sowie für Altlastenbewertung und -sanierung mit dem Bundes-Bodenschutzgesetz (BBodSchG) und der dazugehörigen Bodenschutz- und Altlastenverordnung (BBodSchV) seit Ende der 1990er-Jahre eine bundeseinheitliche Rechtsgrundlage zur Verfügung. Das BBodSchG dient dazu, nachhaltig die Funktionen des Bodens zu sichern oder wiederherzustellen. Es sind schädliche Bodenveränderungen abzuwehren, der Boden und Altlasten sowie hierdurch verursachte Gewässerverunreinigungen zu sanieren und Vorsorge gegen nachteilige Einwirkungen auf den Boden zu treffen. Die auf dem BBodSchG basierenden Bodenschutzgesetze in den Bundesländern sind teilweise um explizite Regelungen bezüglich der Bodenplanungsgebiete im Sinne der Bodensanierung und gebietsbezogenen Bodenschutzes erweitert.

- Wasser

Mit der im Dezember 2000 in Kraft getreten Wasserrahmenrichtlinie (WRRL ${ }^{1}$ ) wurde der Schutz der Binnenoberflächengewässer, der Übergangsgewässer, der Küstengewässer und des Grundwassers in der Europäischen Gemeinschaft harmonisiert. Das Ziel der Richtlinie ist es, den guten Zustand bzw. das gute ökologische Potenzial und den guten chemischen Zustand aller Oberflächengewässer sowie den guten mengenmäßigen und chemischen Zustand des Grundwassers bis zum Jahr $2015 \mathrm{zu}$ erreichen. Zugleich wurden auch der integrierte Gewässerschutz sowie die koordinierte Bewirtschaftung der Gewässer innerhalb von Flusseinzugsgebieten, auch über die Staats- und Landesgrenzen hinweg, initiiert. Die vorab innerhalb der politischen Grenzen realisierte Bewirtschaftung der Gewässer wird nun entsprechend der Flusseinzugsgebiete koordiniert. Auch für das Grundwasser wird der gute quantitative und chemische Zustand bis 2015 angestrebt, die relevanten Ziele, Qualitätsnormen und Maßnahmen sind in der Grundwasserrichtlinie (Richtlinie 2006/118/ EG) formuliert. Es wurden und werden prioritäre Stoffe definiert, wobei sowohl

\footnotetext{
${ }^{1}$ Richtlinie 2000/60/EG des Europäischen Parlaments und des Rates vom 23. Oktober 2000 zur Schaffung eines Ordnungsrahmens für Maßnahmen der Gemeinschaft im Bereich der Wasserpolitik.
} 
Emissionen und Immissionen sowie Einzelstoffe und Gruppenparameter berücksichtigt werden.

Mit Blick auf die Umsetzung der WRRL und das Erreichen der festgelegten Ziele werden unter anderen auch landnutzungsrelevante Maßnahmen eingesetzt. So fordert die WRRL die Umsetzung und Erfüllung aller Normen und Ziele in den für die Bewirtschaftung der Gewässer relevanten Schutzgebieten, insbesondere in den Natura 2000-Gebieten. Ebenso wird u. a. die Wiederherstellung und Neuschaffung von Feuchtgebieten angestrebt. Zur Vermeidung von Nährstoffeinträgen in Gewässer werden beispielsweise in der Landwirtschaft vielfältige Maßnahmen gefördert und die Einhaltung von Auflagen gefordert, beispielsweise Gewässerrandstreifen zur Verminderung diffuser Nährstoffeinträge.

In Deutschland wurden die wesentlichen Grundsätze der WRRL mit der Novellierung des Wasserhaushaltgesetzes, das 2002 in Kraft getreten ist, umgesetzt und mittels Reglungsaufträgen in die Landeswassergesetze übertragen. Nach Umsetzung der Föderalismusreform 2006 wurde 2009 das deutsche Wasserrecht im Wasserhaushaltsgesetz (WHG) neu geregelt. Nach dem Inkrafttreten des WHG 2010 und der neuen Grundwasserverordnung wurden die Ziele und Vorgaben der WRRL im deutschen Wasserrecht verankert. Die Übertragung in das jeweilige Landesrecht ist teilweise bereits erfolgt oder aktuell in Bearbeitung. Die Qualitätsnormen für Nitrat und Pflanzenschutzmittel sowie die Kriterien zur Ermittlung signifikanter und anhaltend steigender Schadstoffbelastungstrends wurden in die Grundwasserverordnung, die Düngeverordnung, die Pflanzenschutzmittelverordnung und das Wasserhaushaltsgesetz übernommen.

Ein weiteres wichtiges Instrument zum Schutz der Gewässer ist die Nitrat-Richtlinie (Richtlinie 91/676/EWG). Sie soll verhindern, dass Grund- und Oberflächengewässer durch Nitrateinträge aus der Landwirtschaft verunreinigt werden. Die Richtlinie trat in Deutschland 1996 durch die Düngeverordnung in Kraft, welche 2012 sowie 2017 novelliert wurde.

Die Düngeverordnung ist eine Verordnung über die Anwendung von Düngemitteln, Bodenhilfsstoffen, Kultursubstraten und Pflanzenhilfsmitteln nach den Grundsätzen der guten fachlichen Praxis beim Düngen. Wesentlicher Kernpunkt ist hierbei, dass das Ausbringen von Düngemitteln zeitlich und mengenmäßig so erfolgt, dass die Nährstoffe von den Pflanzen größtenteils aufgenommen werden können und Einträge in Gewässer und die Atmosphäre minimiert werden. Neben dem geeigneten Zeitpunkt spielt auch die zur Ausbringung verwendete Technik eine wesentliche Rolle bei der Reduzierung von Austrägen. Des Weiteren muss eine Düngebedarfsermittlung erfolgen, welche die Obergrenze für den Stickstoffbedarf standort- und ertragsbezogen für die angebaute Kultur festlegt. Sperrfristen der Ausbringung sind ein weiterer Bestandteil der Düngeverordnung.

Aus Sicht des Europäischen Gerichtshofes reichen die Vorgaben der novellierten Düngeverordnung allerdings nach wie vor nicht aus, um den Vorgaben der Nitrat-Richtlinie auf nationaler Ebene gerecht zu werden, sodass die Bundesrepublik Deutschland hier nachbessern muss, um die Nitratbelastungen zu reduzieren. 
- Naturschutz und Biodiversität

Die Erhaltung und der Schutz der biologischen Vielfalt liegen im Fokus des Übereinkommens über die biologische Vielfalt (Convention on Biological Diversity, CBD), das 1992 in Rio De Janeiro durch die UNCED beschlossen und 2000 durch das Cartagena-Protokoll und das Nagoya-Protokoll überarbeitet wurde. In der EU bilden die FFH-Richtlinie ${ }^{2}$ und die Vogelschutzrichtlinie ${ }^{3}$ den gemeinschaftlichen Rahmen des Naturschutzes und der Biodiversität. Dabei ist für die Landnutzung von Bedeutung, dass zur Wiederherstellung oder Wahrung eines günstigen Erhaltungszustandes der natürlichen Lebensräume und der Arten von gemeinschaftlichem Interesse besondere Schutzgebiete auszuweisen, Lebensräume zu pflegen, zerstörte Lebensstätten wiederherzustellen und neue Biotope zu schaffen sind. Die Schutzgebiete sollen ein kohärentes Netzwerk (Natura 2000) ergeben und bilden zusammen mit den Artenschutzbestimmungen für den Naturschutz ein umfassendes rechtliches Instrumentarium zum Lebensraum- und Artenschutz.

Die initiale Umsetzung der Biodiversitätskonvention in deutsches Recht erfolgte 2002 durch die Formulierung des Vorsatzes der Erhaltung und Entwicklung der biologischen Vielfalt in $\S 1$ als Ziel des Naturschutzes und der Landschaftspflege im Bundesnaturschutzgesetz (BNatSchG). Im Jahr 1999 wurden die Konzeption zu den genetischen Ressourcen für Ernährung, Land- und Forstwirtschaft sowie die Strategie „Forstwirtschaft und biologische Vielfalt" veröffentlicht. Basierend auf dem Cartagena-Protokoll wurde 2007 die Nationale Strategie zur biologischen Vielfalt (NBS) erarbeitet und vom Bundeskabinett beschlossen. Übergeordnetes Ziel der NBS ist es, mit einem Zeithorizont bis zum Jahr 2020 den Rückgang der biologischen Vielfalt aufzuhalten und den Trend umzukehren. Mit der Novellierung des Bundesnaturschutzgesetzes 2009 wurden die Ziele der WRRL auch im deutschen Naturschutzrecht verankert.

Grundsätzlich fällt der Naturschutz in Deutschland in den Kompetenzbereich der Bundesländer, die beispielsweise für die Ausweisung von Natura 2000-Schutzgebieten zuständig sind. Die Bedeutung für die Landnutzung resultiert aus den besonderen Bewirtschaftungsauflagen für die land- und forstwirtschaftliche Nutzung in den Schutzgebieten sowie in deren Nähe. Auch außerhalb der besonderen Schutzgebiete soll die Leistungsund Funktionsfähigkeit des Naturhaushaltes und des Landschaftsbildes erhalten werden. Lassen sich Eingriffe in Natur und Landschaft, z. B. durch Siedlungs- und Verkehrswegebauten, nicht vermeiden, sind sie nach den $\S \S 13 \mathrm{ff}$ des BNatSchG durch landschaftspflegerische Maßnahmen (sogenannte Ausgleichs- und Ersatzmaßnahmen) zu kompensieren. Mit diesem Vorgehen wird ein auf alle Schutzgüter des Naturhaushaltes und des Landschaftsbildes bezogener flächendeckender Ansatz verfolgt.

\footnotetext{
${ }^{2}$ Richtlinie 92/43/EWG des Rates vom 21. Mai 1992 zur Erhaltung der natürlichen Lebensräume sowie der wildlebenden Tiere und Pflanzen.

${ }^{3}$ Richtlinie 79/409/EWG des Rates vom 2. April 1979 über die Erhaltung der wildlebenden Vogelarten.
} 
Der Maßnahmenkatalog der europäischen Biodiversitätskommission wurde 2006 veröffentlicht. Des Weiteren wurde 2007 durch das Waldforum der Vereinten Nationen das Übereinkommen zur nachhaltigen Bewirtschaftung und Entwicklung der Wälder verabschiedet, das durch ein begleitendes Arbeitsprogramm zur Umsetzung bis 2015 ergänzt wird. Rechtlich sind diese Regelungen jedoch nicht verbindlich.

\subsubsection{Forstpolitik}

Die rechtliche Basis der Forstpolitik in Deutschland ist das Forstrecht, das einen eigenen Rechtsbereich darstellt (lex specialis). Das Recht zur Gesetzgebung (wie auch deren Vollzug) steht hier nach dem Grundgesetz (GG) grundsätzlich den Ländern zu (Art. 70 (1) GG); Teilbereiche fallen jedoch unter die konkurrierende Gesetzgebung, insbesondere die Förderung der land- und forstwirtschaftlichen Erzeugung (Art. 74 (1) Nr. 17 sowie Art. 91a GG). Entsprechend sind neben dem Bundeswaldgesetz die jeweiligen Landeswaldgesetze forstpolitisch relevant, welche ähnliche, aber nicht identische Regeln aufweisen. Ziele des Bundeswaldgesetzes sind, den Wald zu erhalten, ggf. zu mehren und seine ordnungsgemäße Bewirtschaftung nachhaltig zu sichern, die Forstwirtschaft zu fördern und einen Interessensausgleich zwischen Allgemeinheit und Waldbesitzern herzustellen (BWaldG, § 1). Die EU hat, anders als in der Gemeinsamen Agrarpolitik, keine speziellen forstpolitischen Kompetenzen. Auch auf internationaler Ebene existiert keine rechtsverbindliche „Waldkonvention“, wie sie etwa mit der Klimarahmenkonvention UNFCCC 1992 oder der Biodiversitätskonvention UN-CBD 1992 für die Klimapolitik bzw. den Schutz der biologischen Vielfalt verabschiedet worden sind; vielmehr verteilen sich Elemente einer europäischen und internationalen Forstpolitik fragmentiert über etliche andere Politikbereiche (vgl. u. a. Schwoerer 2015).

Die forstliche Förderung in Deutschland erfolgt auf Basis der Gemeinschaftsaufgabe „Verbesserung der Agrarstruktur und des Küstenschutzes“ (GAK) gemeinsam durch Bund und Länder, unter finanzieller Beteiligung der EU. Im Rahmen der GAK entfällt auf den Förderbereich „Forsten“ nur ein relativ geringer Teil der gesamten Fördermittel. So umfasst der derzeit aktuelle GAK-Rahmenplan 2015-2018 insgesamt ein Mittelvolumen von ca. 935 Mio. € für das Jahr 2015, von denen lediglich ca. 49 Mio. € (5,2 \%) für Forsten vorgesehen sind (BMEL 2015b). Gefördert werden können Maßnahmen aus vier Bereichen: naturnahe Waldbewirtschaftung (u. a. Waldumbau, Jungbestandspflege), forstwirtschaftliche Infrastruktur (Wegebau, Holzkonservierungsanlagen), forstwirtschaftliche Zusammenschlüsse (Waldpflege, Mitgliederinformation und Zusammenfassung des Holzangebotes) sowie Erstaufforstung. Bezogen auf die Fläche der Privatwaldbetriebe betragen die tatsächlich ausgeschütteten Fördermittel knapp $15 € /$ a/ha (Möhring und Mestemacher 2009; vgl. auch Elsasser et al. 2016). Die forstpolitischen Möglichkeiten, über finanzielle Anreize aus der GAK Einfluss auf die Waldbewirtschaftung zu nehmen, sind derzeit also recht begrenzt.

Ähnliches gilt für den Waldklimafonds, aus dem Fördermittel (seit 2013) speziell zur Anpassung der Wälder an den Klimawandel sowie zur besseren Erschließung des Kohlenstoff-Minderungspotenzials von Wald und Holz zur Verfügung stehen. Der Wald- 
klimafonds ist ein Programmbestandteil des Sondervermögens Energie- und Klimafonds der Bundesregierung. Die Finanzierung erfolgt aus Erlösen der Zertifikatversteigerungen im Europäischen Emissionshandelssystem. Das jährliche Mittelvolumen des Waldklimafonds betrug seither jeweils um 15 Mio. €/a, also etwa ein Drittel der GAK-Förderung (Haushaltsgesetze 2014, S. 3197; 2015, S. 2828; 2016, S. 3032). Aktuell werden daraus überwiegend Forschungs- und Demonstrationsvorhaben gefördert. ${ }^{4}$

Forstpolitisch erwähnenswert sind ferner einige Regeln der internationalen Klimapolitik (ausführlicher dazu Hartje et al. 2015, insb. Kapitel 6). Nach den derzeit gültigen Anrechnungsregeln des Kyoto-Protokolls (KP) müssen Emissionsquellen und -senken auf die Emissionsbilanzen der beteiligten Staaten angerechnet werden, die aus Entwaldung und Aufforstung (KP, Art. 3.3), aus Veränderungen in den bestehenden Wäldern (KP, Art. 3.4) sowie aus Veränderungen in den Holzproduktespeichern stammen (decision 2/CMP.7, UNFCCC 2011). Unter derzeitigen Bedingungen entlastet dies die deutsche Emissionsbilanz. Der finanzielle Gegenwert dieser Entlastung wurde für die erste Verpflichtungsperiode des KP unter den damaligen Bedingungen auf etwa 90 Mio. €/a beziffert (Elsasser 2008). Da das Kyoto-Protokoll ausschließlich Rechtsverhältnisse zwischen Staaten regelt, können die dadurch ermöglichten Erträge forstund holzwirtschaftlicher Klimaschutzmaßnahmen allerdings nur von den beteiligten Staaten realisiert werden, nicht aber von einzelnen Betrieben. Schließlich bietet auch die Emissionshandelsrichtlinie der Europäischen Union (EU 2003) keinen Hebel zur politischen Lenkung forstbetrieblicher Klimaschutzmaßnahmen, da sie zumindest bis 2020 keine Integration forstlicher Senkenzertifikate in das Europäische Emissionshandelssystem vorsieht (EU 2004, 2009; vgl. auch Ciccarese et al. 2011).

Insgesamt lässt sich zusammenfassen, dass der bundesdeutschen Forstpolitik nur relativ schwache rechtliche und finanzielle Instrumente zur Verfügung stehen, welche als Gegengewicht zu Marktentwicklungen und zu Politikmaßnahmen außerhalb des Forstsektors geeignet wären und Ansatzpunkte dafür böten, die Bewirtschaftung der Wälder stärker auf klimapolitische Ziele auszurichten (Hartje et al. 2015, S. 155 f.).

\subsubsection{Agrarökonomische Rahmenbedingungen}

Die Reformen der GAP hin zu einer stärkeren Ausrichtung der Produktion am Markt schlagen sich in der Entwicklung der Agrarpreise nieder. Bis Mitte des Jahres 2006 sind beispielsweise die Erzeugerpreise für Weizen in Deutschland kontinuierlich gesunken. Seitdem ist ein Anstieg der Preisschwankungen bei einem insgesamt leicht ansteigenden Preisniveau erkennbar. Der Preisanstieg bei Ölsaaten hat im Vergleich zum Getreide einige Jahre früher eingesetzt, sodass sich die relative Wettbewerbskraft zwischen Getreide und Ölsaaten zugunsten von Ölsaaten verschoben hat (Abb. 2.1).

\footnotetext{
${ }^{4}$ Siehe dazu www.waldklimafonds.de/projekte (zitiert am 12.03.2018).
} 


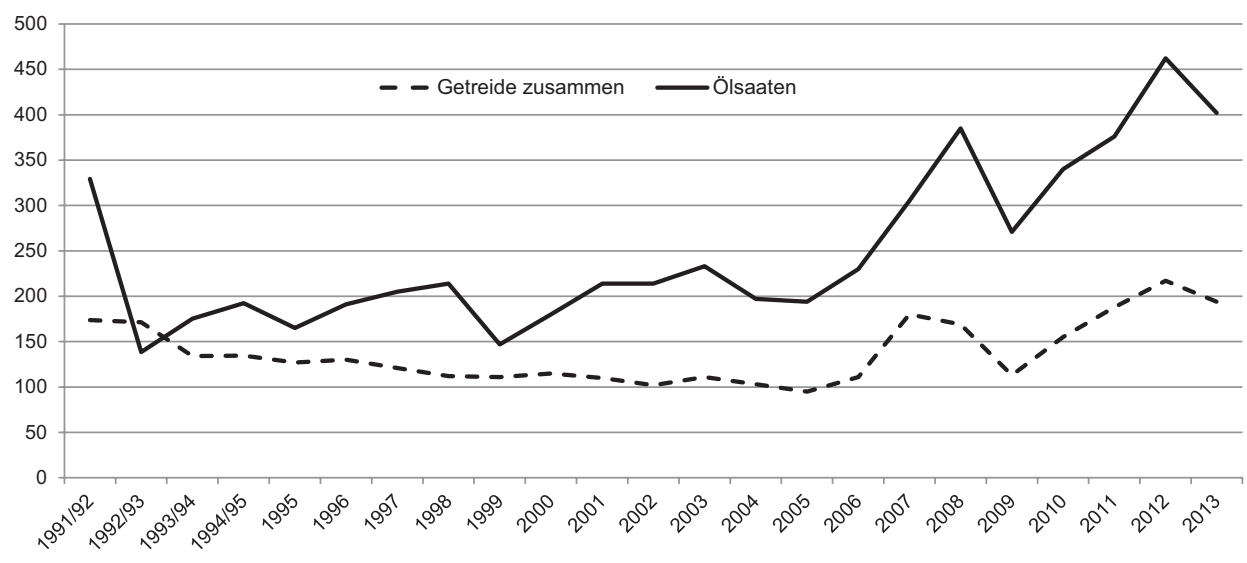

Abb. 2.1 Entwicklung der Erzeugerpreise für Getreide und Ölsaaten in Deutschland (1991 bis 2013). (Quelle: Statistisches Bundesamt)

Die Produktivitätsentwicklung gemessen an den Flächenerträgen landwirtschaftlicher Kulturen hat sich sehr unterschiedlich entwickelt. Grundsätzlich ist ein langfristiger Anstieg der Flächenerträge bei allen Kulturen erkennbar. Im Zeitraum von 1950 bis 1995 hat sich beispielsweise der Getreideertrag verdreifacht, wobei der stärkste Zuwachs bei Körnermais und Weizen erzielt wurde. Ab Mitte der 1990er-Jahre ist eine Abflachung des Ertragsanstiegs und Zunahme der mittelfristigen Schwankungen zu beobachten (vgl. Abb. 2.2). Demgegenüber weist der Flächenertrag für Zuckerrüben einen kontinuierlichen Ertragszuwachs bei höheren jährlichen Schwankungen auf.

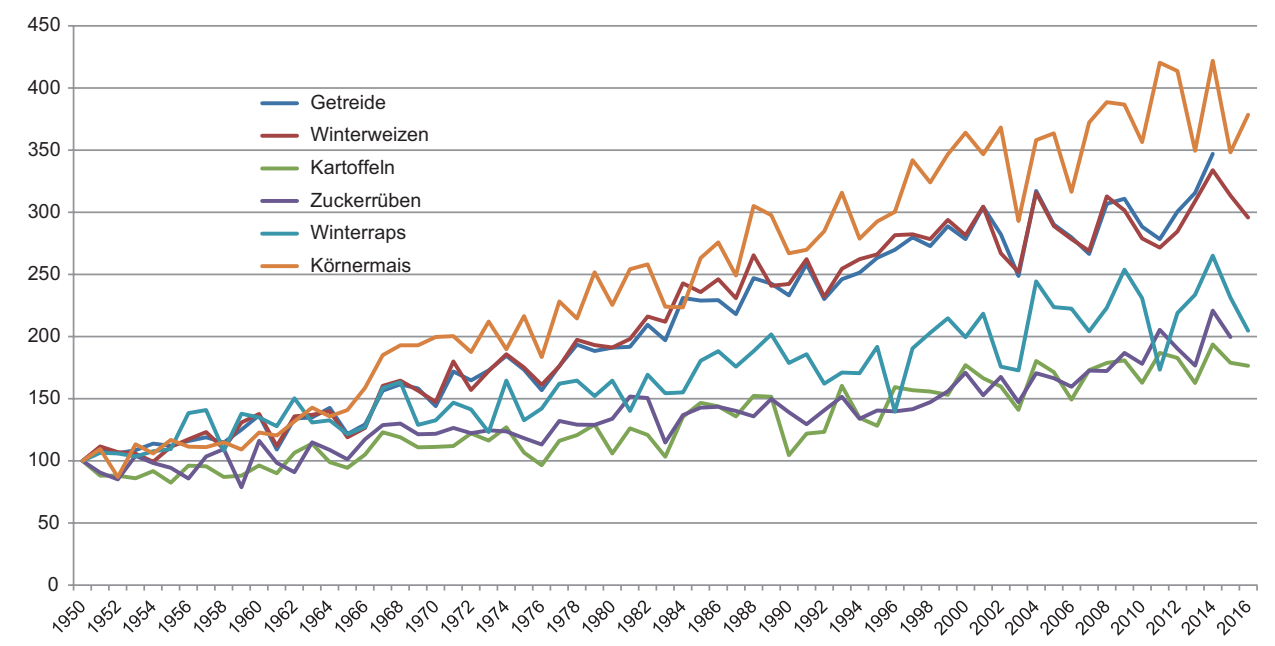

Abb. 2.2 Entwicklung der Flächenerträge in Deutschland. (Quelle: Stat.Jb. BMELV versch. Jgg.) 


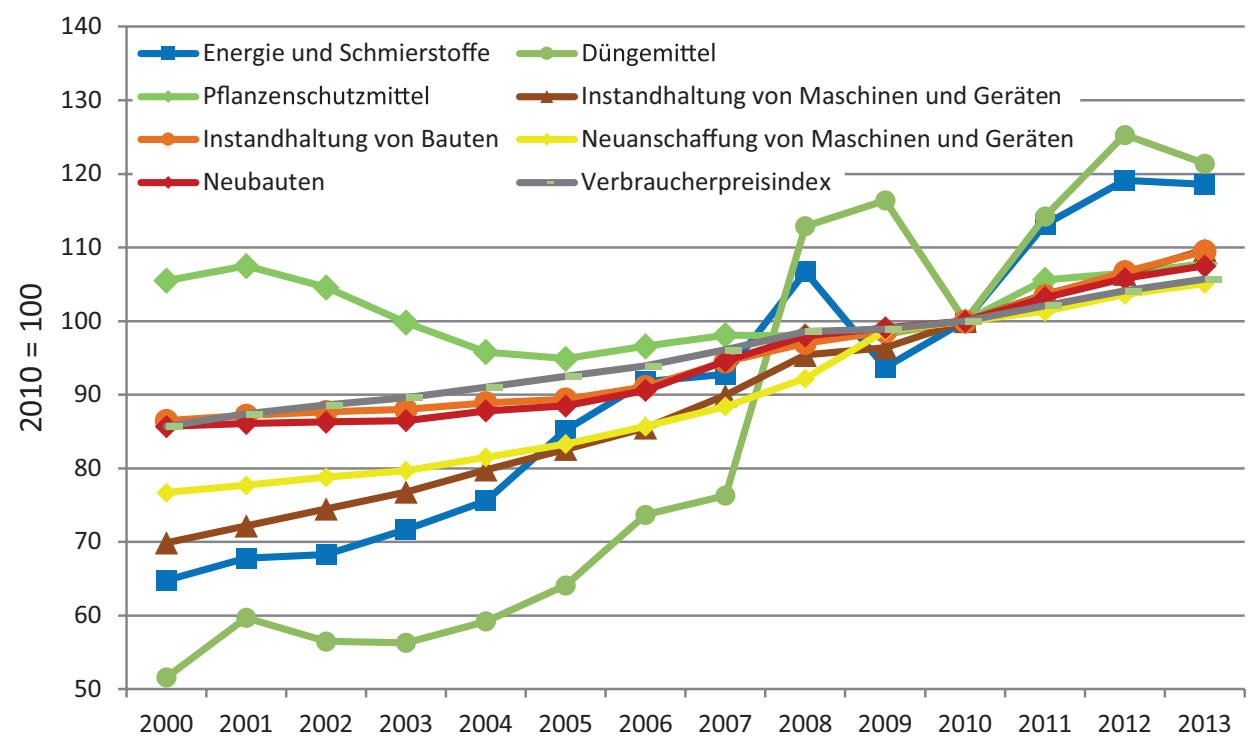

Abb. 2.3 Index der Einkaufspreise landwirtschaftlicher Betriebsmittel. (Quelle: Statistisches Bundesamt, versch. Jgg.)

Die Preisentwicklung für landwirtschaftliche Vorleistungen verlief in den letzten 20 Jahren sehr unterschiedlich für einzelne Produktgruppen (vgl. Abb. 2.3). Seit Längerem sind im Bereich Energie überproportionale Preissteigerungen zu beobachten, welche sich auch auf die Preise von anderen Produktionsfaktoren (z. B. Düngemitteln) ausgewirkt haben. Der Anstieg der Erzeugerpreise für landwirtschaftliche Produkte hat darüber hinaus zu einer Erhöhung der Nachfrage für landwirtschaftliche Produktionsmittel geführt und dadurch deren Preisniveau angehoben (Offermann et al. 2014).

Die Energiepolitik wirkt sich über den Energiemarkt auf den Produktionssektor der erneuerbaren Energien sowie auf die Produktionskosten (z. B. Treibstoffpreis) aus. Die regionalen Produktionsbedingungen bestimmen die Erträge und Produktionskosten und hängen von Standortbedingungen, von technischen Entwicklungen und den Marktentwicklungen der Produktionsfaktoren ab.

\subsubsection{Forstökonomische Rahmenbedingungen}

Die bisherige Entwicklung der naturalen Produktion der deutschen Forstwirtschaft kann grob in zwei Phasen eingeteilt werden (Küppers et al. 2009). Bis zum Anfang der 1990er-Jahre blieb der Jahreseinschlag (mit Ausnahme von Kalamitätsjahren) mit unter 30 Mio. $\mathrm{m}^{3}$ Rohholzäquivalenten fast konstant; demgegenüber ist der Verbrauch von Holz seit Ende des Zweiten Weltkrieges kontinuierlich angestiegen. Während der Verbrauch um 1950 noch etwa die gleiche Größenordnung aufwies wie der inländische 
Jahreseinschlag, lag er Anfang der 1990er-Jahre bei etwa dem zweieinhalbfachen des Jahreseinschlags. Die dadurch entstehende Lücke wurde zum Teil über (Netto-)Einfuhren sowie auch über das steigende Altpapieraufkommen geschlossen. Seit etwa Mitte der 1990er-Jahre wurde der nachhaltige Jahreseinschlag, aufgrund der bestehenden Altersklassenstruktur und begünstigt durch steigende Holzpreise, deutlich gesteigert. ${ }^{5}$ Seit 2004 ist Deutschland nunmehr Nettoexporteur von Holz und holzbasierten Produkten. Da der inländische Holzverbrauch keine ähnlich starke Steigerung aufwies, ist die Lücke zwischen Einschlag und inländischem Verbrauch damit wieder kleiner geworden.

In monetärer Hinsicht lässt sich der Wert der Produktionsleistungen der Forstwirtschaft der Forstwirtschaftlichen Gesamtrechnung entnehmen, welche sich des Testbetriebsnetzes des Bundesministeriums für Ernährung und Landwirtschaft als wesentliche Datenquelle bedient. Die zur Zeit der Manuskripterstellung aktuellsten Daten beziehen sich auf die Jahre bis einschließlich 2009 (Dieter 2011). Die Erzeugung des Wirtschaftsbereiches Forstwirtschaft (Bruttowertschöpfung plus Vorleistungen) betrug danach 2009 3,3 Mrd. €. Im Vergleich zum Zeitraum zwischen 1991 und 2001, in dem die Ergebnisse um etwa 2,5 Mrd. € schwankten, ist der Produktionswert bis 2007 stetig auf ein bisheriges Maximum von 4,4 Mrd. € gestiegen (der darauf folgende Rückgang ist $u$. a. durch die globale Wirtschaftskrise bedingt). Mehr als die Hälfte des Produktionswertes (56\% bzw. 1,9 Mrd. €) entfällt auf Nadelholz (Stamm- und Faserholz), welches auch wesentlich für die zurückliegende Steigerung des Produktionswertes verantwortlich ist. An zweiter Stelle stehen forstliche Dienstleistungen $(21 \%$ bzw. 0,7 Mrd. €). Laubholz (Stamm- und Faserholz) trägt lediglich $7 \%$ bei (0,2 Mrd. €). Die Nachfrage nach Brennholz ist, entgegen der in jüngster Zeit wieder sinkenden Tendenz der Gesamtnachfrage, angestiegen; der Anteil von Brennholz am gesamten Produktionswert des Wirtschaftsbereiches macht inzwischen $10 \%$ aus.

Die Nettounternehmensgewinne ${ }^{6}$ ergeben sich, wenn man vom Wert der Erzeugung Vorleistungen, Abschreibungen, Arbeitnehmerentgelte und sonstige Produktionsabgaben abzieht und Subventions-, Pacht- und Zinszahlungen berücksichtigt. Sie sind - nach einer langen defizitären Phase in der zweiten Hälfte des letzten Jahrhunderts - erst seit 2004 ausnahmslos positiv, allerdings ebenfalls seit 2007 rückgängig. Im Jahr 2009 betrugen die Nettounternehmensgewinne des Wirtschaftsbereiches Forstwirtschaft 192 Mio. €; das sind knapp $6 \%$ des Produktionswertes bzw. durchschnittlich 19 €/ha Holzbodenfläche.

\footnotetext{
${ }^{5}$ Aufgrund der Reparationshiebe war die Altersstruktur des deutschen Waldes stark abgesenkt worden. Erst nach ca. 50 Jahren wuchsen diese Bestände wieder langsam ins hiebsreife Alter, was in Folge den Jahreseinschlag erhöhte. Holzpreissteigerungen steigerten den Jahreseinschlag zusätzlich. Durch Variation der Baumartenwahl bei der Neubegründung der ehemaligen Reparationsaufforstungen entsteht zukünftig, aufgrund der unterschiedlichen Hiebsreife der neubegründeten Baumarten, ein kontinuierlich höherer Jahreseinschlag als noch in den Jahren vor 1990, wobei das aktuell hohe Niveau mit der Endnutzung der letzten Reparationsaufforstungen nicht ganz gehalten werden kann.

${ }^{6}$ Ohne nicht genutzten Zuwachs.
} 
Die Verbesserung der Wirtschaftsergebnisse ist nicht allein auf eine günstige Holzpreisentwicklung zurückzuführen. Sie ist auch Ergebnis gezielter Kosteneinsparungen, die zu erheblichen strukturellen Änderungen in der Forstwirtschaft geführt haben. So werden seit etwa 1990 zunehmend Anteile der forstlichen Arbeiten nicht mehr in Eigenregie, sondern von Dienstleistern ausgeführt. Korrespondierend dazu ist der verwendungsseitige Anteil der Arbeitnehmerentgelte an der Erzeugung des Wirtschaftsbereiches seit den 1990er-Jahren von etwa $70 \%$ auf etwa ein Fünftel gefallen. Insbesondere etliche staatliche Forstverwaltungen sind in jüngerer Zeit betrieblich und organisatorisch neu ausgerichtet worden, indem sie aus der traditionellen Verwaltungsstruktur herausgelöst und $\mathrm{zu}$ mehr oder weniger eigenständigen Unternehmen umgestaltet wurden, welche oft wesentlich stärker erwerbswirtschaftlich orientiert sind (Küppers et al. 2009). Dies ist mit einer signifikanten Reduktion der Anzahl von Forstämtern, -revieren und des entsprechenden Fachpersonals verbunden, womit gleichzeitig ein entsprechender Rückgang der forstfachlichen Flächenpräsenz einherging.

\subsubsection{Gesellschaftliche Rahmenbedingungen}

Die sozioökonomische Entwicklung spannt einerseits den Rahmen für die Entwicklung der Siedlungsflächennutzung auf, beeinflusst diese allerdings nur in begrenztem Umfang. Ein Zusammenhang zwischen demographischer Entwicklung und der Entwicklung der Siedlungs- und Verkehrsfläche ist statistisch kaum nachweisbar, vor allem dann, wenn die Bevölkerungszahl rückläufig ist. Infolge einer Verkleinerung der Haushaltsgrößen stieg die Anzahl der Haushalte in den letzten 20 Jahren kontinuierlich an und führte - ebenso wie steigende Haushaltseinkommen - zur Zunahme der pro-Kopf-Inanspruchnahme von Wohnfläche. Seit den 1990er-Jahren überstieg zunächst in Ostdeutschland, später auch in strukturschwachen ländlichen Regionen Westdeutschlands das Wohnungsangebot die Nachfrage (BBSR 2012). Diese hängt in der Regel ursächlich mit dem nicht mehr marktfähigen Ausstattungsstandard von Wohnungen und Wohngebäuden zusammen und führt zu deren Leerstand bei gleichzeitigem Neubau von Wohnungen meist am Siedlungsrand (Dosch 2008, S. 44). Demgegenüber haben Veränderungen ökonomischer Größen wie wirtschaftliche Wertschöpfung und Haushaltseinkommen oder die Beschäftigungsentwicklung entweder keine oder nur eine untergeordnete Bedeutung für die Siedlungs- und Verkehrsflächenentwicklung.

In BMVBS und BBSR (2009) wurden die Einflussfaktoren der Neuinanspruchnahme von Flächen detailliert untersucht. Die Ergebnisse zeigen, dass die Flächeninanspruchnahme ,nicht alleine mit der Nachfrage nach Siedlungsflächen aus Bevölkerung und Wirtschaft erklärt werden kann“. So konnten keine signifikant positiven Zusammenhänge zwischen Flächeninanspruchnahme und Beschäftigtenzahl, BIP oder Beschäftigtendichte gefunden werden. Vielmehr weisen die Ergebnisse darauf hin, dass sich Beschäftigungswachstum und Flächeninanspruchnahme nicht zwingend bedingen. Die Bereitstellung von Gewerbeflächen zieht also nicht unbedingt Beschäftigungseffekte 
nach sich, wenn es sich z. B. um die Verlagerung eines Betriebsstandortes handelt. Ein weiterer Erklärungsansatz ist der massive Beschäftigungszuwachs der letzten zehn Jahre in den Kernstädten, vor allem im Dienstleistungssektor, der ohne eine weitere Flächeninanspruchnahme vonstatten ging. Dieser Ansatz wird durch die Analyse der Beschäftigtendichte bestätigt. Die Flächenausweisung für Gewerbe-/Industrieentwicklung wird den Untersuchungen zufolge u. a. durch die Bereitstellung von Mitteln aus der Gemeinschaftsaufgabe zur Verbesserung der regionalen Wirtschaftsstruktur gefördert. Hohe Bodenpreise und der Trend zur höheren Flächenproduktivität bremsen demgegenüber den gewerblichen Flächenverbrauch.

Andererseits bestimmt die Angebotsplanung, d. h. die Baulandausweisung, durch die Kommunen den Flächenverbrauch maßgeblich mit. Üppige Baulandangebote werden in der Regel mit stadtentwicklungspolitischen und fiskalischen Interessen begründet und solange sich das kommunale Einnahmesystem in Deutschland stark an den Bevölkerungszahlen der Gemeinden orientiert, sehen sich Kommunen gezwungen, untereinander um neue Einwohner und insbesondere um junge Familien zu konkurrieren. Daher weisen entsprechende Untersuchungen auf einen Zusammenhang zwischen der Zuwanderung von Personen im für den Eigenheimerwerb relevanten Alter und der Intensität des Flächenverbrauchs hin (Einig 2011).

Bezogen auf die Entwicklung der THG-Emissionen aufgrund von Landnutzungsänderungen im Bereich Siedlung und Verkehr lassen sich bisher keine belastbaren Aussagen ableiten. Durch die Flächeninanspruchnahme werden einerseits Böden versiegelt und andererseits bei der Entwicklung von urbanen Grünflächen auch THG-Senken geschaffen.

Für die Entwicklung der THG-Emissionen sind vor allem wirtschaftliche Entwicklungen relevant, die nicht unmittelbar und zwingend mit einer Änderung von natürlicher oder landwirtschaftlicher Landnutzung hin zu Siedlungs- und Verkehrsfläche einhergehen müssen. So steigen die Emissionen mit stärkerer wirtschaftlicher Entwicklung auch auf bereits bebauten Flächen (BMUB 2013). Eine weitere Ausdehnung der Siedlungs- und Verkehrsfläche für wirtschaftliche Nutzungen kann darüber hinaus ebenfalls die THG-Emissionen erhöhen.

\subsection{Landnutzung in Deutschland}

Jana Hoymann, Sarah Baum, Peter Elsasser und Johanna Fick

\section{Zusammenfassung}

Der Definition von Landnutzung folgend wird zunächst die Landnutzung in Deutschland in ihrer flächenhaften Ausprägung dargestellt. Anschließend wird auf die Bewirtschaftung von land- und forstwirtschaftlichen Flächen eingegangen, die unter Berücksichtigung der Herausforderungen des fortschreitenden Klimawandels einen Beitrag zum Klimaschutz leisten kann. 


\subsubsection{Sektorübergreifende Flächennutzung}

Auf die Gesamtfläche Deutschlands mit rund 35,7 Mio. ha verteilen sich die Hauptnutzungsarten Landwirtschaft, Wald sowie Siedlung und Verkehr wie folgt: Im Jahr 2013 beanspruchte Siedlungs- und Verkehrsfläche 13,7 \% der Gesamtfläche Deutschlands. 52,5\% entfielen auf landwirtschaftliche Fläche und 30,5\% auf Waldflächen. Auf Gewässer und sonstige Nutzungen entfielen rund $3 \%$ der Fläche. Die Waldfläche verzeichnete seit 1992 einen Zuwachs von ca. 0,26 Mio. ha auf 10,8 Mio. ha im Jahr 2013. Während die Waldfläche somit seit dem Jahr 1992 um rund 0,7 Prozentpunkte der Gesamtfläche zunahm, wurden die Flächen für Siedlung und Verkehr kontinuierlich vor allem zu Lasten der Landwirtschaftsfläche ausgedehnt. So stieg der Anteil der Siedlungs- und Verkehrsfläche im Zeitraum von 1992 bis 2013 von 4,1 Mio. ha auf knapp 4,9 Mio. ha um gut 2,2 Prozentpunkte an der Gesamtfläche. Demgegenüber nahm die Landwirtschaftsfläche im gleichen Zeitraum von 19,9 Mio. ha auf 18,7 Mio. ha um 3,2 Prozentpunkte an der Gesamtfläche ab (vgl. Abb. 2.4).

Die Entwicklung der Flächennutzung vollzieht sich regional differenziert. Dies gilt für die gesamtdeutsche Entwicklung und für die Entwicklung innerhalb der Nutzungsarten (Siedlungsstruktur, Acker- und Grünlandnutzung, Baumartenzusammensetzung) (Abb. 2.5).

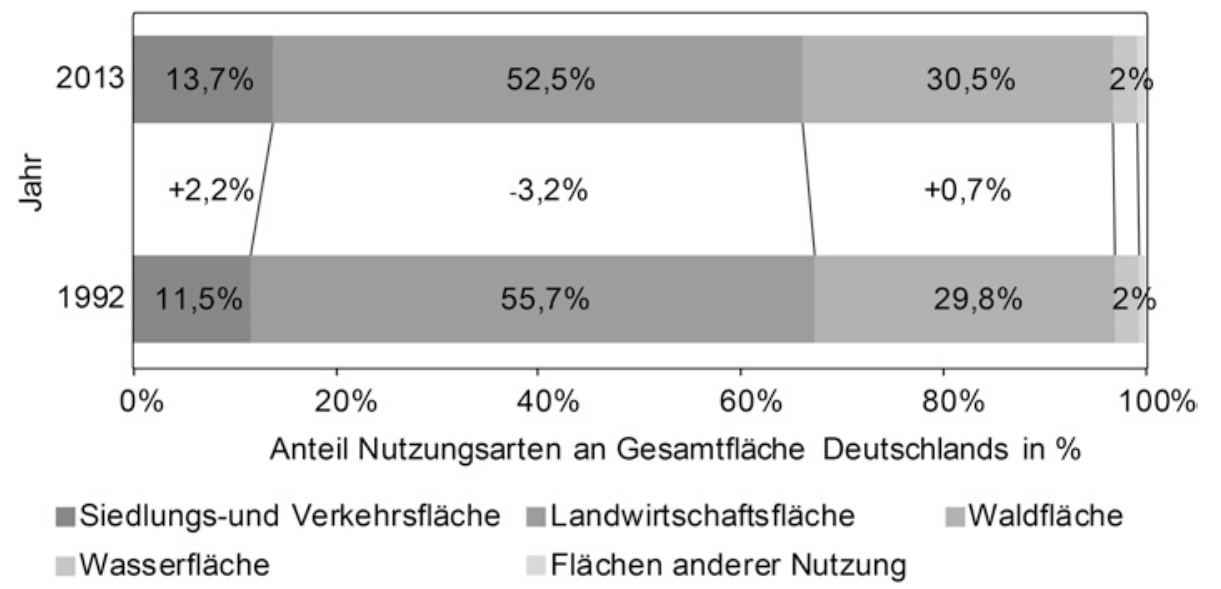

Abb. 2.4 Bodenfläche nach Nutzungsarten in Deutschland 1992 und 2013. (Quelle: Statistisches Bundesamt 2015) 
a

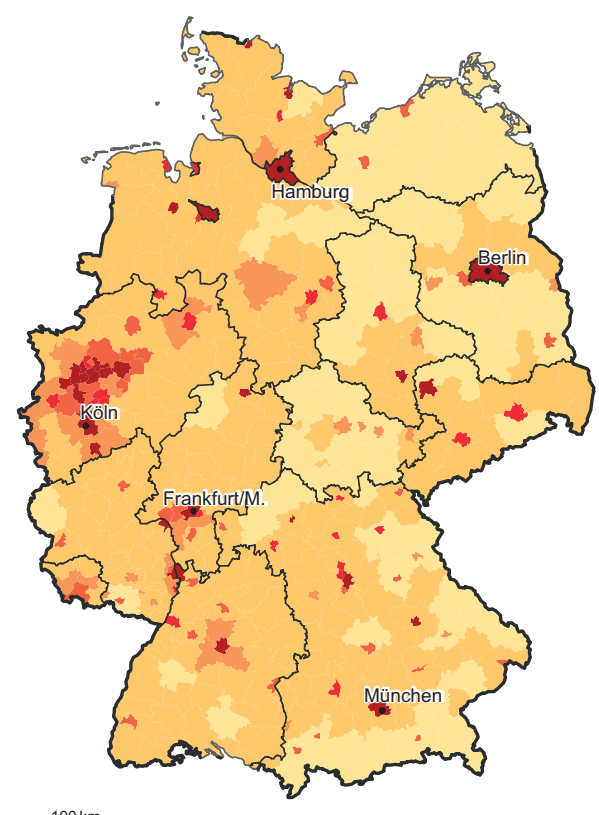

$100 \mathrm{~km}$ b

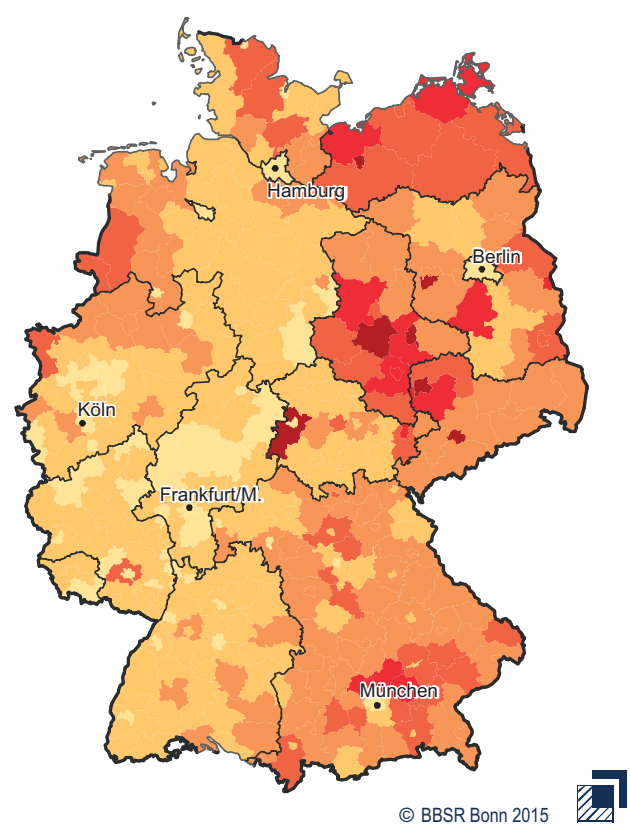

Anteil bzw. Veränderung der Siedlungsund Verkehrsfläche in Prozent

\begin{tabular}{|c|c|}
\hline & bis unter \\
\hline 10 & bis unter \\
\hline 20 & bis unter \\
\hline 30 & bis unter \\
\hline 40 & bis unter \\
\hline 50 & und mehr \\
\hline
\end{tabular}

Datenbasis: Laufende Raumbeobachtung des BBSR

Geometrische Datenbasis: BKG/BBSR Kreise, 31.12.2012

Die Entwicklung der Siedlungs- und Verkehrsfläche wird vor allem in Mecklenburg-Vorpommern,Sachsen-Anhalt und SchleswigHolstein auf Grund von Umschlüsselungen in der Statistik überschätzt.

Bearbeitung: J. Hoymann

Abb. 2.5 Flächennutzung in den Kreisen Deutschlands a Anteil der Siedlungs- und Verkehrsfläche an der Katasterfläche 2012, b Veränderung der Siedlungs- und Verkehrsfläche 1992 bis 2012 in \%, c Anteil der Landwirtschaftsfläche an der Katasterfläche 2012, d Veränderung der Landwirtschaftsfläche 1992 bis 2012 in \%, e Anteil der Waldfläche an der Katasterfläche 2012, f Veränderung der Waldfläche 1992 bis 2012 in \% 
C

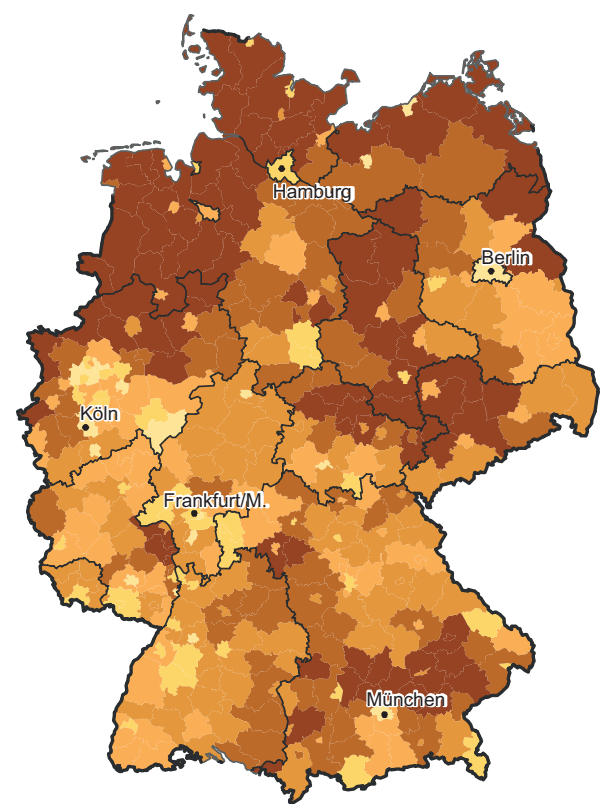

$100 \mathrm{~km}$ d

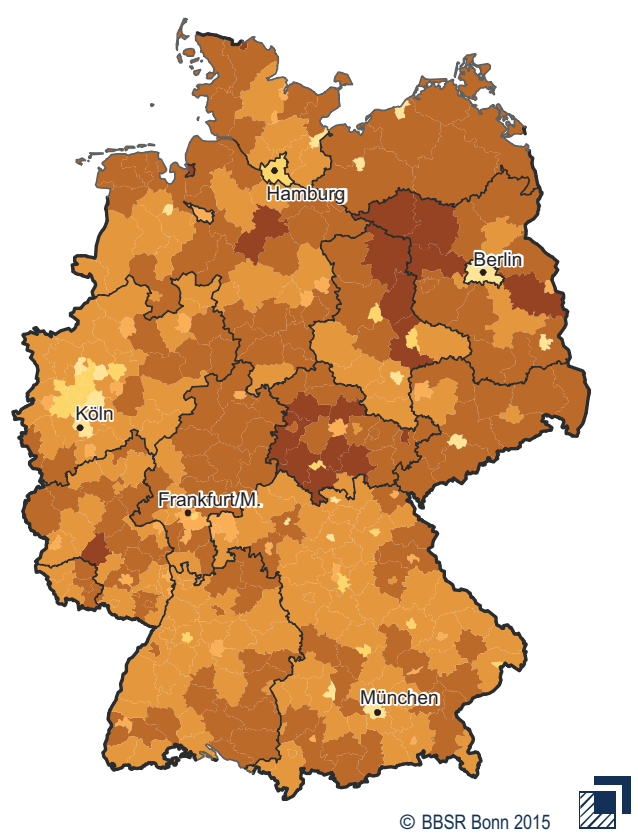

Anteil der Landwirtschaftsfläche an der Veränderung der Landwirtschaftsfläche Katasterfläche 2012 in Prozent 1992 bis 2012 in Prozent

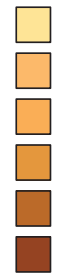

$\begin{array}{lll} & \text { bis unter } & 20 \\ 20 & \text { bis unter } & 30 \\ 30 & \text { bis unter } & 40 \\ 40 & \text { bis unter } & 50 \\ 50 \text { bis unter } & 60 \\ 60 \text { und mehr } & \end{array}$

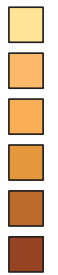

$\begin{array}{ccr} & \text { bis unter } & -20 \\ -20 & \text { bis unter } & -15 \\ -15 & \text { bis unter } & -10 \\ -10 & \text { bis unter } & -5 \\ -5 & \text { bis unter } & 0 \\ \text { Zuwachs } & \end{array}$

Datenbasis: Laufende Raumbeobachtung des BBSR

Geometrische Datenbasis: BKG/BBSR Kreise, 31.12.2012 Bearbeitung: J. Hoymann

Abb. 2.5 (Fortsetzung) 
e

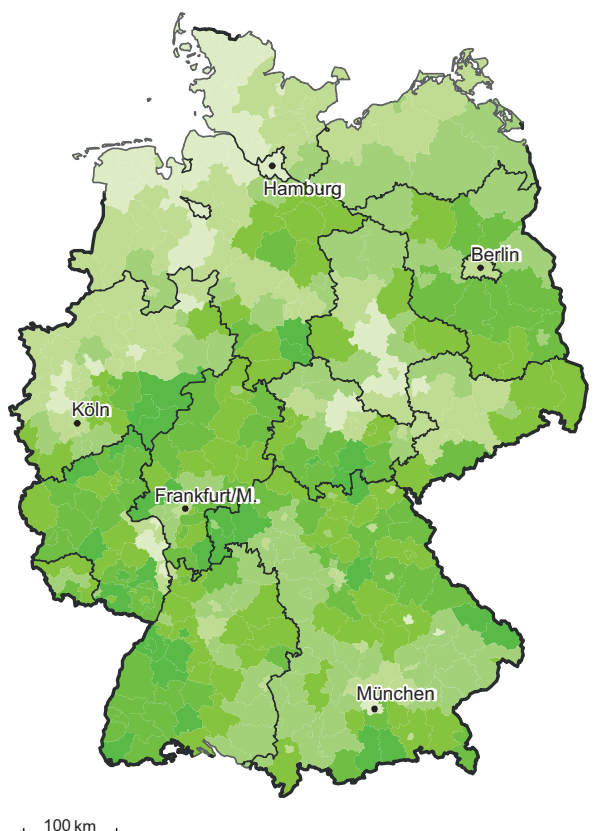

Anteil der Waldfläche an der Katasterfläche 2012 in Prozent

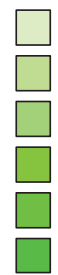

$\begin{array}{lll} & \text { bis unter } & 10 \\ 10 & \text { bis unter } & 20 \\ 20 & \text { bis unter } & 30 \\ 30 & \text { bis unter } & 40 \\ 40 & \text { bis unter } & 50 \\ 50 & \text { und mehr } & \end{array}$

Datenbasis: Laufende Raumbeobachtung des BBSR Geometrische Datenbasis: BKG/BBSR Kreise, 31.12.2012 Bearbeitung: J. Hoymann f

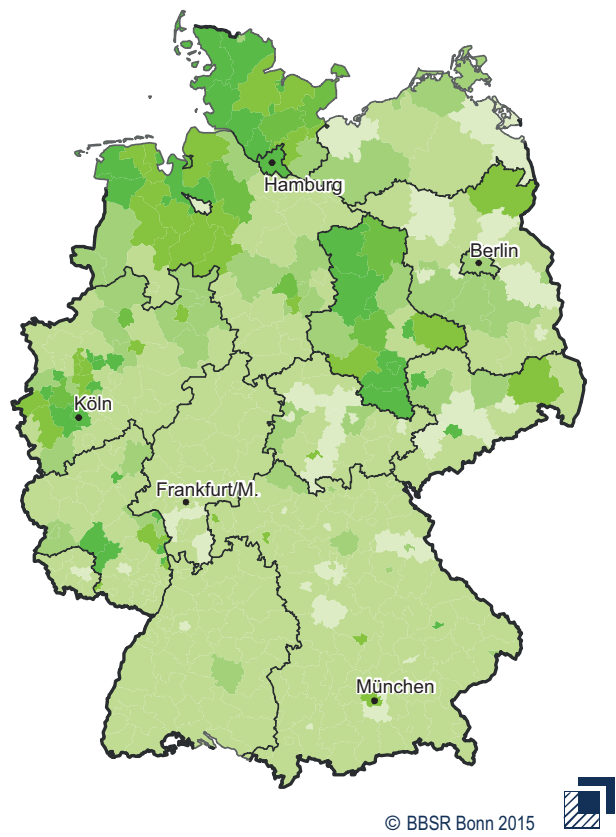

Veränderung der Waldfläche 1992 bis 2012 in Prozent

\begin{tabular}{|c|c|}
\hline & Verluste \\
\hline 0 & bis unter \\
\hline 5 & bis unter \\
\hline 10 & bis unter \\
\hline 15 & bis unter \\
\hline 20 & und mehr \\
\hline
\end{tabular}

Abb. 2.5 (Fortsetzung)

\subsubsection{Siedlungs- und Verkehrsfläche}

Die Siedlungs- und Verkehrsfläche teilt sich auf die Nutzungsarten Gebäude- und Freiflächen (51\%), Erholungsflächen (einschließlich Friedhöfe, 9,5\%), Betriebsflächen (ohne Abbauland, 1,9\%) und Verkehrsflächen (37,3\%) auf (Statistisches Bundesamt 2014). Die Zunahme der Siedlungs- und Verkehrsfläche hat sich seit Jahren verlangsamt. Im Mittel der Jahre 2009 bis 2013 betrug der Zuwachs 73 ha/Tag, während im Erhebungszeitraum 1997 bis 2000 noch ein Zuwachs von 129 ha/Tag verzeichnet 
wurde. Die jeweiligen Zuwächse der einzelnen Nutzungsarten haben sich allerdings unterschiedlich entwickelt. Die Flächenneuinanspruchnahme für Gebäude und Freiflächen ging von rund 78 ha/Tag im Zeitraum 1997 bis 2000 auf gut 26 ha/Tag im Zeitraum 2009 bis 2013 zurück. Nach vielen Jahren auf einem stabilen Niveau von rund 22 ha/Tag sank die Zunahme der Verkehrsflächen zuletzt deutlich auf knapp 17 ha/Tag. Die Flächeninanspruchnahme für Erholungsflächen nahm - bedingt durch statistische Umstellungen - zunächst von 20 ha auf über 40 ha zu, um nun wieder auf rund 22 ha am Tag zu sinken (Statistisches Bundesamt 2014). ${ }^{7}$

Die Entwicklungen der Siedlungs- und Verkehrsfläche zwischen Ost- und Westdeutschland verlaufen entgegengesetzt. Während in Ostdeutschland die Agglomerationsräume die stärksten prozentualen Zuwächse der Siedlungs- und Verkehrsfläche verzeichnen, trifft dies in Westdeutschland für die ländlichen Räume zu. Allerdings schrumpft in den ländlichen Räumen die Bevölkerung in beiden Landesteilen am stärksten, wobei es erhebliche Unterschiede im Umfang des Bevölkerungsrückgangs gibt. Einhergehend mit dieser Entwicklung nimmt die einwohnerbezogene Flächeninanspruchnahme in Regionen mit Bevölkerungsrückgang besonders stark zu, denn durch den Rückgang verteilen sich die geringeren Einwohnerzahlen auf eine weitgehend gleichbleibende SuV-Fläche. Dies trifft beispielsweise auf die ländlichen Kreise in Brandenburg, Sachsen-Anhalt und Mecklenburg zu. In wirtschaftlich und demographisch wachsenden Regionen stabilisieren sich die Siedlungsdichten, oder die proKopf-Flächeninanspruchnahmen nehmen sogar leicht ab. $\mathrm{Zu}$ diesen Regionen zählen z. B. Berlin, Hamburg, Düsseldorf, Köln, Bonn, Mainz, Wiesbaden und München (Dosch und Beckmann 2011, S. 6 f.).

Auch innerhalb der Siedlungs- und Verkehrsflächen spielen sich strukturelle Veränderungen $\mathrm{ab}$. Während einerseits neu gebaut wird, kann in vielen Regionen eine Zunahme des Wohnungs- und Gewerbeleerstands beobachtet werden. Vor allem in ländlichen Räumen sind Leerstände, die deutlich über die Fluktuationsreserven hinausgehen, zu verzeichnen. In ländlich-peripheren Räumen besteht eine geringe Aussicht auf Nachnutzung, sodass ein Trend zu Siedlungs-Perforation zu beobachten ist. Ost- und Westdeutschland sind von dieser Entwicklung gleichermaßen betroffen, wobei der Umfang der Brachflächenentwicklung sowie des Leerstandes in Ostdeutschland deutlich höher liegt.

Andererseits konnte Ostdeutschland im Gegensatz zu Westdeutschland die Leerstandsquoten in den vergangenen Jahren deutlich reduzieren. Dies ist vor allem auf die im Rahmen des Programms „Stadtumbau Ost“ durchgeführten Rückbaumaßnahmen zurückzuführen. Ursachen für Leerstände sind sinkende Nachfragen im Segment des

\footnotetext{
${ }^{7}$ Die massiven Zunahmen der Erholungsflächen sind nicht allein auf tatsächliche Nutzungsänderungen zurückzuführen. Aufgrund einer mehrjährigen Umstellungsphase der Flächenstatistik kommt es zu Umschlüsselungen und einer beeinträchtigten Auswertbarkeit der Datensätze. Nach Schätzungen des BBSR wird die Flächeninanspruchnahme durch Erholungsflächen um fast 20 ha überschätzt (Dosch und Beckmann 2011, S. 4).
} 
Mietgeschosswohnungsbaus aufgrund abnehmender Bevölkerung, sich verändernder Wohnpräferenzen oder schlechter Bausubstanz (BBSR 2012).

Während die meisten Regionen Deutschlands bereits seit einigen Jahren Bevölkerungsrückgänge verzeichnen, werden in einigen Kernstädten aktuell noch deutliche Bevölkerungszuwächse verzeichnet. Einflussfaktoren, die diese ,Renaissance der Großstädte“ begünstigen, sind die doppelten Abiturjahrgänge, die zum Studieren in die Stadt wandern, sind ältere Menschen, die in einer Stadt der kurzen Wege wichtige Einrichtungen fußläufig erreichen wollen und ist der Besatz mit Beschäftigten sogenannter Kreativberufe. Die Erschließung innerstädtischer Lagen mit der Entwicklung neuer Stadtquartiere begünstigt die Entwicklungen weiter. Dafür werden vor allem innerstädtische Brachflächen wieder der Nutzung zugeführt (Göddecke-Stellmann 2011, S. 5). Während somit in einigen Städten Konzentrationsprozesse zu beobachten sind, findet in den meisten Räumen Deutschlands nach wie vor eine disperse Siedlungsentwicklung statt.

Obwohl die Siedlungs- und Verkehrsfläche im Vergleich zu anderen Landnutzungen nur knapp $14 \%$ der Landesfläche bedeckt, wird aber der überwiegende Teil der anthropogen verursachten Treibhausgase von diesen Flächen emittiert. ${ }^{8}$ Darüber hinaus geht der Zuwachs der Siedlungs- und Verkehrsfläche vornehmlich zu Lasten qualitativ hochwertiger landwirtschaftlicher und naturnaher Flächenanteile, die in ihrer Funktion oft unwiderruflich verloren gehen. Ursache für diesen Trend ist, dass sich Siedlungsgebiete historisch oft in landwirtschaftlich ertragreichen Gebieten entwickelt haben. Zusätzlich führt der Flächenverbrauch zu Zerschneidungen der Landschaft, zu Einschränkungen der biologischen Vielfalt und der Erholungsfunktion (Dosch und Beckmann 2011). Das wichtigste Ziel für den Bereich Siedlung und Verkehr ist hiernach die nachhaltige Entwicklung, mit einer Begrenzung der täglichen Flächeninanspruchnahme auf 30 ha bis zum Jahr 2020. Das bedeutet, dass die räumliche Planung von Maßnahmen geprägt ist, die zu diesem Nachhaltigkeitsziel beitragen.

\subsubsection{Landwirtschaftliche Flächennutzung}

Die landwirtschaftliche Flächennutzung gliedert sich in Ackerflächen, Grünland und Dauerkulturen. Dabei sind die Landwirtschaftsfläche laut Katasterangaben (vgl. Abschn. 2.2.1) und die landwirtschaftlich genutzte Fläche laut Erhebung bei den landwirtschaftlichen Betrieben zu unterscheiden. Im Jahr 2013 umfasste die Landwirtschaftsfläche 18,6 Mio. ha, die landwirtschaftlich genutzte Fläche 16,7 Mio. ha (BMEL 2015a). Die durch die unterschiedlichen Erfassungsmethoden resultierende Differenz von etwa

${ }^{8}$ Dazu zählen Emissionen aus den Bereichen Energie, Industrieprozesse sowie Abfall und Abwasser, die im Jahr 2014 einen Anteil an den THG-Emissionen von über $90 \%$ haben (BMUB 2014). 
2 Mio. ha ist vor allem auf nicht-landwirtschaftliche Nutzungen wie beispielsweise Flächen für den Hobby- und Leistungsreitsport zurückzuführen.

Nachfolgend wird für die landwirtschaftliche Flächennutzung von der landwirtschaftlich genutzten Fläche (LF) ausgegangen, die im Jahr 2013 zu $71 \%$ als Ackerfläche, $28 \%$ als Grünland und zu $1 \%$ für Dauerkulturen genutzt wurde (BMEL 2015a). Der oben beschriebene Rückgang der Landwirtschaftsfläche zeigt sich auch in der landwirtschaftlich genutzten Fläche. Seit Mitte der 1990er-Jahre bis 2013 nahm diese Fläche insgesamt um rund 600.000 ha $(3,5 \%)$ ab. Der Rückgang erfolgte vor allem zu Lasten des Grünlandes, das trotz besonderem Schutz (Grünlandumbruchverbot) im gleichen Zeitraum um etwa 630.000 ha abnahm. Der Anteil von Grünland an der landwirtschaftlich genutzten Fläche ging damit von $31 \%$ um 3 Prozentpunkte zurück. Demgegenüber blieb die Ackerfläche im gleichen Zeitraum ebenso wie die Flächen für Dauerkulturen nahezu konstant bei knapp 12 Mio. ha bzw. rund 200.000 ha (BMEL 2015a). Bei der Interpretation der Entwicklung sind die Anhebungen der statistischen Erfassungsgrenzen für landwirtschaftliche Betriebe in den Jahren 1999 und 2010 auf 2 bzw. 5 ha zu beachten. Dadurch wurden jeweils rund 180.000 ha nicht mehr erfasst, wobei davon auszugehen ist, dass diese Kleinstbetriebe überwiegend Grünland bewirtschaften.

Die regionale landwirtschaftliche Nutzung hängt in erster Linie von den jeweiligen natürlichen Standortbedingungen ab. In der Regel werden Flächen in der Landwirtschaft als Dauergrünland genutzt, wenn aufgrund der natürlichen Voraussetzungen eine Ackernutzung nicht sinnvoll (nicht wirtschaftlich) ist (vgl. Abb. 2.6). Bei einem durchschnittlichen Grünlandanteil von rund $30 \%$ sind weit überdurchschnittliche Grünlandanteile von mehr als $40 \%$ für Küstenregionen, Mittelgebirge und das Voralpenland charakteristisch. Die Änderungen des Grünlandanteils sind im Zeitraum von 1999 bis 2010 regional sehr unterschiedlich. Während in den Küstenregionen, in SchleswigHolstein, Nordwest-Niedersachsen, am Niederrhein, Teilen der Eifel sowie den Voralpenregionen der Grünlandanteil teilweise um mehr als 10 Prozentpunkte der LF zurückging, wurde er in einigen Mittelgebirgsregionen und Teilen Brandenburgs ausgedehnt. Die ausgewiesenen Anteilsänderungen können sehr unterschiedliche Gründe haben. Beispielsweise wurde in dem Zeitraum Grünland in die Entkopplung der Direktzahlungen als zahlungsberechtigte Fläche einbezogen, sodass ein Anreiz bestand, bisher nicht erfasstes Grünland wieder in Bewirtschaftung zu nehmen. Ein weiterer Grund ist die Umwandlung von Grünland in Ackerland im Zuge steigender Nachfrage nach Agrarrohstoffen.

Die Änderungen der Rahmenbedingungen in der Landwirtschaft schlagen sich in der Struktur der Ackernutzung nieder. Infolge der GAP-Reform von 1992 belief sich die eingeführte Flächenstilllegung in den drei darauffolgenden Jahren auf durchschnittlich rund $11 \%$ der Ackerfläche (vgl. Abb. 2.7). Seit Mitte der 1990er-Jahre trat der Charakter der Flächenstilllegung in dem Maße in den Hintergrund wie der Anbau nachwachsender Rohstoffe auf der stillzulegenden Fläche an Bedeutung gewann. Infolge des Aussetzens 
a

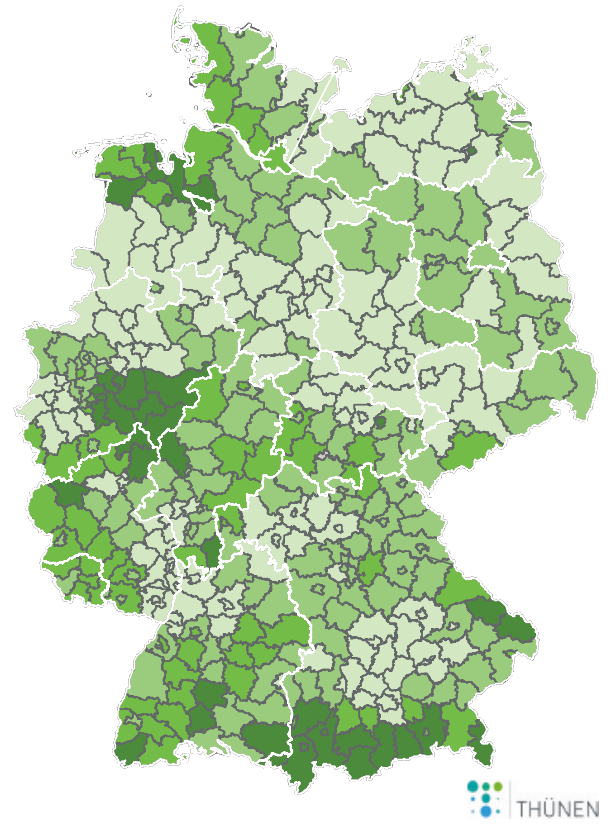

\section{Landwirtschaftlich genutzte Fläche Grünland 2010 in \%}

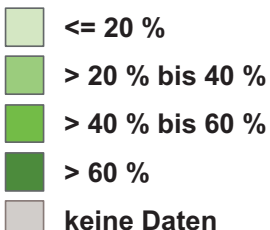

Quelle: Thünen Atlas (Gocht \& Röder, 2014), Datenbasis der Stat. Ämter der Länder, Kreisdaten der Landwirtschaftszählung 2010; Darstellung: Gebietsstand der Landwirtschaftszählung 2010 06.08.2014 nach VG250, BKG b

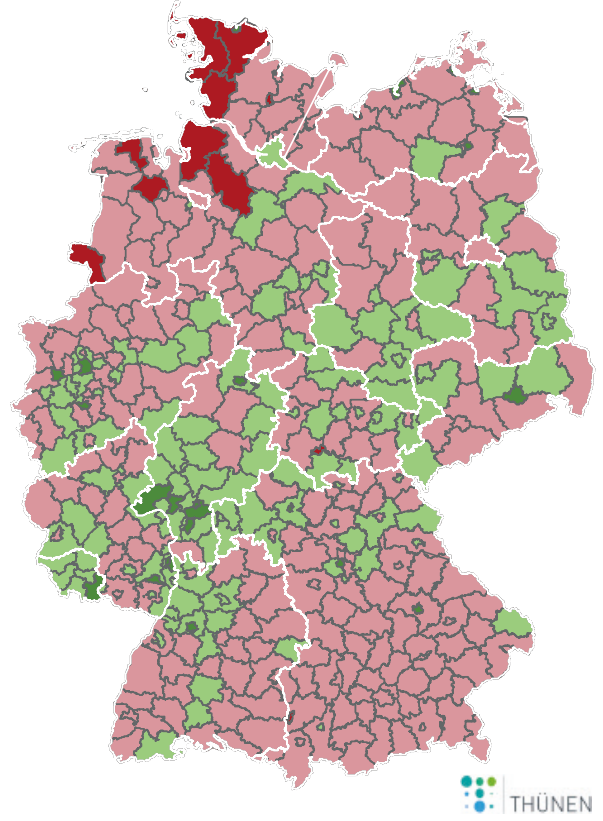

Veränderung der landwirtschaftlich genutzten Fläche Grünland 2010 zu 1999 in \%

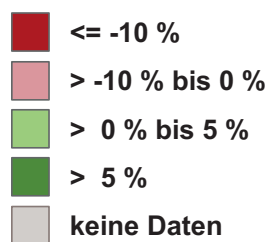

Quelle: Thünen Atlas (Gocht \& Röder, 2014), Datenbasis der Stat. Ämter der Länder, Kreisdaten der Landwirtschaftszählung 2010; Darstellung: Gebietsstand der Landwirtschaftszählung 2010 06.08.2014 nach VG250, BKG

Abb. 2.6 Regionale Grünlandanteile (in \% der LF) in 2010 (a) und deren Änderung 1999 bis 2010 (in Prozentpunkten der LF) (b)

der obligatorischen Flächenstilllegung im Jahr 2007 umfasst die Stilllegungsfläche lediglich freiwillig stillgelegte Flächen.

Die im Vergleich zu Getreide günstigere Preisentwicklung bei Ölsaaten führte in den letzten 20 Jahren zu einer Ausdehnung des Ölsaatenanbaus um etwa ein Drittel, und zwar von rund 1 Mio. ha auf etwa 1,5 Mio. ha (vgl. Abb. 2.7). Dieser Zuwachs ist nicht zuletzt auf die steigende Nachfrage nach Ölsaaten für die Biodieselerzeugung zurückzuführen. 


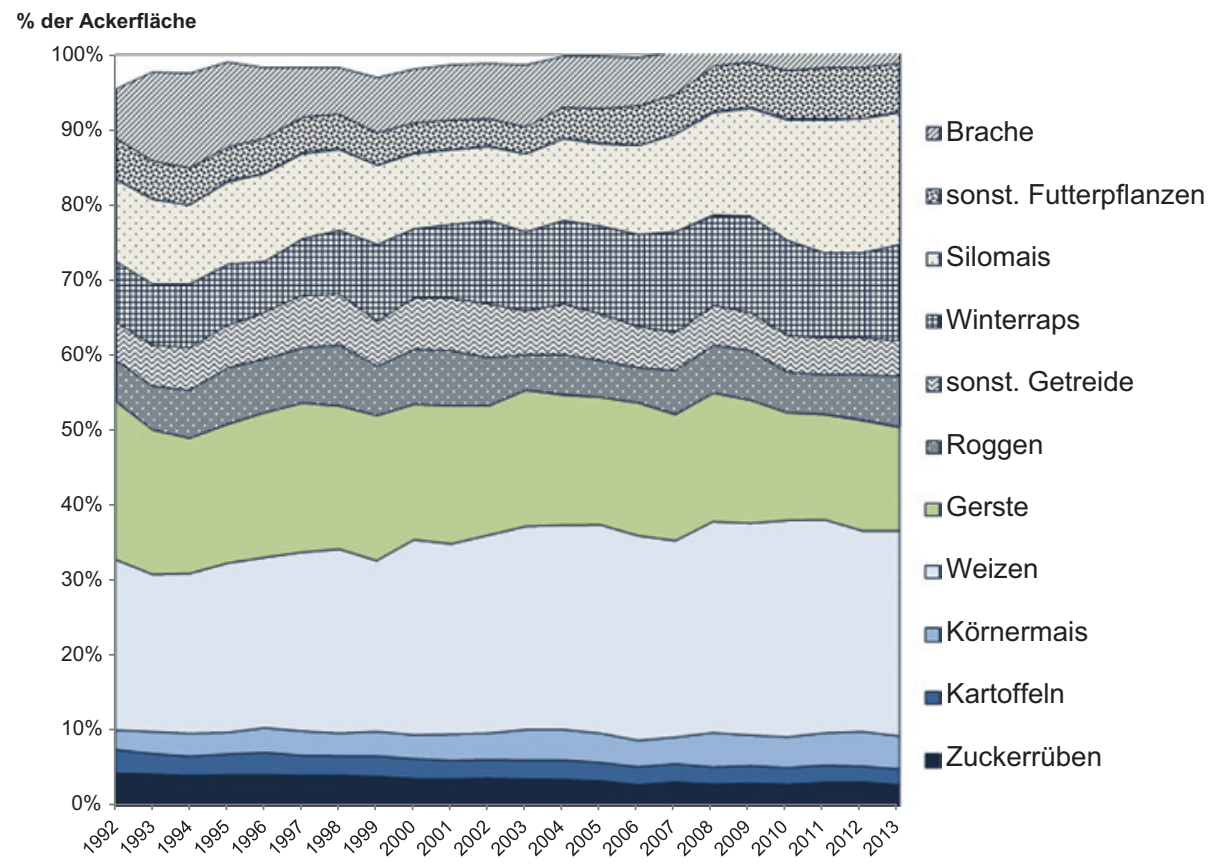

Abb. 2.7 Entwicklung der Ackernutzung in Deutschland nach Fruchtarten. (Quelle: Statistisches Bundesamt, Berechnungen des Thünen-Instituts)

Eine weitere markante Änderung der Ackerflächennutzung ergab sich durch die Förderung des Biomasseanbaus zur Biogaserzeugung, insbesondere infolge der Einführung des NawaRo-Bonus im Rahmen der Novellierung des Erneuerbare-Energien-Gesetzes 2004. Dieses löste einen starken Anstieg des Ackerfutteranbaus aus, insbesondere von Silomais um rund 1 Mio. ha, sodass der Ackerfutteranbau von 2000 bis 2013 von gut 13 auf knapp $22 \%$ der Ackerfläche zunahm.

In Deutschland ist ein anhaltender Trend einer dualen Entwicklung der Landnutzung zu beobachten. Während auf Gunststandorten eine Intensivierung stattfindet, wird die Produktion in weniger wettbewerbsfähigen Regionen extensiviert. Diese Entwicklung geht einher mit einer regionalen Spezialisierung der Produktion, beispielsweise bei Sonderkulturen wie Gemüse und Kartoffeln, aber auch bei der Milch- und Fleischproduktion.

Als Nutzer natürlicher Ressourcen hat die landwirtschaftliche Produktion verschiedene Umweltwirkungen. Auf der einen Seite trägt sie zur Offenhaltung der Landschaften bei und gewährleistet den Erhalt der Agrobiodiversität. Auf der anderen Seite erhöht sie durch Konzentration des Anbaus auf weniger Kulturen und der Intensivierung der Produktion den Druck auf Natur und Umwelt, wobei die Düngung mit Stickstoff (N) und Phosphor (P) eine wichtige Rolle spielt. Über die Prozesse der Nitrifizierung 
und Denitrifizierung im Stickstoffkreislauf bekommt Stickstoff eine relevante Funktion als Treibhausgas und als Gewässer belastender Einflussfaktor. Weitere Einflüsse auf das Klima gehen von Methan-Emissionen aus der Haltung von Wiederkäuern (Rinder) sowie Freisetzung von Kohlendioxid bei der landwirtschaftlichen Nutzung von organischen Böden (Moore) aus. Die insgesamt 5,1\% der deutschen Gesamtfläche umfassenden Moore sind zu ca. $62 \%$ Niedermoor-, $25 \%$ Anmoor- und $14 \%$ Hochmoorböden. Bedeutende Anteile der Moorflächen befinden sich vor allem in Niedersachsen (38\%), Mecklenburg-Vorpommern (20\%) und Brandenburg (16\%) (Flessa et al. 2012). Etwa $69 \%$ der Moorflächen werden landwirtschaftlich genutzt, wobei rund $33 \%$ auf Ackerund $67 \%$ auf Grünlandnutzung entfallen (Berechnung: S. Baum 2015).

\subsubsection{Forstliche Flächennutzung}

Umfassende, überwiegend naturale Informationen über Stand und Entwicklungspotenzial der Wälder in Deutschland gehen aus den Bundeswaldinventuren (BWI) hervor (vgl. Abb. 2.8). Aufgrund der erst gegen Ende der Studie veröffentlichten Vorabergebnisse der dritten Bundeswaldinventur (Oktober 2014) basieren die meisten Zahlenangaben für dieses Projekt auf Ergebnissen der zweiten Bundeswaldinventur aus dem Stichjahr 2002 (BMELV 2004, 2005; ergänzende, allerdings weniger umfassende Informationen bot die „Inventurstudie 2008“, Oehmichen et al. 2011). Daher wird im Folgenden der dieser Studie zugrundeliegende Stand nach der zweiten BWI (BWI $\left.{ }^{2}\right)$ (Stichjahr 2002) festgehalten [wo sich nach der neueren BWI ${ }^{3}$ (Stichjahr 2012) wesentliche Änderungen ergeben, wird jeweils in eckigen Klammern hingewiesen].

- Der Holzboden ${ }^{9}$ ist im Stichjahr 2002 zu etwa $58 \%$ mit Nadel- und zu $40 \%$ mit Laubbäumen bestockt; der Rest sind Lücken und Blößen [2012 hat sich dieses Verhältnis auf 54:43 angenähert]. Der größte Flächenanteil entfällt auf die Baumartengruppen Fichte $(28 \%)$ und Kiefer $(23 \%)$, gefolgt von Buche $(15 \%)$ und Eiche $(10 \%)$. Aufgrund unterschiedlicher standörtlicher, naturräumlicher und historischer Voraussetzungen variieren diese Anteile regional erheblich. So sind fast drei Viertel der brandenburgischen Waldfläche mit Kiefer bestockt. Die Fichtenanteile sind v. a. in den südlichen Bundesländern hoch (Bayern: $45 \%$, Thüringen: $42 \%$; Baden-Württemberg: $38 \%$; Sachsen: $35 \%$ ). Laubbaumreich mit jeweils über $50 \%$ der Waldfläche sind die Länder Saarland, Rheinland-Pfalz, Hessen und Nordrhein-Westfalen sowie SchleswigHolstein.

\footnotetext{
${ }^{9}$ Der Nichtholzboden (ca. 300.000 ha) ist ebenfalls ein Teil der Waldfläche und erfüllt wichtige Funktionen für den Forstbetrieb (z. B. als Holzlagerplätze), für die Erholung (z. B. Waldwege) und als Lebensraum für licht- und wärmebedürftige Tier- und Pflanzenarten.
} 


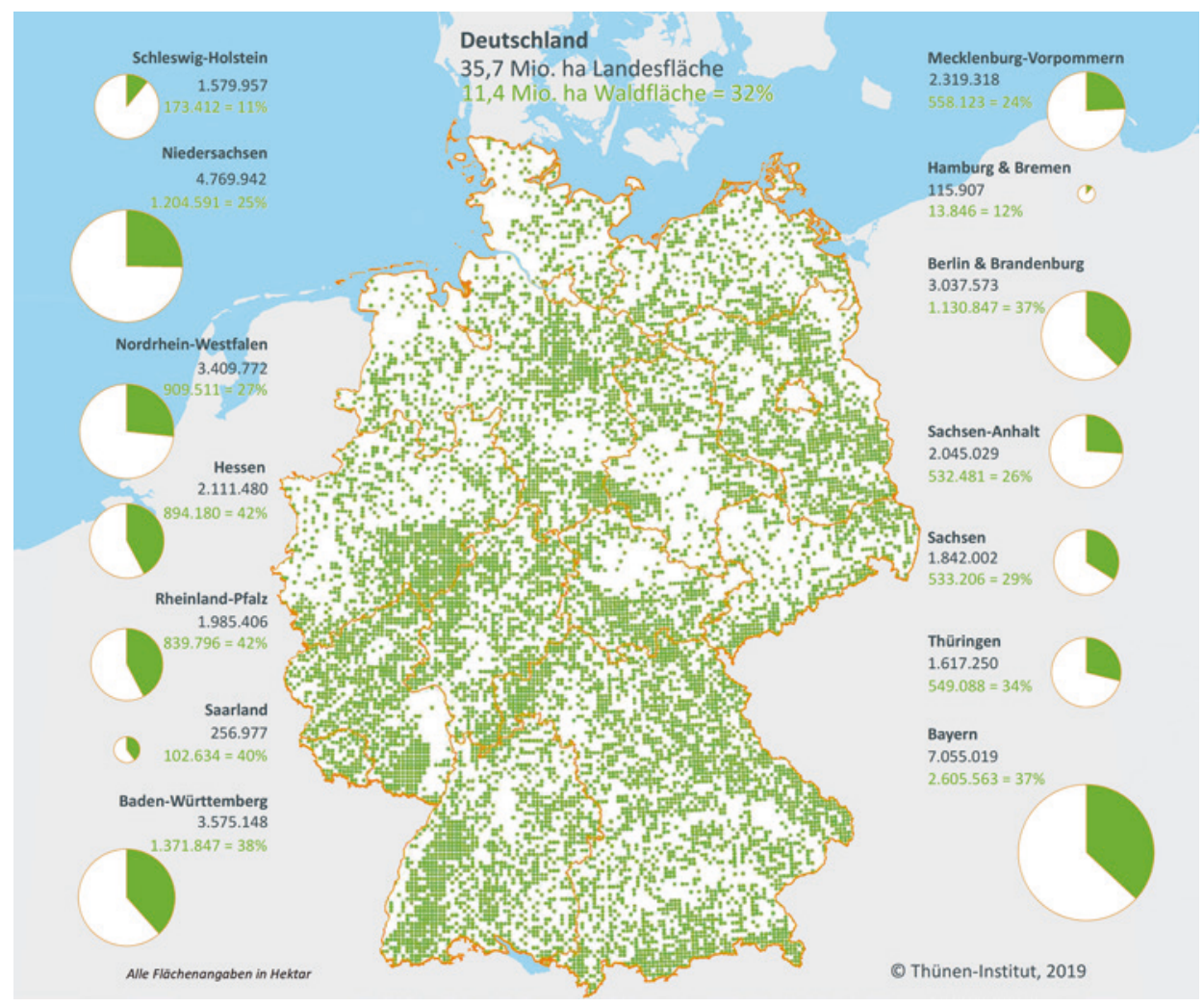

Abb. 2.8 Die Waldverteilung in Deutschland. (Datenquelle: Bundeswaldinventur)

- Die Altersstruktur der Wälder ist immer noch von den Folgen des Zweiten Weltkrieges (Zerstörungen, Reparationshiebe und nachfolgende Wiederaufforstungen) geprägt. Entsprechend finden sich überproportional viele Wälder im Alter um etwa 50 Jahre (21\% der Fläche entfallen auf die dritte Altersklasse von 41 bis 60 Jahren). Aufgrund dieser ungleichmäßigen Altersstruktur sind für die Zukunft Schwankungen der Holzvorräte vorprogrammiert, welche sich entsprechend auf Nutzungspotenziale und Kohlenstoffspeicherung auswirken und indirekt das Angebot weiterer Ökosystemleistungen des Waldes beeinflussen.

- Die Holzvorräte sind im Stichjahr 2002 auf durchschnittlich $320 \mathrm{~m}^{3} /$ ha angewachsen [2012: $336 \mathrm{~m}^{3} / \mathrm{ha}$ ], mit leicht überdurchschnittlichen Werten im Privatwald (338 [352] $\mathrm{m}^{3} / \mathrm{ha}$ ) und leicht unterdurchschnittlichen im Landes- und Bundeswald (311 bzw. 227 [327 bzw. 251] $\mathrm{m}^{3} / \mathrm{ha}$ ). Insgesamt stockten in Deutschland im Jahr 2002 Holzvorräte in Höhe von 3,4 Mrd. $\mathrm{m}^{3}$, die zu etwa zwei Dritteln auf Nadel- und zu einem Drittel auf Laubbäume entfielen [im Jahr 2012 waren sie weiter auf 3,7 Mrd. $\mathrm{m}^{3}$ angestiegen]. Über ein Drittel des gesamten Vorrates besteht allein aus Fichte (36\%), 
gefolgt von Kiefer $(21 \%)$. Buche folgt mit $17 \%$ an dritter Stelle. Der hohe Vorrat der Fichte, verglichen mit den prozentualen Flächenanteilen, resultiert aus dem historisch bedingten Schwerpunkt der Altersklassenverteilung der Fichte (u. a. Reparationsaufforstungen, s. o.) in den besonders vorratsreichen Jahrgängen zwischen 40 bis 100 Jahren.

- Der Zuwachs der Bäume ist für die zusätzliche Kohlenstoffspeicherung und damit für die Senkenleistung des Waldes entscheidend. Dieser konnte im Stichjahr 2002 nur für die alten Bundesländer bestimmt werden [2012 betrug er für alle Bundesländer und über alle Baumarten und Altersklassen hinweg durchschnittlich 11,2 $\mathrm{m}^{3}$ / ha*a]. Den höchsten Zuwachs erzielte die Altersklasse von 41 bis 60 Jahren $\left(16,6 \mathrm{~m}^{3}\right.$ / ha*a). Besonders zuwachsstark sind die Nadelbäume Douglasie, Tanne und Fichte; über alle Altersklassen hinweg sind hier durchschnittlich 19,4, 16,4 bzw. 16,0 m³ ha*a zugewachsen. Laubbäume, bei denen die Zuwachskurve allerdings mit dem Alter weniger stark abfällt, folgen mit erheblichem Abstand (angeführt von Buche mit durchschnittlich $\left.11,7 \mathrm{~m}^{3} / \mathrm{ha}^{*} \mathrm{a}\right)$.

Die Altersstruktur in Verbindung mit Vorräten bzw. Zuwachs haben wesentlichen Einfluss auf den Holzeinschlag. Dieser geht aus der $\mathrm{BWI}^{2}$ wiederum nur für die alten Bundesländer hervor. Hier betrug er durchschnittlich $8,3 \mathrm{~m}^{3} / \mathrm{ha}$ [2012 über alle Bundesländer: $8,9 \mathrm{~m}^{3} / \mathrm{ha}$ ] (jeweils gemessen in Vorratsfestmetern); beide Zahlen liegen deutlich unter dem Zuwachs, mit der Folge eines entsprechenden Vorratsaufbaus. Besonders im Laubholz kommt es aufgrund höherer Umtriebszeiten (Uz), vielfach fehlender Verarbeitungs- und Verwendungsmöglichkeiten und dem Mangel an innovativen Technologien sowie zukunftsträchtigen Absatzmärkten zu einer Kumulation der Vorräte in den höheren Altersklassen. Derzeit werden über alle Baumarten hinweg $93 \%$ des Zuwachses geerntet; nur bei der Fichte, deren Flächenanteile im Zuge des Waldumbaus abgesenkt werden soll, übersteigt die Nutzung den Zuwachs um etwa $30 \%$ (Oehmichen et al. 2011).

\subsection{Einordnung landnutzungsinduzierter THG-Emissionen}

Rene Dechow, Sarah Baum, Martin Gutsch und Johanna Fick

\section{Zusammenfassung}

Nach einem Überblick zu den THG-Emissionen in Deutschland werden die landnutzunginduzierten THG-Emissionen der Landwirtschaft und der Forstwirtschaft sowie von Siedlungs- und Verkehrsflächen beschrieben. Abschließend werden detailliert die landnutzungsinduzierten THG-Emissionen in den Fokusregion Altmark und Rhein erläutert. 


\subsubsection{Allgemeiner Überblick über THG-Emissionen in Deutschland}

In den letzten Dekaden ist ein paralleler Anstieg der globalen Temperatur und der atmosphärischen THG-Emissionen zu verzeichnen. Beobachtungen, Klimamodelle und Prozessverständnis deuten darauf hin, dass ein Großteil der Temperaturerhöhung auf den Anstieg der atmosphärischen THG-Konzentration zurückzuführen ist, die wiederum aus dem Ungleichgewicht von THG-Entstehung und -abbau resultiert. Seit Anfang des letzten Jahrhunderts tragen die stetig wachsenden anthropogenen Emissionen aus der Verbrennung fossiler Energieträger, industrieller und landwirtschaftlicher Produktion zum Anstieg der atmosphärischen THG-Konzentration bei. Des Weiteren werden natürliche Klimagassenken wie Wälder, Moore und Ozeane durch konkurrierende Landnutzungsansprüche und globale Klimaänderungen zunehmend in ihrer Wirkung beeinträchtigt. Im Rahmen internationaler Abkommen (UNFCCC, Kyoto-Protokoll) werden die anthropogenen Emissionen der aufgrund ihrer Abundanz und Klimawirksamkeit wesentlichen Treibhausgase durch die teilnehmenden Nationen dokumentiert.

Natürlich vorkommende Treibhausgase, die in den nationalen Emissionsinventaren erfasst werden, sind Kohlendioxid $\left(\mathrm{CO}_{2}\right)$, Lachgas $\left(\mathrm{N}_{2} \mathrm{O}\right)$ und Methan $\left(\mathrm{CH}_{4}\right)$. Hinzu kommen neuartige Treibhausgase wie Fluorchlorkohlenwasserstoffe (FCKW), Halone, vollfluorierte Kohlenwasserstoffe (FKW), teilfluorierte Kohlenwasserstoffe (HFKW) und Schwefelhexafluorid $\left(\mathrm{SF}_{6}\right)$. Die Klimawirksamkeit eines Treibhausgases (Treibhauspotenzial: Global Warming Potential (GWP)) ergibt sich aus der Verweilzeit in der Atmosphäre und der Fähigkeit, Infrarotstrahlung in einem bestimmten Wellenlängenbereich zu absorbieren. Dieser relative Beitrag zum THG-Effekt wird in Abhängigkeit des betrachteten Zeitraums in Kohlendioxid-Äquivalenten $\left(\mathrm{CO}_{2}\right.$ - ̈̈qu.) angegeben und beschreibt die Menge an $\mathrm{CO}_{2}$-Emissionen, die nötig ist, um die Klimawirksamkeit einer Gewichtseinheit des entsprechenden Gases zu substituieren. Bezogen auf einen Zeitraum von 100 Jahren wären dies $310 \mathrm{~kg} \mathrm{CO}$ für $1 \mathrm{~kg}$ Lachgas und $21 \mathrm{~kg} \mathrm{CO}_{2} / \mathrm{kg}$ Methan (Tab. 2.2).

Tab. 2.2 Nationale THG-Emissionen (936 Mio. $\mathrm{C} \mathrm{CO}_{2}$ - ̈̈qu.) und Hauptverursacher. (Quelle: NIR 2014)

\begin{tabular}{l|l|l|l}
\hline Treibhausgase & \%-Anteil & Hauptverursacher & $\begin{array}{l}\text { Relatives } \\
\text { THG-potenzial }\end{array}$ \\
\hline $\mathrm{CO}_{2}$ & 87,4 & $\begin{array}{l}\text { Verbrennung fossiler Energieträger } \\
(82,1 \%), \text { industrielle Prozesse }(5,6 \%), \\
\text { Moordegradierung (4,2 \%) }\end{array}$ & 1 \\
\hline $\mathrm{N}_{2} \mathrm{O}$ & 6,0 & $\begin{array}{l}\text { Landwirtschaft, industrielle Prozesse, } \\
\text { Verbrennung fossiler Brennstoffe }\end{array}$ & 310 \\
\hline $\mathrm{CH}_{4}$ & 5,2 & $\begin{array}{l}\text { Tierhaltung, Brennstoffverteilung, } \\
\text { Deponiewirtschaft }\end{array}$ & 21 \\
\hline $\begin{array}{l}\text { Fluorierte } \\
\text { Treibhausgase }\end{array}$ & 1,4 & Industrieprozesse & $140-23.900$ \\
\hline
\end{tabular}


Trotz des relativ geringen THG-Potenzials ist der Beitrag von Kohlendioxidemissionen $\mathrm{zu}$ den deutschen Gesamt-Emissionen nach dem jährlich erstellten deutschen THG-Inventar am höchsten (NIR 2014) (Tab. 2.2). Dies ist vor allem auf die Verbrennung fossiler Energieträger zurückzuführen. Daneben entstehen relevante Kohlendioxidemissionen in Zusammenhang mit industriellen Prozessen (Metall- und Chemieindustrie) und der Degradierung organischer Böden. Die Landwirtschaft ist die Hauptquellgruppe für Lachgas und Methan. Neuartige Treibhausgase wie fluorierte Treibhausgase aus der industriellen Produktion machen trotz der hohen bis sehr hohen THG-Potenziale nur einen geringen Anteil an der nationalen Gesamt-Emission aus.

Bei der Klimaberichterstattung werden sechs Sektoren unterschieden (Abb. 2.9), wobei der Sektor Energie mit rund $84 \%$ der größte THG-Verursacher ist. Zweitgrößter Emittent ist mit 7,4 \% bzw. 69.490 kt $\mathrm{CO}_{2}$-Äqu. der Sektor Landwirtschaft. Der Sektor Landnutzung, Landnutzungsänderung und Forstwirtschaft (LULUCF) ist trotz der hohen Emissionen von rund $48.500 \mathrm{kt} \mathrm{CO}_{2}$ - Äqu. insgesamt eine THG-Senke, da den Emissionen $\mathrm{CO}_{2}$-Sequestierung von etwa $52.000 \mathrm{kt} \mathrm{CO}$-Äqu. entgegensteht, die überwiegend aus Bodenhumus- und Biomasseaufbau des Waldes stammt (NIR 2014).

Die deutschen THG-Emissionen sind rückläufig (Abb. 2.10) und weisen für das Jahr 2012 eine Einsparung von 23,8 \% gegenüber dem Jahr 1990 auf. Dies ist vor allem auf Einsparungen von $\mathrm{CO}_{2}$-Emissionen im Energiesektor zurückzuführen. Die

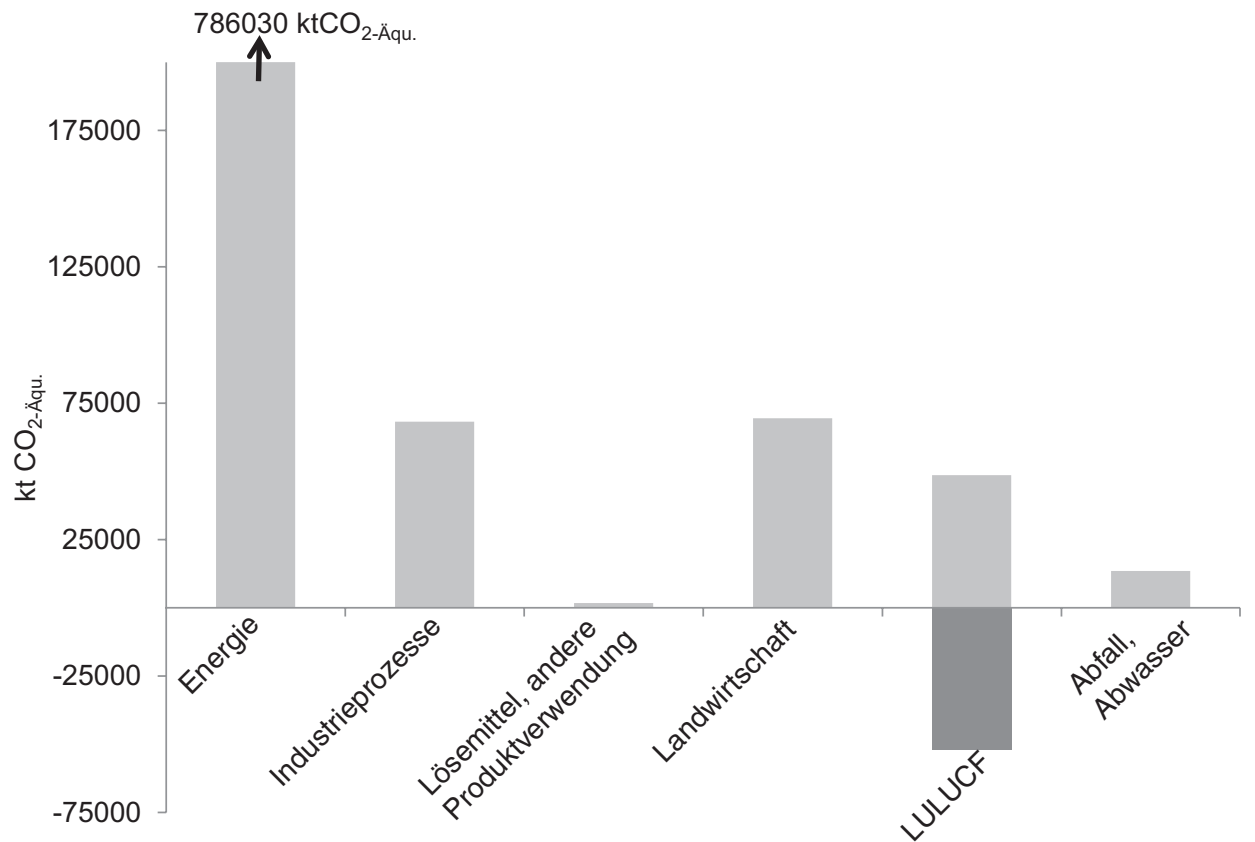

Abb. 2.9 THG-Emissionen nach Sektoren im Jahr 2012 in Deutschland. (Quelle: R. Dechow nach Angaben des NIR 2014) 


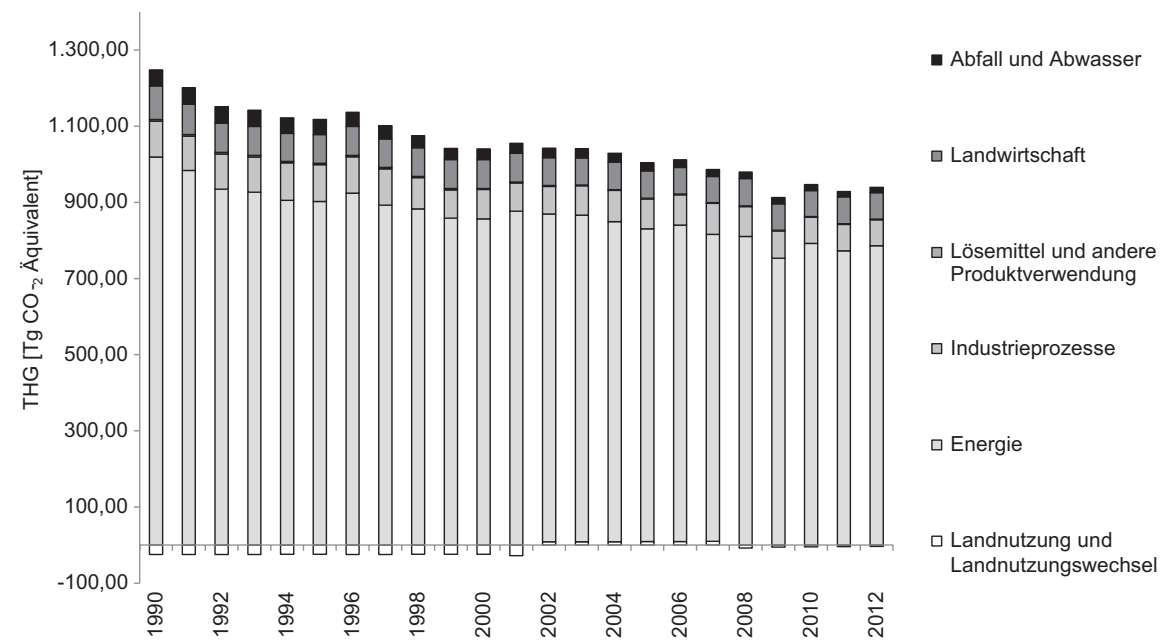

Abb. 2.10 Entwicklung der THG-Emissionen in Deutschland (LULUCF: Landnutzung und Landnutzungsänderung). (Quelle: NIR 2014)

Hauptursachen für den negativen Trend der Kohlendioxidemissionen sind die Folgen von Umstrukturierungsprozessen im östlichen Teil Deutschlands, die Umstellung auf emissionsärmere Energieträger und die Substitution von Benzin durch Diesel und Biokraftstoffe. Die Minderung von Methan-Emissionen um 55,2 \% wurde hauptsächlich durch eine bessere Abfalltrennung und den Rückgang der Tierbestände insbesondere in Ostdeutschland im Zuge der Wiedervereinigung erzielt, während eine Einsparung von Lachgas-Emissionen um 34,3\% vorwiegend auf technische Minderungsmaßnahmen im Industriesektor zurückzuführen ist. Der Anteil der landnutzungsbedingten Emissionen an den Gesamt-Emissionen, auf die im Folgenden eingegangen wird, erhöhte sich von 5,1 \% im Jahr 1990 auf 7 \% im Jahr 2012, bedingt durch eine verstärkte Nutzung forstwirtschaftlicher Produkte und die relativ geringere THG-Minderung der Sektoren Landwirtschaft und Landnutzung/Landnutzungsänderung im Vergleich zu den GesamtEmissionen.

\subsubsection{Landnutzungsinduzierte THG-Emissionen}

Als landnutzungsinduzierte THG-Emissionen werden hier alle THG-Quellen und -Senken verstanden, die sich direkt aus der Landnutzung ergeben, während THGEmissionen und -Einsparungen aus vor- und nachgelagerten Produktionsschritten nicht betrachtet werden. Unter Voraussetzung dieser Systemgrenzen ergeben sich THGEmissionen als Komponenten der Kohlenstoff- und Stickstoffkreisläufe anthropogen beeinflusster Ökosysteme. Kohlenstoff und Stickstoff werden über natürliche 
und anthropogene Pfade sowohl zugeführt (natürlich: Photosynthese, symbiotische Fixierung; anthropogen: Düngung) als auch abgeführt (natürlich: Auswaschung, gasförmige Emissionen; anthropogen: Ernte, Holzeinschlag). Ob ein System eine THGQuelle oder -Senke ist, ergibt sich aus der Bilanz von THG-Aufnahme und -Abgabe. Die am THG-Austausch beteiligten Stoffflüsse werden maßgeblich durch die Biozönose, insbesondere die Vegetation und Mikroorganismen, reguliert. Ökosysteme haben ein begrenztes Potenzial, als Klimagassenken zu fungieren. Das hat zwei Ursachen: limitierte THG-Aufnahmeraten und begrenzte Speicherung von abbaubaren Kohlenstoff- und Stickstoffverbindungen im Ökosystem. Die Aufnahmerate von Treibhausgasen wird durch die geringen bis sehr geringen atmosphärischen Konzentrationen dieser Gase eingeschränkt. Dies gilt insbesondere für die Treibhausgase Methan und Lachgas. Atmosphärisches Methan und Lachgas können durch Mikroorganismen im Boden aufgenommen und in die weniger klimarelevanten Gase Kohlendioxid und Stickstoff umgewandelt werden. Allein die Nachlieferung der Treibhausgase über diffusiven Transport aus der Atmosphäre in den Boden ist der Flaschenhals dieser Reaktionspfade, der einen relevanten Beitrag zur THG-Minderung verhindert. Atmosphärisches Kohlendioxid hingegen liegt in Konzentrationen vor, die im Rahmen der Photosynthese relevante Aufnahmeraten durch Ökosysteme ermöglichen. Schätzungen von LeQuere et al. (2009) gehen davon aus, dass die durch terrestrische Ökosysteme aufgenommene Menge atmosphärischen Kohlendioxids etwa einem Drittel der globalen anthropogenen Kohlendioxid-Emissionen entspricht.

Die Speicherfähigkeit von THG-Vorläufern ist ein weiterer wesentlicher Aspekt, der über die Effizienz eines Ökosystems, als THG-Senke zu fungieren, entscheidet. Anthropogene Ökosysteme wie Äcker, Grünland und Wälder speichern über Photosynthese und N-Fixierung gewonnenen Kohlenstoff und Stickstoff hauptsächlich in der Biomasse und in den Bodenhumusvorräten. Diese C- und N-Vorräte sind selbst Ausgangspunkt mikrobiell induzierter Abbauprozesse, die oft auf die Produktion von $\mathrm{CO}_{2}$ und zuweilen auf die Produktion von Lachgas und Methan hinauslaufen. Dabei entscheiden die Konzentration und die Vulnerabilität der C- und N-Ressourcen gegenüber mikrobiellem Abbau über die THG-Produktionsraten von Ökosystemen. Ökosysteme im Gleichgewichtszustand zeichnen sich dadurch aus, dass C- und N-Importe den C- und $\mathrm{N}$-Exporten entsprechen. Das heißt, bezogen auf $\mathrm{CO}_{2}$-Emissionen sind diese Systeme klimaneutral. Unter den im nationalen THG-Inventar getroffenen Annahmen (NIR 2014) gilt dies annähernd für alle landwirtschaftlich genutzten mineralischen Böden, die keinen Landnutzungswechseln unterliegen. Ungleichgewichte zwischen Importen und Exporten treten bei mineralischen Böden im Zuge von Landnutzungsänderungen auf (z. B. Umwandlung von Grünland zu Ackerland), was etwa $4 \%$ der THG-Emissionen der landwirtschaftlichen Bodennutzung hervorruft (vgl. Tab. 2.3). Demgegenüber sind genutzte organische Böden starke $\mathrm{CO}_{2}$-Quellen, da hier im Zuge der Bewirtschaftung durchgeführte Wasserstandsregulierungen Bedingungen für einen beschleunigten Abbau des über Jahrtausende gespeicherten Bodenkohlenstoffs schaffen, der durch Kohlenstoffimporte nicht kompensiert werden kann. Obgleich der Anteil der genutzten organischen 
Böden nur $7 \%$ der Landwirtschaftsfläche beträgt, sind diese Flächen für rund $50 \%$ der THG-Emissionen aus dem Bereich landwirtschaftliche Bodennutzung verantwortlich (vgl. Tab. 2.3).

Neben $\mathrm{CO}_{2}$-Emissionen organischer Böden sind Lachgas-Emissionen die zweite wesentliche THG-Quelle im Sektor Landwirtschaft und machen etwa $70 \%$ der nationalen Lachgas-Emissionen aus. Sie entstehen bei der landwirtschaftlichen Nutzung durch Überschüsse leicht verfügbaren Stickstoffs, der über die Düngung, Humusmineralisierung insbesondere drainierter organischer Böden, symbiotische N-Fixierung oder durch atmosphärische Deposition in den Boden gelangt. Hohe Stickstoffverluste (Ammoniak, $\mathrm{NO}_{\mathrm{x}}$-Auswaschung) und auch Lachgas-Emissionen treten in solchen Systemen auf, in denen große Mengen verfügbaren Stickstoffs als Stickstoffüberschüsse vorliegen. Für die Lachgasproduktion relevante Stickstoffüberschüsse finden sich in erster Linie in landwirtschaftlich genutzten Böden. Landwirtschaftlich genutzte Böden sind auch meist Ausgangspunkt lateraler Stickstoffflüsse, die natürliche und naturnahe Ökosysteme kontaminieren und auch dort zur Lachgasbildung beitragen. Demgegenüber sind natürliche Ökosysteme meist stickstofflimitiert, d. h., es sind nur geringe

Tab. 2.3 THG-Emissionen der landwirtschaftlichen Bodennutzung in Deutschland 2012. (Quelle: Eigene Darstellung von Thünen-Institut/R. Dechow, Daten aus dem NIR 2014)

\begin{tabular}{|c|c|c|c|}
\hline Quellgruppe & $\mathrm{CO}_{2}(\mathrm{kt})$ & $\mathrm{N}_{2} \mathrm{O}$ (kt $\mathrm{CO}_{2}$ - $\left.\mathrm{Äqu}.\right)$ & $\begin{array}{l}\text { Anteil an Emissionen } \\
\text { landwirtschaftliche } \\
\text { Bodennutzung }(\%)\end{array}$ \\
\hline Mineraldüngerausbringung & & 9540 & 11,37 \\
\hline Wirtschaftsdüngerausbringung & & 4693 & 5,59 \\
\hline Weidegang & & 1315 & 1,57 \\
\hline Ernterückstände & & 6171 & 7,36 \\
\hline Auswaschung & & 11.596 & 13,82 \\
\hline Deposition & & 2214 & 2,64 \\
\hline Kalkung & 1844 & & 2,20 \\
\hline Ackerland (org. Böden) & 22.617 & 2352 & 29,76 \\
\hline Grünland (org. Böden) & 10.178 & 2399 & 14,99 \\
\hline $\begin{array}{l}\text { LUC zu Ackerland (Mineral- } \\
\text { boden) }\end{array}$ & 3368 & 444 & 4,54 \\
\hline $\begin{array}{l}\text { LUC zu Ackerland (org. } \\
\text { Boden) }\end{array}$ & 3360 & & 4,00 \\
\hline $\begin{array}{l}\text { LUC zu Grünland (Mineral- } \\
\text { boden) }\end{array}$ & -727 & & $-0,87$ \\
\hline Biomasse aus LUC & 1293 & & 1,54 \\
\hline weitere Quellgruppen & 610 & 636 & 1,48 \\
\hline GESAMT & 42.544 & 41.360 & 100,00 \\
\hline
\end{tabular}


Auswaschungsverluste und Emissionen gasförmiger Stickstoffverbindungen zu verzeichnen. Die einzige Quelle, um Stickstoffverluste eines Ökosystems auszugleichen, wäre bei Vernachlässigung lateraler Flüsse die biologische Stickstofffixierung durch mit Leguminosen vergesellschafteten Knöllchenbakterien, bei der atmosphärischer Stickstoff zu biologisch verfügbarem Stickstoff transformiert wird. Da es sich hier um eher geringe Bildungsraten handelt und Mikroorganismen und Pflanzengesellschaften um diese knappen Ressourcen konkurrieren, sind Stickstoffkreisläufe natürlicher Ökosysteme relativ effizient.

Methanflüsse zwischen Atmosphäre und Ökosystemen sind, verglichen mit dem THG-Potenzial des $\mathrm{CO}_{2}$ - und $\mathrm{N}_{2} \mathrm{O}$-Austauschs, weniger relevant. Forstlich und landwirtschaftlich genutzte mineralische Böden sind in der Regel leichte Methansenken, während überstaute organische Böden oft größere Mengen Methan emittieren.

Die Landnutzungskategorien Landwirtschaft, Forstwirtschaft und Siedlung und Verkehr differieren bezüglich ihrer Klimawirksamkeit, was auf die Landnutzungsintensität, beteiligte Prozesse und Flächen zurückzuführen ist. Während die THG-Emissionen des Sektors Landwirtschaft vor allem durch anthropogen gesteuerte bodenbürtige Lachgas-Emissionen und THG-Emissionen organischer Böden bestimmt werden, sind forstwirtschaftlich genutzte Böden aufgrund der Bilanz aus photosynthetisch gebundenem Kohlenstoff und dem Kohlenstoffexport relevante Senken. Emissionen aus organischen Waldböden und Lachgas-Emissionen fallen weniger ins Gewicht. Die jüngsten nationalen Waldinventuren und Bodenzustandserhebungen zeigen, dass die forstwirtschaftlich genutzten Flächen mehr Kohlenstoff binden als über Respiration und Holzabfuhr aufgezehrt wird. Daher kompensierten die Wälder Deutschlands im Jahr 2012 etwa 5,5\% der anthropogenen Gesamt-Emissionen. Die Umwandlung von landwirtschaftlich und forstwirtschaftlich genutzten Flächen in Siedlungs- und Verkehrsfläche verursacht nur geringfügige THGEmissionen (Abb. 2.11).

\subsubsection{Landnutzungsinduzierte THG-Emissionen in der Landwirtschaft}

Die Emissionen des Sektors Landwirtschaft machen 7,4\% der deutschen GesamtEmissionen aus - bezogen auf das Jahr 2012 (NIR 2014) - und werden bei der Nationalen Klimaberichterstattung drei Quellgruppen zugeordnet: THG-Emissionen aus der Fermentation und Verdauung bei der Nutztierhaltung sind in erster Linie MethanEmissionen und mit etwa einem Drittel an den THG-Emissionen des Sektors Landwirtschaft beteiligt. Etwa $11 \%$ der landwirtschaftlichen THG-Emissionen entstehen durch Lagerung und Transport von Wirtschaftsdünger. Bei beiden vorab genannten Quellen handelt es sich nicht um landnutzungsbedingte Emissionen, weshalb sie hier nicht weiter berücksichtigt werden. Bei der dritten Quellgruppe handelt es sich um bodenbürtige Lachgas-Emissionen (59\% des Sektors Landwirtschaft; 4,4\% der deutschen Gesamt-Emissionen). Daneben sind der Landwirtschaft die Emissionen der Kategorie Landnutzung und Landnutzungsänderung zuzuordnen, an denen landwirtschaftlich genutzte Böden beteiligt sind. In der Summe emittieren landwirtschaftliche Böden unter Berücksichtigung der in Tab. 2.3 aufgeführten Kategorien aus den Quellgruppen 


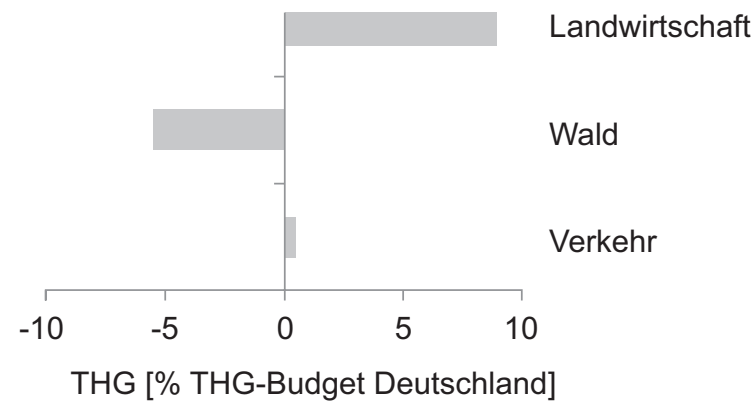

Abb. 2.11 Anteil landnutzungsbedingter THG-Emissionen am nationalen THG-Gesamtbudget („Verkehr“ repräsentiert Landnutzungswechsel zu Siedlungs- und Verkehrsflächen; negative Werte sind Senken). (Quelle: NIR 2014, Berechnung R. Dechow)

„Landwirtschaftliche Böden“ und „Landnutzung und Landnutzungsänderung“ ca. $9 \%$ (83.904 kt $\mathrm{CO}_{2}$-̈̈qu.) der gesamten THG-Emissionen, die im NIR für Deutschland berichtet werden. Etwa die Hälfte landnutzungsbedingter THG-Emissionen in der Landwirtschaft stammt aus der Nutzung organischer Böden (Tab. 2.3). Sie unterliegen einer hohen räumlichen Heterogenität, die im Wesentlichen der Verteilung von Nieder- und Hochmooren und der jeweiligen Nutzungsintensität folgt (Abb. 2.12).

In ungestörten organischen Böden (Niedermoore, Hochmoore, Anmoore) verhindern oder verzögern konstant oder periodisch hohe Bodenwassergehalte den mikrobiellen Abbau von Pflanzenresiduen, sodass beständig organische Substanz akkumuliert wird. Je nach Dauer dieses Prozesses und den hydrologischen Gegebenheiten entstehen C-reiche Torfhorizonte mit Mächtigkeiten von wenigen Zentimetern bis zu mehreren Metern. Die land- und forstwirtschaftliche Nutzung dieser Standorte geht meist mit einer künstlichen Absenkung des Grundwasserstandes einher, um Bewirtschaftung zu gewährleisten und optimale Erträge zu erzielen (Befahrbarkeit, Weidenutzung). Da mit der Absenkung des Grundwasserstandes nunmehr die bisher limitierende Sauerstoffverfügbarkeit gegeben ist, werden die unter diesen Bedingungen leicht abbaubaren Torfe mikrobiell zersetzt. Die damit verbundene Respiration führt zur Bildung von $\mathrm{CO}_{2}$. Die $\mathrm{CO}_{2}$-Emission genutzter organischer Böden hängt deshalb in erster Linie von den hydrologischen Verhältnissen $\mathrm{ab}$ (Jahreswasserstände als Indikator). Die Manipulation dieses Umweltfaktors bewirkt, dass über Jahrtausende angereicherte C-Speicher aufgezehrt werden. Die heterotrophe Respiration wird daneben auch über andere Systemfaktoren beeinflusst. $\mathrm{Zu}$ nennen sind hier die Abbaubarkeit des Ausgangssubstrats und die Bodentemperatur.

Die durch abgesenkte Wasserstände hohen Torfmineralisierungsraten führen zur Freisetzung von Ammonium und Nitrat. Dies sind Ausgangstoffe der Lachgas-bildenden 


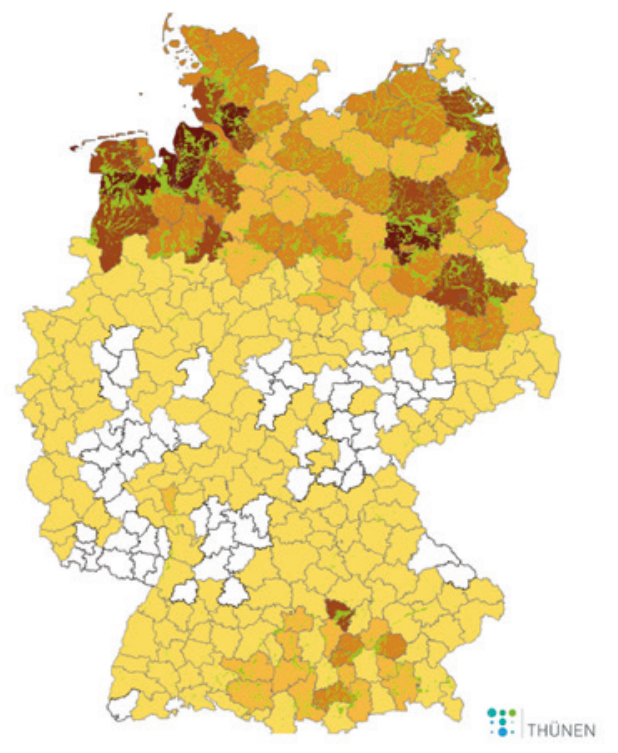

Treibhausgasemissionen organischer Böden $\mathrm{CO}_{2}$-Äquiv. [t $\left.\mathrm{CO}_{2} \mathrm{~km}^{2}\right]$

$\square$ keine org. Böden
$\square \quad$ unter 0.1
$\square 0.1$ bis $\quad 0.2$
$\square 0.2$ bis $\quad 0.3$
$\square 0.3$ bis $\quad 0.5$
$\square 0.5$ bis 0.9
$\square$ Org. Böden

Abb. 2.12 Verteilung modellierter THG-Emissionsraten organischer Böden pro Jahr und $\mathrm{km}^{2}$, bezogen auf die Landkreisfläche

Prozesse Nitrifikation und Denitrifikation. Während in mineralischen Böden die niedrigen Bodenwassergehalte limitierend für die Denitrifikation sind, stellen sich in dränierten organischen Böden oft optimale Wassergehalte ein. Aus diesen Gründen können dränierte organische Böden hohe Lachgasquellen sein. Dem wird bei der Klimaberichterstattung durch die Annahme einer einheitlichen Emissionsrate von $8 \mathrm{~kg}$ $\mathrm{N}_{2} \mathrm{O}-\mathrm{N}$ ha/a für genutzte (und damit meist drainierte) organische Böden Rechnung getragen. Zum Vergleich: Es gibt nur wenige Messungen auf landwirtschaftlich genutzten mineralischen Böden, auf denen ähnlich hohe Jahresraten gemessen wurden (Jungkunst et al. 2006). Naturnahe Moore emittieren kaum $\mathrm{N}_{2} \mathrm{O}$, da hier die Bodenwassergehalte meist zu hoch für die N-Mineralisierung sind und aufgrund des meist hohen $\mathrm{O}_{2}$-Defizits die Denitrifikationskette bis zum $\mathrm{N}_{2}$ durchlaufen wird. Methan entsteht bei der Umsetzung verfügbarer Biomasse durch methanogene Bakterien, vorzugsweise unter sauerstofflimitierten Bedingungen. Von entscheidender Bedeutung für die Methan-Emission ist die Aufenthaltszeit des produzierten Methans in der ungesättigten Bodenschicht beim Aufstieg in die Atmosphäre. Unter ungesättigten Bedingungen wird Methan durch methanotrophe Bakterien äußerst effektiv zu $\mathrm{CO}_{2}$ oxidiert. Die Qualität des abbaubaren Materials prägt in entscheidender Weise die Methanproduktion. 
Pflanzenresiduen wirtschaftlich genutzter Kulturen verfügen gegenüber der originären Vegetation über ein höheres Methanbildungspotenzial (Hahn-Schöfl et al. 2011). Der Grundwasserstand ist hinsichtlich der $\mathrm{CO}_{2}$-Emission - als auch der Methan-Emission als wichtige Steuergröße anzusehen. Besonders sensitiv reagieren $\mathrm{CH}_{4}$-Emissionen auf die Änderung jährlicher Wasserstände in einem Bereich von 10 bis $30 \mathrm{~cm}$ unter Flur.

Eine weitere bedeutende THG-Quelle landwirtschaftlich genutzter Böden sind Lachgas-Emissionen durch leicht abbaubare Stickstoffverbindungen, die über die Ausbringung von Mineraldünger, Wirtschaftsdünger und Klärschlamm, Weidegang, Ernterückständen und Leguminosen in die Böden gelangen (Tab. 2.3). Lachgas entsteht als ein Nebenprodukt der Nitrifikation bzw. als Zwischenprodukt der Denitrifikation und Nitrifier-Denitrifikation. Diese Prozesse werden durch im Boden oder Wasser lebende Mikroorganismen induziert. Die Nitrifikation ist eine Oxidation von Ammonium zu Nitrat, wobei Mikroorganismen die entstehende Energie zum Aufbau organischer Substanz und zur Erhaltungsatmung nutzen. Bei der Denitrifikation kompensieren Bakterien oder Pilze einen Mangel an Sauerstoff durch die Reduktion von $\mathrm{NO}_{3}$ in einer Kette über $\mathrm{NO}, \mathrm{N}_{2} \mathrm{O}$ $\mathrm{zu} \mathrm{N} \mathrm{N}_{2}$. Externe Faktoren, welche den Umsatz der mikrobiologischen Masse begünstigen, können sich demzufolge positiv auf die $\mathrm{N}_{2} \mathrm{O}$-Produktion auswirken. Hierzu zählen die Verfügbarkeit organischer Biomasse, die Temperatur und der pH-Wert. Sauerstoffmangel, verursacht durch einen hohen Wassergehalt und/oder eine erhöhte $\mathrm{CO}_{2}$-Produktion, begünstigt die Denitrifikation als die Hauptquelle der Lachgasbildung. Die Verfügbarkeit von Ammonium und Nitrat spielt eine Schlüsselrolle für die beschriebenen Prozesse. Die direkte $\mathrm{N}_{2} \mathrm{O}$-Emission zeichnet sich durch eine sehr hohe räumliche und zeitliche Dynamik aus. Frost-Tau-Zyklen und die Auffeuchtung trockener Standorte durch Niederschläge können über einen relativ kurzen Zeitraum sehr hohe Emissionen bedingen, wobei diese Emissionsspitzen bis zu 50 \% der jährlichen Emissionen ausmachen können (Dörsch 1999; Syväsalo et al. 2004; Dobbie et al. 2003). Das Auftreten derartiger Bedingungen ist demzufolge entscheidend für die freigesetzte Jahresemission (Freibauer et al. 2003).

Mehrere Auswertungen gemessener $\mathrm{N}_{2} \mathrm{O}$-Jahresemissionen in Mitteleuropa und Deutschland (Jungkunst et al. 2006; Freibauer et al. 2003; Dechow und Freibauer 2011) weisen darauf hin, dass Klima und Bodeneigenschaften eine starke räumliche Variabilität der Emissionspotenziale und somit der Mitigationspotenziale bedingen (Abb. 2.13).

Diese Studien zeigen für Deutschland, dass die Variabilität von $\mathrm{N}_{2} \mathrm{O}$-Emissionen aus Grünland fast ausschließlich durch Stickstoffdüngung beschrieben wird, während die Emissionspotenziale von Ackerstandorten ausgeprägten Ost-West- und Nord-SüdGradienten folgen, und damit die standörtliche Präferenz bezüglich Bodenfeuchte und Frost-Tau-Zyklen beschreiben. Neben Niedrigemissionsstandorten, auf denen Mitigationsmaßnahmen nur sehr geringe $\mathrm{N}_{2} \mathrm{O}$-Einsparungen versprechen, finden sich Regionen, in denen die Umsetzung von Minderungsmaßnahmen hohe Emissionseinsparungen erzielen kann.

Unter der Kategorie ,indirekte Emissionen“ werden die $\mathrm{N}_{2} \mathrm{O}$-Emissionen zusammengefasst, die nicht am Ort der Landnutzung entstehen, die aber durch verlagerte N-Ressourcen aus dem System verursacht werden. Dabei gibt es zwei Verlagerungspfade. 
a

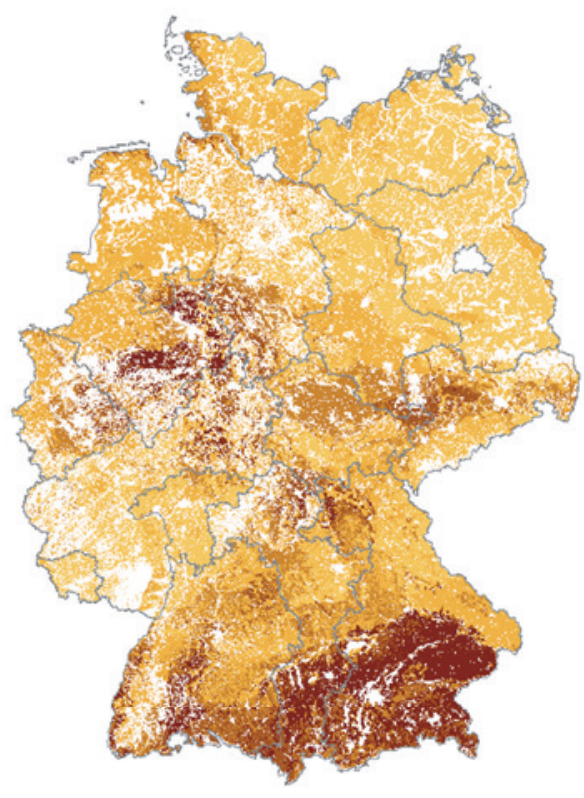

$\mathrm{N}_{2} \mathrm{O}$-Emissionen aus mineralisch genutzten Böden unter Acker [kg N$\left.{ }_{2} \mathrm{O}-\mathrm{N} \mathrm{ha}^{-1} \mathrm{a}^{-1}\right]$

$\square \quad$ unter 0.75
$\square 0.75$ bis 1.00
$\square 1.00$ bis 2.00
$\square .00$ bis 3.00
3.00 bis 4.00
4.00 bis 5.00
5.00 und mehr

b

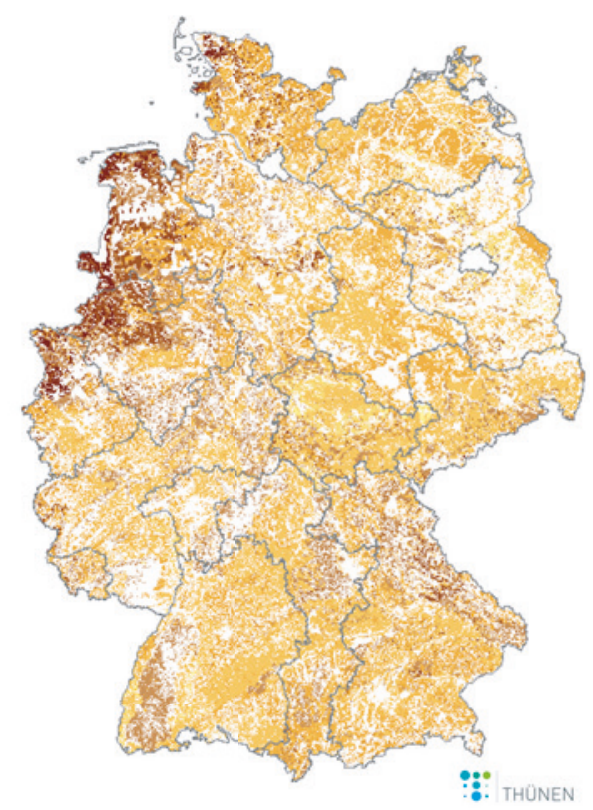

$\mathrm{N}_{2} \mathrm{O}$-Emissionen aus mineralisch genutzten Böden unter Grünland [kg N $\mathrm{N}_{2} \mathrm{O}-\mathrm{N} \mathrm{ha}^{-1} \mathrm{a}^{-1}$ ]

$\square$
$\square$
$\square .75$ bis 1.00
$\square$
1.00 bis 2.00
$\square .00$ bis 3.00
3.00 bis 4.00
4.00 bis 5.00
5.00 und mehr

Quelle: Dechow und Freibauer (2011)

Abb. 2.13 Modellierte Verteilung der mittleren Lachgas-Emissionen (1990-2005) Acker (a) und Grünland (b)

Reaktive Stickstoffverbindungen können über Oberflächenabfluss und Transportprozesse im Boden ins Grundwasser und Oberflächengewässer (Drainage) ausgewaschen werden, wo aufgrund der anaeroben Verhältnisse $\mathrm{N}_{2} \mathrm{O}$ als Zwischenprodukt der Denitrifikation entsteht und entweicht (11.596 kt $\mathrm{CO}_{2}$ - ̈̈qu.; 13,8 \%). Denitrifikation und Verflüchtigung von Ammoniak bei der Ausbringung von N-Düngern verursachen Emissionen gasförmiger reaktiver Stickstoffverbindungen $\left(\mathrm{NO}, \mathrm{NH}_{3}\right)$, die räumlich verlagert und an 
anderer Stelle (Wälder, genutzte und natürliche Ökosysteme, Inlandgewässer) über trockene und nasse (Auswaschung) Deposition eingetragen werden, wo sie als Ausgangsund Zwischenprodukte für Nitrifikation und Denitrifikation zur Verfügung stehen. Die über diesen Mechanismus gebildeten $\mathrm{N}_{2} \mathrm{O}$-Emissionen werden im NIR 2014 für das Jahr 2012 mit etwa 5,6 \% der gesamten $\mathrm{N}_{2} \mathrm{O}$-Emission aus dem Sektor Landwirtschaft quantifiziert.

\subsubsection{Landnutzungsinduzierte THG-Emissionen der Forstwirtschaft}

Wie Hochrechnungen zeigen (NIR 2014; BMEL 2014), sind deutsche Wälder Kohlenstoffsenken. Das heißt, im Schnitt sind die jährlichen Biomasseentnahmen und Respirationsverluste geringer als der jährliche Zuwachs. Der Nettozuwachs verteilt sich über die Waldbiomasse, Totholz und die Kohlenstoffspeicher in Streu und Boden. Im Jahr 2012 betrug der gesamte Kohlenstoffvorrat im Wald 2,02 Gt C. Gegenüber 1990 (1,68 Gt C) ist er damit um $20 \%$ gewachsen. Die Verteilung über die einzelnen Kohlenstoffspeicher im Wald ist in Tab. 2.4 dargestellt.

Die Akkumulation von Biomasse in Wäldern ist vom Alter des Bestandes abhängig (Jandl et al. 2007). Junge Bestände zeichnen sich durch vergleichsweise hohe Wachstumsraten aus, die sich bis zum Erreichen der Seneszenz verringern (Dieter und Elsasser 2002). In Anbetracht der Tatsache, dass derzeit der Anteil junger Bestände relativ hoch ist, ist nach Pistorius (2007) mit einer weiteren kontinuierlichen Reduktion dieser THG-Senke bis zum Erlöschen zu rechnen. Kohlmaier et al. (2007) vermuten, dass dies im Jahr 2040 der Fall sein wird, während Köhl und Dieter (2007) bereits ab 2030 mit einer ausgeglichenen C-Bilanz rechnen.

Die Quantifizierung des $\mathrm{CO}_{2}$-Austausches über Waldflächen wird im nationalen THG-Inventar über die Bilanzierungen verschiedener Waldinventuren (Bundeswaldinventur 1987, Datenspeicherwaldfonds für ostdeutschen Bundesländer, Bundeswaldinventur 2002, Inventurstudie 2008, Bundeswaldinventur 2012) und Bodenzustandserhebungen (BZE I, BioSoil, BZE II) realisiert (NIR 2014). Die im Inventar berechneten Nettozuwächse der Biomasse und die Änderungen der Bodenkohlenstoffvorräte entsprechen in ihrer zeitlichen Auflösung den Intervallen zwischen den jeweiligen Inventuren. Aktuell werden etwa 5,4\% des deutschen THG-Aufkommens über Biomasse und Bodenkohlenstoffzuwächse gespeichert. Davon stammen $9 \%$ aus Aufforstungsflächen. Im Mittel sind Aufforstungsflächen pro Flächeneinheit eine höhere temporäre $\mathrm{CO}_{2}$-Senke als bestehende Wälder (Abb. 2.14). Gleichwohl ist ihr Anteil am Gesamtbudget gering.

Tab. 2.4 Kohlenstoffvorrat im Wald. (Quelle: Wellbrock et al. 2014; BMEL 2014)

\begin{tabular}{l|l|l|l|l|l}
\hline & $\begin{array}{l}\text { Oberirdische } \\
\text { Biomasse [Mt C] }\end{array}$ & $\begin{array}{l}\text { Totholz } \\
{[\text { Mt C] }}\end{array}$ & $\begin{array}{l}\text { Streuauflage } \\
{[\text { Mt C] }}\end{array}$ & $\begin{array}{l}\text { Mineralboden } \\
\text { bis 30 cm [Mt C] }\end{array}$ & $\begin{array}{l}\text { Unterirdische } \\
\text { Biomasse } \\
{[\text { Mt C] }}\end{array}$ \\
\hline $\mathbf{1 9 9 0}$ & 748 & 11 & 203 & 595 & 123 \\
\hline $\mathbf{2 0 1 2}$ & 993 & 20 & 191 & 659 & 156 \\
\hline
\end{tabular}




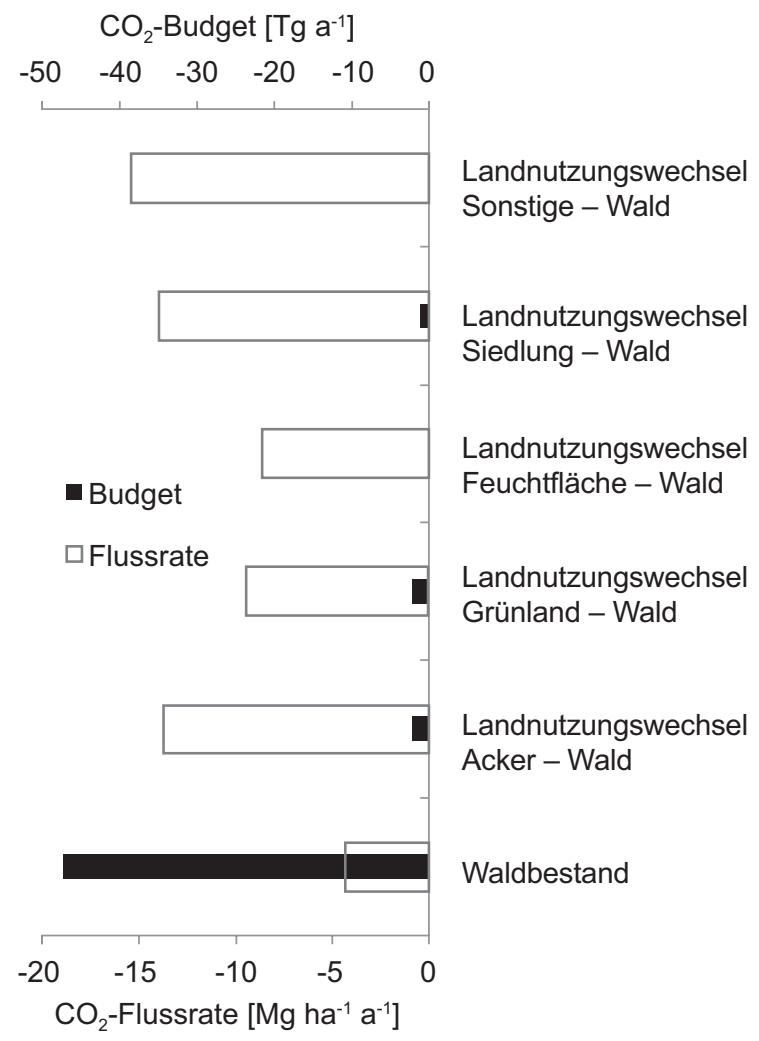

Abb. 2.14 Kohlendioxidsenke durch bestehende Forstflächen und Landnutzungsänderungen zu Forst als nationales Budget (schwarz) und Flussrate (grau). (Quelle: Daten aus NIR 2014 für das Jahr 2012)

Durchschnittlich wurden zwischen 2002 und 2012 jährlich 98,5 Mio. $\mathrm{m}^{3} \mathrm{Holz}$ (Nutzung, Ernteverluste, Rinde) entnommen (BMEL 2014). Die geschätzten jährlichen Substitutionseffekte des entnommenen Holzes belaufen sich auf 30,1 Tg $\mathrm{CO}_{2}$ - ̈̈qu. für energetische und 56,7 $\mathrm{Tg} \mathrm{CO}_{2}$ - ̈̈qu. für die stoffliche Nutzung (Rüter 2011), insgesamt also $86,8 \mathrm{Tg} \mathrm{CO}_{2}$ - $\mathrm{Äqu}$., was 9,3\% des deutschen THG-Aufkommens entspricht. Wie auch bei anderen terrestrischen Ökosystemen wirkt sich die Aufrechterhaltung eines hohen C-Imports positiv auf die Bodenkohlenstoffvorräte aus. Eine den Boden- und Klimabedingungen angepasste Artenwahl kann Störungen durch Windfall sowie Schädlingsbefall limitieren und damit indirekt zur Bewahrung der Kohlenstoffvorräte beitragen. Alte Baumbestände weisen verringerte C-Senkenfunktionen auf oder können sich gar in C-Quellen verwandeln (Jandl et al. 2007; Dieter und Elsasser 2002). Eine Alternative zur konservierenden Bewirtschaftung ist die Substitution fossiler Energieträger durch die Nutzung der Waldbiomasse hochproduktiver Wälder. Die so erzielte indirekte Einsparung von $\mathrm{CO}_{2}$-Emissionen ist im Gegensatz zur Kohlenstoffanreicherung in Wäldern zeitlich unbegrenzt (Janssens et al. 2003). 
Etwa $10 \%$ der organischen Böden befinden sich unter Wald. Den weniger intensiven Drainagemaßnahmen für Waldstandorte auf organischen Böden wird im nationalen Emissionsinventar über geringere Emissionsfaktoren Rechnung getragen. Demnach emittieren Waldstandorte im Mittel etwa $0,7 \mathrm{t} \mathrm{CO}_{2} \mathrm{C}$ ha/a durch Torfmineralisierung, während dies für organische Böden unter Acker- und Grünlandböden 11 bzw. 4,7 t $\mathrm{CO}_{2} \mathrm{C}$ ha/a sind ${ }^{10}$. Dementsprechend sind die $\mathrm{CO}_{2}$-Verluste durch Torfmineralisierung mit $612 \mathrm{Gg}$ pro Jahr (NIR 2014) vergleichsweise gering (etwa $2 \%$ der $\mathrm{CO}_{2}$-Verluste organischer Böden unter landwirtschaftlicher Nutzung). Landnutzungsbedingte Lachgas-Emissionen über Deposition und lateralen Transport im Grund- und Oberflächenwasser durch anthropogene Einträge leicht verfügbarer Stickstoffverbindungen fallen unter die indirekten Emissionen.

\subsubsection{Landnutzungsinduzierte THG-Emissionen der Siedlungs- und Verkehrsflächen}

THG-Emissionen durch Siedlungs- und Verkehrsflächen sind in erster Linie $\mathrm{CO}_{2}$-Verluste aus dem Abbau von oberirdischer und unterirdischer Biomasse (4149 $\mathrm{Gg} \mathrm{CO}_{2}$ ). Etwas mehr als die Hälfte der $\mathrm{CO}_{2}$-Emissionen aus Landnutzung und Landnutzungsänderung (LULUCF) in 2012 wurde durch die Drainage organischer Böden verursacht (NIR 2014), während die restlichen $\mathrm{CO}_{2}$-Emissionen aus der Entstehung neuer Siedlungsfläche vormaliger landwirtschaftlich und forstwirtschaftlich genutzter Flächen auf Mineralböden stammen. Die THG-Emissionsraten sind über Siedlungs- und Verkehrsflächen organischer Böden am höchsten, während landnutzungswechselbedingte THG-Emissionen in Abhängigkeit von der ursprünglichen Landnutzung variieren (Abb. 2.15). Die THG-Emissionen des Sektors Siedlung und Verkehr folgen dem Trend einer stetigen Zunahme der Siedlungsflächen.

\subsubsection{Landnutzung und THG-Emissionen in den Fokusregionen}

\section{Fokusregionen: Struktur der landwirtschaftlichen Landnutzung}

Die Fokusregionen Altmark und Rhein unterscheiden sich stark hinsichtlich ihrer landwirtschaftlichen Struktur. Folglich sind auch verschiedene Hauptquellen der THGEmissionen zu identifizieren. Im Folgenden werden diese Unterschiede im Vergleich zu Deutschland näher betrachtet. Die Analysen erfolgten auf Basis des deutschen Landschaftsmodells (DLM, 2010) des Bundesamtes für Kartographie und Geodäsie (BKG), das die Landnutzung abbildet. Vorteilhaft an dieser Datenbasis ist die einheitliche,

\footnotetext{
${ }^{10} \mathrm{Im}$ Zeitraum der Erstellung der Studie wurden Anpassungen vorgenommen, die hier nicht mehr berücksichtigt werden konnten: $-2,25 \mathrm{t} \mathrm{CO}_{2} \mathrm{C}$ ha/a (Wald); $-8,1 \mathrm{t} \mathrm{CO}_{2} \mathrm{C}$ ha/a (Acker); $-6,19 \mathrm{t}$ $\mathrm{CO}_{2} \mathrm{C}$ ha/a (Grünland).
} 
Abb. 2.15 THG-

Emissionsraten für bestehende

Siedlungs- und Verkehrsflächen und Landnutzungswechsel

zu Siedlungs- und

Verkehrsflächen

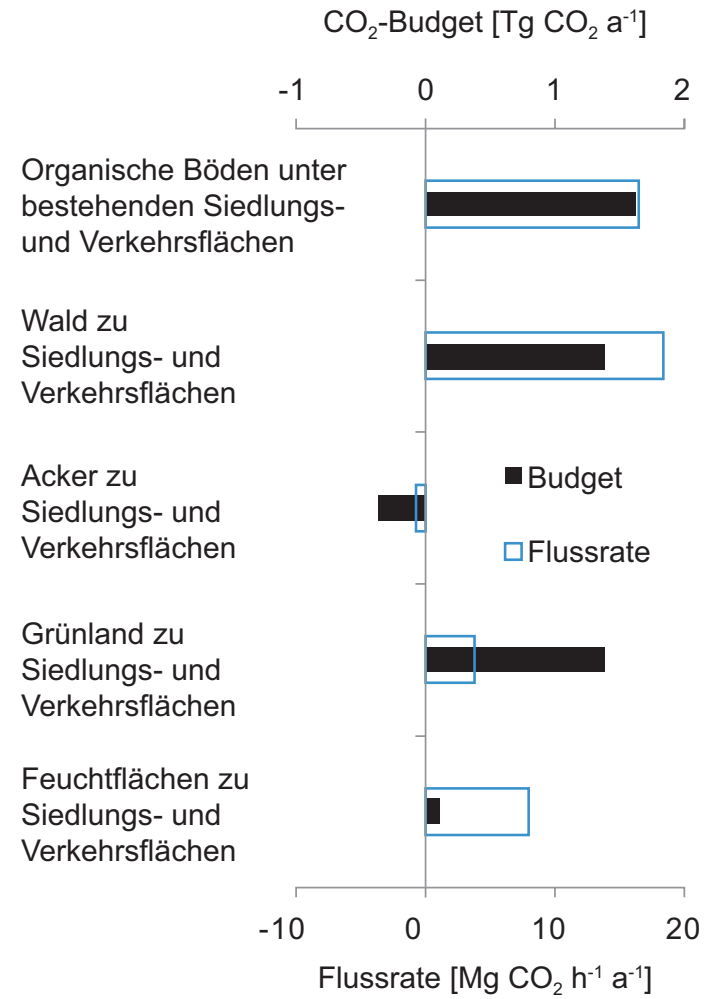

flächendeckende, georeferenzierte Nutzungsinformation für Deutschland sowie die konsistente Erfassungsmethode. Die Qualität der Datenbasis ist durch fehlende Aktualität der Daten aufgrund eines sechsjährigen Aktualisierungszyklusses, noch vorhandenen technischen Einschränkungen und Ungenauigkeiten z. B. bei den Daten aus Befliegungen sowie Zuordnungen von Flächen nach dem Belegungsprinzip eingeschränkt. Wie Röder und Grützmacher (2012) für organische Böden darstellen, führt die Nutzung des DLM zu einer Überschätzung der landwirtschaftlichen Nutzung. Jedoch liegt im Datenumfang und den möglichen Verschneidungen beispielsweise von Flächenkulissen mit besonderem Schutzsstatus (z. B. Landschaftsschutzgebiet, Nationalpark) das besondere Potenzial des DLM und der Grund für die Nutzung in der vorliegenden Analyse.

\section{Fokusregion Altmark (Landkreise Stendal und Altmarkkreis Salzwedel)}

Die Altmark ist mit einem Anteil von 12,2 \% der Landwirtschaftsfläche auf organischen Böden stärker als der Bundesdurchschnitt durch organische Böden geprägt, wo es 7,0 \% sind. Eine separate Betrachtung der beiden Landkreise zeigt, dass der Anteil vor allem 
im Altmarkkreis Salzwedel mit 18,1 \% hoch ist, während im Landkreis Stendal 7,0 \% der Landwirtschaftsfläche auf organischen Böden liegen.

Die Altmark verfügt über 320.000 ha Landwirtschaftsfläche, deren Nutzung der deutschlandweiten gleicht. Ackerflächen nehmen mit 68,9 \% in der Altmark bzw. 65,5 \% in Deutschland den jeweils größten Teil der Landwirtschaftsfläche ein, wobei 3,0 \% bzw. $2,1 \%$ der Ackerflächen auf organischen Böden sind. In der Altmark werden 30,9\% als Dauergrünland bewirtschaftet, wovon ein großer Teil auf organischen Böden liegt und etwa $30 \%$ des Dauergrünlands entspricht. In Deutschland sind dies 32,6\% bzw. 4,8 \%. Gartenland und Sonderkulturen nehmen in der Altmark lediglich 0,01 \% der Fläche ein, während es in Deutschland 1,9 \% (0,05 \% auf organischen Böden) sind (Abb. 2.16).

Sowohl in Deutschland als auch in der Altmark wird auf der Hälfte der Ackerfläche Getreide angebaut. Den zweitgrößten Anteil hat Silomais mit $20 \%$ in der Altmark bzw.
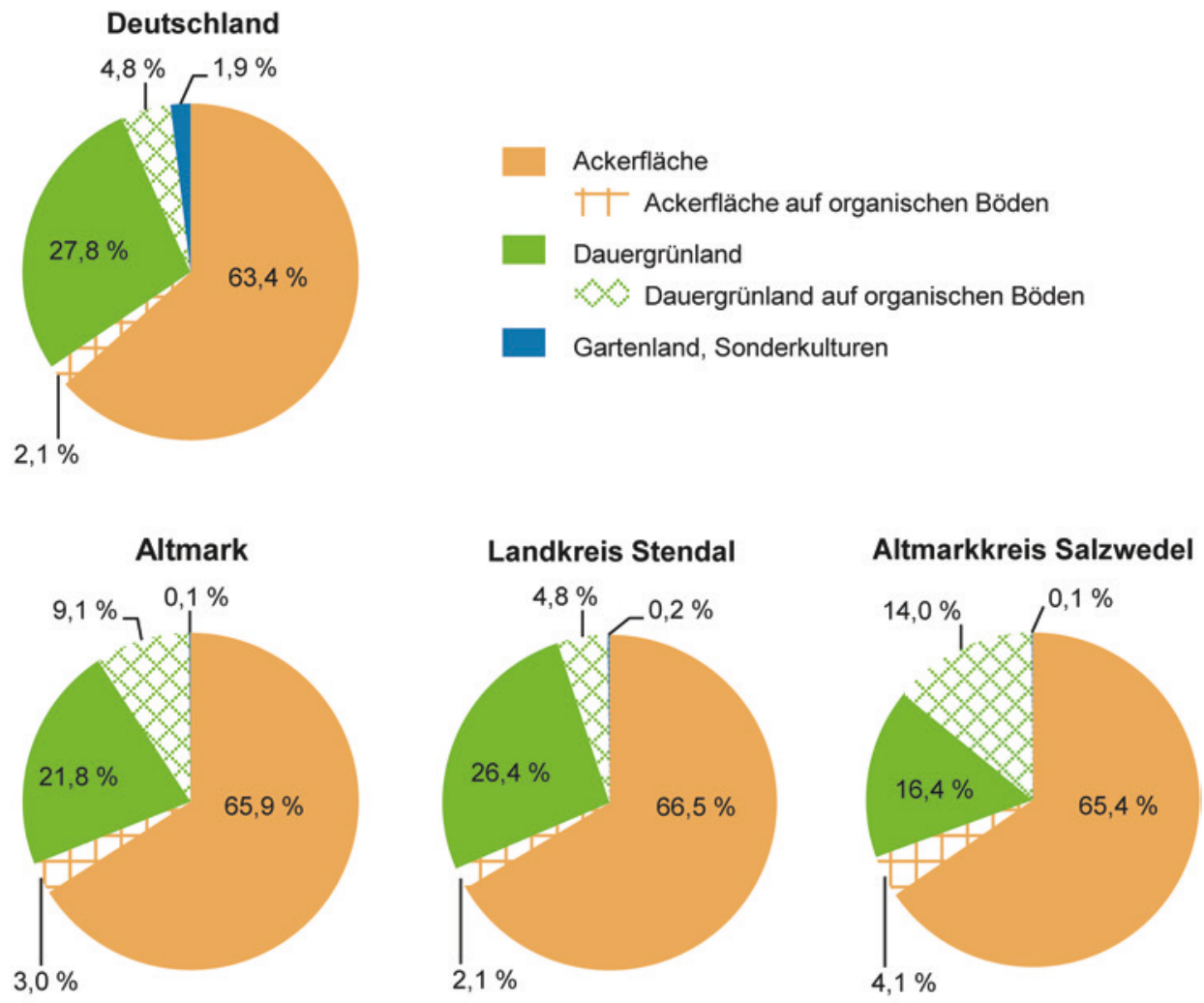

Die Fläche organischer Böden ist in der Rhein-Region gering und wird daher nicht abgebildet.

Abb. 2.16 Landwirtschaftliche Nutzfläche in Deutschland und der Altmark differenziert nach organischen und mineralischen Böden. (Quelle: Basis-DLM @ GeoBasis-DE/BKG 2016) 
Tab. 2.5 Nutzung der Ackerfläche und Dauerkulturen in Deutschland und in den Fokusregionen Altmark und Rhein. (Quelle: ASE-Daten aus dem Jahr 2010)

\begin{tabular}{|c|c|c|c|c|c|c|c|}
\hline $\begin{array}{l}\text { Nutzung } \\
\text { Ackerfläche }\end{array}$ & $\begin{array}{l}\text { Deutsch- } \\
\text { land (\% } \\
\text { der LF) }\end{array}$ & $\begin{array}{l}\text { Region } \\
\text { Altmark } \\
(\% \text { der } \\
\text { LF) }\end{array}$ & $\begin{array}{l}\text { Altmark- } \\
\text { kreis } \\
\text { Salz- } \\
\text { wedel (\% } \\
\text { der LF) }\end{array}$ & $\begin{array}{l}\text { LK } \\
\text { Stendal } \\
\text { (\% der } \\
\text { LF) }\end{array}$ & $\begin{array}{l}\text { Rhein- } \\
\text { Region } \\
\text { (\% der } \\
\text { LF) }\end{array}$ & $\begin{array}{l}\text { Rheinisch- } \\
\text { Bergischer } \\
\text { Kreis (\% } \\
\text { der LF) }\end{array}$ & $\begin{array}{l}\text { Rhein- } \\
\text { Sieg- } \\
\text { Kreis (\% } \\
\text { der LF) }\end{array}$ \\
\hline Getreide & 50,9 & 51,0 & 49,2 & 52,5 & 45,4 & 26,1 & 47,6 \\
\hline Körnermais & 3,9 & 1,3 & 1,6 & 1,0 & 1,5 & 2,3 & 1,5 \\
\hline Ölsaaten & 9,6 & 7,1 & 5,7 & 8,2 & 1,3 & 0,0 & 1,4 \\
\hline Kartoffeln & 2,1 & 1,2 & 2,1 & 0,4 & 0,9 & 0,3 & 1,0 \\
\hline Hülsenfrüchte & 0,8 & 1,5 & 1,6 & 1,4 & 0,6 & 0,0 & 0,7 \\
\hline Hackfrüchte & 3,1 & 2,3 & 3,0 & 1,7 & 11,6 & 0,0 & 12,9 \\
\hline Silomais & 15,2 & 20,4 & 21,6 & 19,4 & 15,7 & 58,8 & 10,8 \\
\hline Raps & 2,9 & 3,8 & 3,0 & 4,4 & 0,3 & 0,0 & 0,4 \\
\hline Gemüse & 1,1 & 0,3 & 0,2 & 0,4 & 7,5 & 0,02 & 8,4 \\
\hline Leguminosen & 2,5 & 2,0 & 1,9 & 2,0 & 2,2 & 4,3 & 1,9 \\
\hline Feldgras & 3,7 & 3,0 & 2,9 & 3,0 & 3,3 & 6,5 & 2,9 \\
\hline $\begin{array}{l}\text { Flächenstill- } \\
\text { legung }\end{array}$ & 2,0 & 5,7 & 6,6 & 5,0 & 1,4 & 0,7 & 1,5 \\
\hline $\begin{array}{l}\text { Sonder- } \\
\text { kulturen }\end{array}$ & 0,7 & 0,4 & 0,4 & 0,4 & 1,6 & 1,1 & 1,7 \\
\hline Obst & 0,5 & 0,05 & 0,0 & 0,1 & 6,6 & 0,1 & 7,3 \\
\hline Rebland & 0,8 & 0,0 & 0,0 & 0,0 & 0,1 & 0,0 & 0,1 \\
\hline Getreide & 50,9 & 51,0 & 49,2 & 52,5 & 45,4 & 26,1 & 47,6 \\
\hline
\end{tabular}

$15 \%$ in Deutschland. Der Anteil der Flächenstilllegung ist in der Altmark mit fast $6 \%$ dreimal höher als in Deutschland (Tab. 2.5).

Bei der Nutztierhaltung überwiegen Rinder, deren Besatzdichte in der Altmark mit 0,35 Großvieheinheiten/ha deutlich niedriger als in Deutschland ist $(0,52 \mathrm{GVE} /$ ha, Tab. 2.6). In beiden betrachteten Räumen handelt es sich in erster Linie um Milchkuhhaltung (Altmark $52 \%$ der Rinder-GVE; Deutschland $47 \%$ ).

Die Betrachtung der Agrarstruktur der Altmark lässt hohe THG-Emissionen aus landwirtschaftlich genutzten, organischen Böden vermuten. Insbesondere aus der Ackernutzung, die ein Viertel der landwirtschaftlich genutzten, organischen Böden ausmacht, sind aufgrund der im Vergleich zur Grünlandnutzung stärkeren Wasserstandsabsenkungen hohe Emissionen je Flächeneinheit zu erwarten. Eine angepasste Nutzung würde zu THG-Einsparung führen. Als von Ackerland dominierte Region sind in der Altmark THG-Emissionen, die mit der Düngung und Auswaschung in Verbindung stehen, relevant. Beim Umbruch von Grünland zu Ackerland würde es insbesondere auf 
Tab. 2.6 Intensität und Ausrichtung der Tierhaltung in Deutschland und in den Fokusregionen Altmark und Rhein. (Quelle: ASE-Daten aus dem Jahr 2010)

\begin{tabular}{l|l|l|l|l|l|l|l}
\hline Nutztiere & $\begin{array}{l}\text { Deutsch- } \\
\text { land } \\
\text { (GVE/ha) }\end{array}$ & $\begin{array}{l}\text { Region } \\
\text { Altmark } \\
(\mathbf{G V E} / \mathbf{h a})\end{array}$ & $\begin{array}{l}\text { Altmark- } \\
\text { kreis } \\
\text { Salzwedel } \\
\text { (GVE/ha) }\end{array}$ & $\begin{array}{l}\text { LK } \\
\text { Stendal } \\
\text { (GVE/ha) }\end{array}$ & $\begin{array}{l}\text { Rhein- } \\
\text { Region } \\
\text { (GVE/ha) }\end{array}$ & $\begin{array}{l}\text { Rheinisch- } \\
\text { Bergischer } \\
\text { Kreis } \\
\text { (GVE/ha) }\end{array}$ & $\begin{array}{l}\text { Rhein- } \\
\text { Sieg-Kreis } \\
\text { (GVE/ha) }\end{array}$ \\
\hline Rinder & 0,52 & 0,35 & 0,37 & 0,33 & 0,86 & 1,22 & 0,62 \\
\hline Schweine & 0,25 & 0,10 & 0,12 & 0,08 & 0,02 & 0,01 & 0,03 \\
\hline Geflügel & 0,06 & 0,02 & 0,02 & 0,02 & 0,03 & 0,03 & 0,04 \\
\hline Schafe & 0,01 & 0,01 & 0,01 & 0,00 & 0,01 & 0,01 & 0,01 \\
\hline $\begin{array}{l}\text { Sonstige } \\
\text { Tier- } \\
\text { haltung }\end{array}$ & 0,01 & 0,00 & 0,00 & 0,00 & 0,03 & 0,03 & 0,03 \\
\hline GESAMT & $\mathbf{0 , 8 5}$ & $\mathbf{0 , 4 8}$ & $\mathbf{0 , 5 2}$ & $\mathbf{0 , 4 4}$ & $\mathbf{0 , 9 5}$ & $\mathbf{1 , 2 9}$ & $\mathbf{0 , 7 3}$ \\
\hline
\end{tabular}

organischen Böden zu hohen THG-Emissionen kommen. Die Viehbesatzdichte der Altmark ist vergleichsweise gering. THG-Emissionen treten bei der Wirtschaftsdüngerausbringung sowie beim Weidegang auf.

\section{Fokusregion Rhein (Landkreise Rheinisch-Bergischer Kreis und Rhein-Sieg-Kreis)}

Die Fokusregion Rhein umfasst insgesamt 69.000 ha Landwirtschaftsfläche, wobei sich der Großteil mit 53.000 ha im Rhein-Sieg-Kreis befindet. Anders als in der Region Altmark weisen die beiden Landkreise der Fokusregion Rhein z. T. große Unterschiede hinsichtlich ihrer landwirtschaftlichen Struktur auf (vgl. Abb. 2.17). Während im Rheinisch-Bergischen Kreis die landwirtschaftliche Nutzfläche zu 81,5\% mit Dauergrünland bedeckt ist, sind es im Rhein-Sieg-Kreis 51,5\%. In beiden Regionen weist das Dauergrünland fast vollständig einen Schutzgebietsstatus auf. Der Anteil der Ackerflächen beträgt 17,2 \% im Rheinisch-Bergischen Kreis und ist im Rhein-Sieg-Kreis mit $42,9 \%$ wesentlich größer. Gartenland und Sonderkulturen liegen im Rhein-Sieg-Kreis mit 5,6\% deutlich über dem Bundesdurchschnitt (1,9\%). Als Schutzgebiete wurden aufgenommen Landschaftsschutzgebiet, Naturschutzgebiete, FFH-Gebiete nach Natura 2000, Gebiete nach Artikel 4 (1) der Vogelschutzrichtlinie (79/409/EWG) zum Schutz der wildlebenden Vogelarten und ihrer Lebensräume, Naturparke, Biosphärenreservate und Nationalparke.

Auch hinsichtlich der Ackerflächennutzung unterscheiden sich die beiden Landkreise: Während im Rhein-Sieg-Kreis in Übereinstimmung mit dem Bundesdurchschnitt der Getreideanbau überwiegt, nimmt Silomais im Rheinisch-Bergischen Kreis $59 \%$ 


\section{Deutschland}
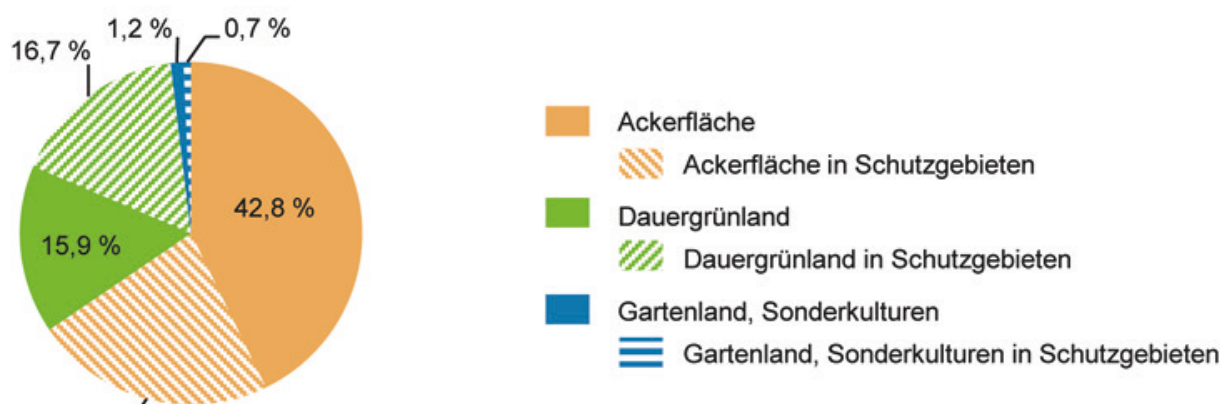

$22,7 \%$

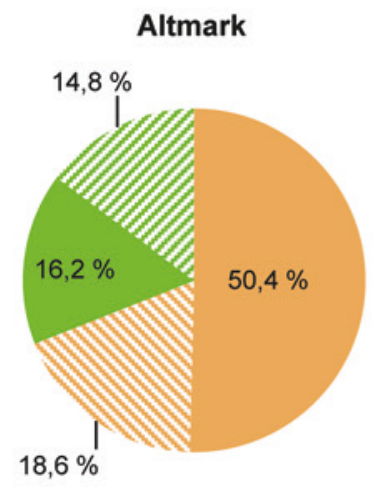

Landkreis Stendal

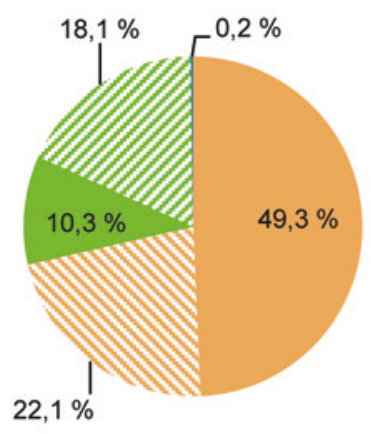

Rheinisch-Bergischer Kreis

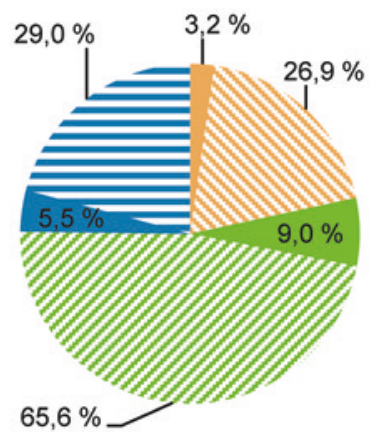

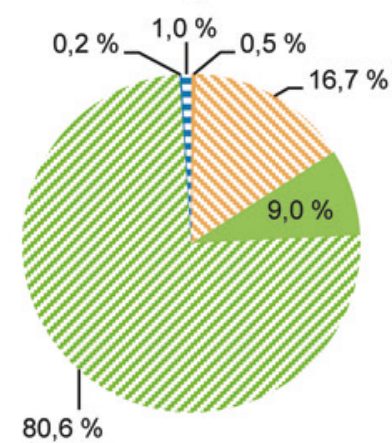

\section{Altmarkkreis Salzwedel}

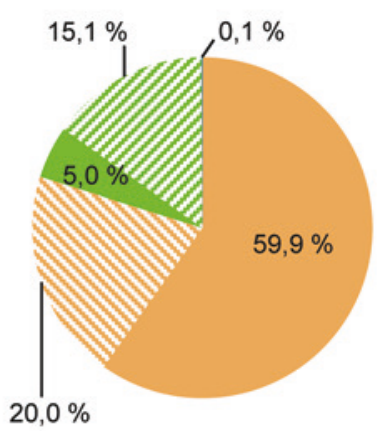

Rhein-Sieg-Kreis

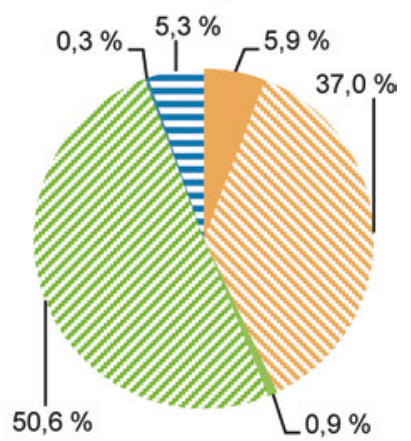

Abb. 2.17 Landwirtschaftliche Nutzfläche in Deutschland, der Altmark und der Rhein-Region differenziert nach der Lage der Flächen in Schutzgebieten. (Quelle: Basis-DLM @ C GeoBasis-DE/ BKG 2016) 
der Ackerfläche ein. Da sich lediglich $23 \%$ der landwirtschaftlich genutzten Fläche der Region in diesem Landkreis befinden, kommt die Fokusregion Rhein insgesamt mit $15,7 \%$ Silomaisanbau nicht über den Bundesdurchschnitt. Weiterhin fällt auf, dass der Flächenumfang für Gemüse- und Obstanbau in der Fokusregion Rhein sieben- bzw. zwölfmal höher sind als im Bundesdurchschnitt. Weiter umfasst der Hackfruchtanbau der Fokusregion Rhein gut das Vierfache der Fläche des Bundesdurchschnitts (Tab. 2.5). Insgesamt, so wie in den einzelnen Landkreisen, überwiegen bei der Nutztierhaltung die Rinder, besonders im Rheinisch-Bergischen Kreis (Tab. 2.6). In allen Fällen dominiert die Milchkuhhaltung (Rhein-Region: $54 \%$ der Rinder, Deutschland $47 \%$ ).

In der Fokusregion Rhein stehen THG-Emissionen besonders mit der Düngung und Auswaschung in Verbindung, da neben dem Ackerbau insbesondere der Obst- und Gemüseanbau hohe Düngergaben erfordert. Aufgrund der vergleichsweise hohen Viehbesatzdichte sind hohe THG-Emissionen, die mit der Wirtschaftsdüngerausbringung und dem Weidegang in Verbindung stehen, zu erwarten.

\section{Literatur}

Bundesanstalt für Landwirtschaft und Ernährung (BLE) (2010) Leitfaden Nachhaltige Biomasseherstellung. Bundesanstalt für Landwirtschaft und Ernährung. www.ble.de. Zugegriffen: 12. März 2019

Bundesinstitut für Bau-, Stadt- und Raumforschung (BBSR) (Hrsg) (2012) Raumordnungsbericht 2011, Bonn

Bundesministerium für Ernährung und Landwirtschaft (BMEL) (2014) Der Wald in Deutschland. Ausgewählte Ergebnisse der dritten Bundeswaldinventur, Berlin, S 56

Bundesministerium für Ernährung und Landwirtschaft (BMEL) (2015) Umsetzung der EU Agrarpolitik in Deutschland. Broschüre. http://www.bmel.de. Zugegriffen: 12. März 2019

Bundesministerium für Ernährung und Landwirtschaft (BMEL) (Hrsg) (2015b) Rahmenplan der Gemeinschaftsaufgabe „Verbesserung der Agrarstruktur und des Küstenschutzes“ für den Zeitraum 2015-2018. Bundesministerium für Ernährung und Landwirtschaft, Bonn

Bundesministerium für Ernährung und Landwirtschaft (BMEL) (Hrsg) (2016) Statistisches Jahrbuch über Ernährung, Landwirtschaft und Forsten der Bundesrepublik Deutschland 2006, Münster. www.bmel-statistik.de. Zugegriffen: 12. März 2019

Bundesministerium für Ernährung, Landwirtschaft und Verbraucherschutz (BMELV) (Hrsg) (2004) Die zweite Bundeswaldinventur - BWI²: Das Wichtigste in Kürze, Bonn, S 87

Bundesministerium für Ernährung, Landwirtschaft und Verbraucherschutz (BMELV) (Hrsg) (2005) Die zweite Bundeswaldinventur - BWI²: Der Inventurbericht Bonn, S 231

Bundesministerium für Ernährung, Landwirtschaft und Verbraucherschutz (BMELV), Bundesministerium für Umwelt, Naturschutz und nukleare Sicherheit (BMU) (2010) Nationaler Biomasseaktionsplan für Deutschland - Beitrag der Biomassefür eine nachhaltige Energieversorgung

Bundesministerium für Umwelt, Bau und Reaktorsicherheit (BMUB) (Hrsg) (2013) Sechster Nationalbericht. Berichterstattung unter der Klimarahmenkonvention der Vereinten Nationen, Berlin

Bundesministerium für Umwelt, Bau und Reaktorsicherheit (BMUB) (2014) Aktionsprogramm Klimaschutz 2020. Kabinettsbeschluss vom 3. Dezember 2014, S 83 
Bundesministerium für Verkehr Bau und Stadtentwicklung (BMVBS) und Bundesinstitut für Bau-, Stadt- und Raumforschung (BBSR) (2009) Einflussfaktoren der Neuninanspruchnahme von Flächen, BBSR-Forschungen Heft 139, Bonn 2009

Bundesregierung (2010) Energiekonzept für eine umweltschonende, zuverlässige und bezahlbare Energieversorgung. https://archiv.bundesregierung.de/resource/blob/656922/779770/794fd0c4 0425acd7f46afacbe62600f6/energiekonzept-final-data.pdf?download=1. Zugegriffen: 1. Aug. 2019

Ciccarese L, Elsasser P, Horattas A, Pettenella D, Valatin G (2011) Innovative market opportunities related to carbon sequestration in EU forests? In: Weiss G, Ollonqvist P, Pettenella D, Slee B (Hrsg) Innovation in forestry: territorial and value chain relationships. CABI, Wallingford, $\mathrm{S}$ 131-153

Dechow R, Freibauer A (2011) Assessment of German nitrous oxide emissions using empirical modelling approaches. Nutr Cycl Agroecosys 91:235-254

Dieter M (2011) Noch positiver Abschluss im Jahr der Wirtschaftskrise; Ergebnisse der Forstwirtschaftlichen Gesamtrechnung 2009. Holz-Zentralblatt 137(15):372-373

Dieter M, Elsasser P (2002) Carbon stocks and carbon stock changes in the tree biomass of Germany's forests. Forstwissenschaftliches Centralblatt 121(4):195-210

Dobbie KE, Smith KA (2003) Nitrous oxide emission factors for agricultural soils in Great Britain: the impact of soil water-filled pore space and other controlling variables. Glob Change Biol 9:204-218

Dörsch P (1999) Nitrous oxide and methane fluxes in differentially managed agricultural soils of a hilly landscabe in southern Germany. Dissertation, Universität München

Dosch F (2008) Siedlungsflächenentwicklung und Nutzungskonkurrenzen. Technikfolgenabschätzung - Theorie und Praxis 17:41-51

Dosch F, Beckmann G (2011) Auf dem Weg, aber noch nicht am Ziel; Trends der Siedlungsflächenentwicklung. Bundesinstitut für Bau-, Stadt- und Raumforschung (BBSR) im Bundesamt für Bauwesen und Raumordnung (BBR), Bonn

Einig K (2011) Die Flächenwende kommt nicht von allein. Land In Form, S 14-15

Elsasser P (2008) Wirtschaftlicher Wert der Senkenleistung des Waldes unter KP-Artikel 3.4 und Ansätze zu dessen Abgeltung in der ersten Verpflichtungsperiode (Economic value of the carbon sequestration service of forests under KP-article 3.4 and compensation options in the first commitment period), vol OEF 2008/6. Arbeitsbericht von-Thünen-Institut, Hamburg

Elsasser P, Kawaletz H, Bormann K, Bösch M, Lorenz M, Moning C, Olschewski R, Roedl A, Schröppel B, Weller P (2016) Ökosystemleistungen von Wäldern. In: von Haaren C, Albert C (Hrsg) Ökosystemleistungen in ländlichen Räumen. Grundlage für menschliches Wohlergehen und nachhaltige wirtschaftliche Entwicklung. Naturkapital Deutschland - TEEB DE. S 72-98

EU (2003) Directive 2003/87/EC of the European Parliament and Council of 13th October 2003 on establishing a scheme for greenhouse gas emission allowance trading within the community. consolidated version (incorporating subsequent amendments). Official Journal of the European Union L 275 (25.10.2003), S 32-46

EU (2004) Directive 2004/1001/EC of the European Parliament and Council of 27th October 2004 amending Directive 2003/87/EC on establishing a scheme for greenhouse gas emission allowance trading within the community, in respect of the Kyoto Protocol's project mechanisms. Official Journal of the European Union L 338 (13.11.2004), S 18-23

EU (2009) Directive 2009/29/EC of the European Parliament and Council of 23rd April 2009 amending Directive 2003/87/EC so as to improve and extend the greenhouse gas emission allowance trading scheme of the community. Official Journal of the European Union L140 (5.6.2009), S 63-87 
EU-KOM (2006) Vorschlag für eine Richtlinie des Europäischen Parlamentes und des Rates zu Schaffung eines Ordnungsrahmens für den Bodenschutz und zur Änderung der Richtlinie 2004/35/EG. KOM (2006) 232 endgültig

EWG (1993) 93/389/EWG: Entscheidung des Rates vom 24. Juni 1993 über ein System zur Beobachtung der Emissionen von CO2 und anderen Treibhausgasen in der Gemeinschaft. AB1. L 167 vom 09.07.1993, S 31-33

Flessa H, Müller D, Plassmann K, Osterburg B, Techen A-K, Nitsch H, Nieberg H, Sanders J, Meyer zu Hartlage O, Beckmann E, Anspach V (2012) Studie zur Vorbereitung einer effizienten und gut abgestimmten Klimaschutzpolitik für den Agrarsektor. Braunschweig: vTI, S 472, Landbauforsch Völkenrode SH 361

Freibauer A et al (2003) Controls and models for estimating direct nitrous oxide emissions from temperate and sub-boreal agricultural mineral soils in Europe. Biogeochemistry 63:93-115

Fürst D, Scholles F (2008) Handbuch Theorien und Methoden der Raum- und Umweltplanung, Dortmund, S 656

Göddecke-Stellmann J (2011) Renaissance der Großstädte; Eine Zwischenbilanz. Bundesinstitut für Bau-, Stadt- und Raumforschung (BBSR) im Bundesamt für Bauwesen und Raumordnung (BBR), Bonn

Gömann H, de Witte T, Peter G, Tietz A (2013) Auswirkungen der Biogaserzeugung auf die Landwirtschaft. Johann Heinrich von Thünen-Institut, Braunschweig, S. 78, Thünen Rep 10

Hahn-Schöfl M, Zak D, Minke M, Gelbrecht J, Augustin J, Freibauer A (2011) Organic sediment formed during inundation of a degraded fen grassland emits large fluxes of $\mathrm{CH} 4$ and $\mathrm{CO} 2$. Biogeosciences 8(6): 1539-1550

Hartje V, Wüstemann H, Bonn A (Hrsg) (2015) Naturkapital und Klimapolitik: Synergien und Konflikte. Naturkapital Deutschland - TEEB DE. TUB/UFZ, Berlin, Leipzig

Haushaltsgesetze (verschiedene Jahrgänge) Bundesgesetzblatt (2014) S 3197; (2015) S 2828; (2016) S 3032

Jandl R, Lindner M, Vesterdal L, Bauwens B, Baritz R, Hagedorn F, Johnson DW, Minkkinen K, Byrne KA (2007) How strongly can forest management influence soil carbon sequestration? Geoderma 2007 137(Jan):253-268

Janssens IA, Freibauer A, Ciais P, Smith P, Nabuurs GJ, Folberth G, Schlamadinger B, Hutjes RWA, Ceulemans R, Schulze ED, Valentini R, Dolman AJ (2003) Europe's Terrestrial Biosphere Absorbs 7 to $12 \%$ of European Anthropogenic CO2 Emissions. Science 2003 300(Jun): 1538-1542

Jungkunst HF, Freibauer A, Neufeldt H, Bareth G (2006) Nitrous oxide emissions from agricultural land use in Germany - a synthesis of available annual field data. J Plant Nutr Soil Sci 169(3):341-351

Köhl M, Dieter M (2007) Wie lässt sich die Senkenwirkung des Waldes in der Praxis nachweisen? Art. 3.4 des Kyoto-Protokolls. AFZ Der Wald 62(11):566-570

Kohlmaier G, Kohlmaier L, Fries E, Jaeschke W (2007) Application of the stock change and the production approach to harvested wood products in the EU-15 countries: a comparative analysis. Eur J Forest Res 126(2):209-223

Küppers J-G, Elsasser P, Dieter M (2009) Forstwirtschaft im Spannungsfeld zunehmender Ansprüche an den Wald. In: Keuffel W, Löwenstein W, Möhring B, Moog M, Olschewski R (Hrsg) Förstökonomie - eine Standortbestimmung. J.D. Sauerländer's, Frankfurt, S 153-175

Le Quéré C, Raupach MR, Canadell JG, Marland G, Bopp L, Ciais P, Woodward FI (2009) Trends in the sources and sinks of carbon dioxide. Nat Geosci 2(12):831-836

Ministerium für Klimaschutz, Umwelt, Landwirtschaft, Natur- und Verbraucherschutz des Landes Nordrhein-Westfalen (MKULNV) (2016) NRW-Programm Ländlicher Raum 2014-2020 Förderung der ländlichen Entwicklung in Nordrhein-Westfalen 
Möhring B, Mestemacher U (2009) Gesellschaftliche Leistungen der Wälder und der Forstwirtschaft und ihre Honorierung. In: Seintsch B., Dieter M (Hrsg) Waldstrategie 2020. Tagungsband zum Symposium des BMELV, 10.-11. Dez. 2008, Berlin, Aufl 327. Landbauforschung/ vTI Agriculture and Forestry Research. vTI, Braunschweig, S 65-73

National Inventory Report (NIR) (2014) Berichterstattung unter der Klimarahmenkonvention der Vereinten Nationen und dem Kyoto Protokoll 2014. Nationaler Inventarbericht zum Deutschen Treibhausgasinventar 1990-2012. Umweltbundesamt, Dessau-Roßlau

Oehmichen K, Demant B, Dunger K, Grüneberg E, Hennig P, Kroiher F, Neubauer M, Polley H, Riedel T, Rock J, Schwitzgebel F, Stümer W, Wellbrock N, Ziche D, Bolte A (2011) Inventurstudie 2008 und Treibhausgasinventur Wald. Braunschweig Landbauforsch SH 343, S 141

Offermann F, Deblitz C, Golla B, Gömann H, Haenel H-D, Kleinhanß W, Kreins P, Ledebur O von, Osterburg B, Pelikan J, Röder N, Rösemann C, Salamon P, Sanders J, Witte T de (2014) Thünen-Baseline 2013-2023: Agrarökonomische Projektionen für Deutschland. Braunschweig: Johann Heinrich von Thünen-Institut, S 112, Thünen Rep 19

Pistorius T (2007) Die Bedeutung von Kohlenstoffbilanzen im Diskurs über die Einbindung der Forstwirtschaft in die nationale Klimapolitik. Dissertation, Fakultät für Forst- und Umweltwissenschaften der Albert-Ludwigs-Universität zu Freiburg im Breisgau

Richtlinie 2003/87/EG des Europäischen Parlaments und des Rates vom 13. Oktober 2003 über ein System für den Handel mit Treibhausgasemissionszertifikaten in der Gemeinschaft und zur Änderung der Richtlinie 96/61/EG des Rates. AB1. L 275, 25.10.2003, S 32. - zuletzt geändert durch Verordnung (EU) Nr. 421/2014 des Europäischen Parlaments und des Rates vom 16. April 2014

Richtlinie 2006/118/EG des Europäischen Parlaments und des Rates vom 12. Dezember 2006 zum Schutz des Grundwassers vor Verschmutzung und Verschlechterung

Röder N, Grützmacher F (2012) Emissionen aus landwirtschaftlich genutzten Mooren - Vermeidungskosten und Anpassungsbedarf. Natur und Landschaft 2(87):56-61

Rüter S (2011) Welchen Beitrag leisten Holzprodukte zur CO2-Bilanz? AFZ-Der Wald 15:15-18

Schwoerer M (2015) What is happening in the International Forest Regime? Environ Pol Law 46(6):281-283

Statistisches Bundesamt (2014) Bodenfläche nach Art der tatsächlichen Nutzung. 2013, Wiesbaden

Succow M, Joosten H (Hrsg) Landschaftsökologische Moorkunde. 2., völlig neu bearb. Aufl 28-38, Stuttgart (Schweizerbart'sche Verlagsbuchhandlung)

Syväsalo E, Regina K, Pihlatie M, Esala M (2004) Emissions of nitrous oxide from boreal agricultural clay and loamy sand soils. Nutr Cycl Agroecosyst 69(2004):155-165

Umweltbundesamt (UBA) (2014) National inventory report for the german greenhouse gas inventory 1990-2012. Submission under the united framework convention on climate change. Umweltbundesamt, Dessau. S 956. http://www.umweltbundesamt.de/publikationen/ submission-under-the-united-nations-framework. Zugegriffen: 19. März 2019

United Nations (UN) (1992) United Nations Framework Convention on Climate Change (Klimarahmenkonvention der Vereinten Nationen). UN, New York, 9. Mai 1992. http://unfccc.int/key_ documents/the_convention/items/2853.php. Zugegriffen: 19. März 2019

United Nations-Convention on Biological Diversity (UN-CBD) (1992) http://www.cbd.int/doc/ legal/cbd-en.pdf (englisch). Zugegriffen: 19. März 2019

United Nations Framework Convention on Climate Change (UNFCCC, Kyoto-Protokoll zur UN Klimarahmenkonvention) (1992) Rahmenübereinkommen der Vereinten Nationen über Klimaänderungen. http://unfccc.int/resource/docs/convkp/convger.pdf. Zugegriffen: 12. März 2018

United Nations Framework Convention on Climate Change (UNFCCC) (1997). UNFCCC, Kyoto, 11. Dezember 1997. https://unfccc.int/resource/docs/convkp/kpger.pdf. Zugegriffen: 12. März 2018 
United Nations Framework Convention on Climate Change (UNFCCC) (1998) Kyoto Protocol to the United Nations Framework Convention on Climate Change. http://unfccc.int/resource/docs/ convkp/kpeng.pdf. Zugegriffen: 12. März 2018

United Nations Framework Convention on Climate Change (UNFCCC) (2011) Decision 2/CMP.7 (Land use, land-use change and forestry). https://unfccc.int/files/meetings/durban_nov_2011/ decisions/application/pdf/awgkp_lulucf.pdf. Zugegriffen: 12. März 2018

Verordnung (EU) Nr. 525/2013 des Europäischen Parlaments und des Rates vom 21. Mai 2013 über ein System für die Überwachung von Treibhausgasemissionen sowie für die Berichterstattung über diese Emissionen und über andere klimaschutzrelevante Informationen auf Ebene der Mitgliedstaaten und der Union und zur Aufhebung der Entscheidung Nr. 280/2004/ EG. ABl. L 165 vom 18.6.2013, S 13-40. Zuletzt geändert durch Verordnung (EU) Nr. 662/2014 des Europäischen Parlaments und des Rates vom 15. Mai 2014

Verordnung (EU) Nr. 662/2014 des Europäischen Parlaments und des Rates vom 15. Mai 2014 zur Änderung der Verordnung (EU) Nr. 525/2013 in Bezug auf die technische Umsetzung des Kyoto-Protokolls zum Rahmenübereinkommen der Vereinten Nationen über Klimaänderungen. ABl. L 189 vom 27.06.2014, S 155-160

Wellbrock N, Grüneberg E, Stümer W, Rüter S, Ziche D, Dunger K, Bolte A (2014) Wälder in Deutschland speichern Kohlenstoff. AFZ-Der Wald 18:38-39

Wissenschaftlicher Beirat für Agrarpolitik (WBA) (2007) Nutzung von Biomasse zur Energiegewinnung - Empfehlungen an die Politik. Wissenschaftlicher Beirat Agrarpolitik beim Bundesministerium für Ernährung, Landwirtschaft und Verbraucherschutz. Bericht verabschiedet im November 2007

Open Access Dieses Kapitel wird unter der Creative Commons Namensnennung 4.0 International Lizenz (http://creativecommons.org/licenses/by/4.0/deed.de) veröffentlicht, welche die Nutzung, Vervielfältigung, Bearbeitung, Verbreitung und Wiedergabe in jeglichem Medium und Format erlaubt, sofern Sie den/die ursprünglichen Autor(en) und die Quelle ordnungsgemäß nennen, einen Link zur Creative Commons Lizenz beifügen und angeben, ob Änderungen vorgenommen wurden.

Die in diesem Kapitel enthaltenen Bilder und sonstiges Drittmaterial unterliegen ebenfalls der genannten Creative Commons Lizenz, sofern sich aus der Abbildungslegende nichts anderes ergibt. Sofern das betreffende Material nicht unter der genannten Creative Commons Lizenz steht und die betreffende Handlung nicht nach gesetzlichen Vorschriften erlaubt ist, ist für die oben aufgeführten Weiterverwendungen des Materials die Einwilligung des jeweiligen Rechteinhabers einzuholen.

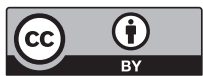

